\title{
MATHEMATICAL MODELING OF THE VOLOXIDATION PROCESS
}

\author{
FINAL REPORT \\ T.G. STANFORD
}

June, 1979

Work Performed Under Contract EY-76-S-09-0944

Form 189 Number 320.03

\author{
UNIVERSITY OF SOUTH CAROLINA \\ COLLEGE OF ENGINEERING \\ COLUMBIA, S.C. 29209
}




\begin{abstract}
"This report was prepared as an account of work sponsored by the United States Government. Neither the United States nor the United States Department of Energy, nor any of their employeess, makes any warranty, express or implied, or assumes any legal liability or responsibility for the accuracy, completeness, or usefulness of any information, apparatus, product, or process disclosed, or represents that its use would not infringe privately owned rights. Reference herein to any specific commerical product, process, or service by trade name, mark manufacturer, or otherwise, does not necessarily constitute or imply its endorsement, recommendation, or favoring by the United States Government or any agency thereof. The views and opinions of authors expressed herein do not necessarily state or reflect those of the United States Government or any agency thereof.
\end{abstract}

Printed in the United States of America

$$
\text { Available from }
$$

National Technical Information Service

U. S. Department of Commerce

5825 Port Royal Road

Springfield, Virginia 22161

Price: Printed Copy $\$ 6.50$; Microfiche $\$ 3.00$ 


\section{DISCLAIMER}

This report was prepared as an account of work sponsored by an agency of the United States Government. Neither the United States Government nor any agency Thereof, nor any of their employees, makes any warranty, express or implied, or assumes any legal liability or responsibility for the accuracy, completeness, or usefulness of any information, apparatus, product, or process disclosed, or represents that its use would not infringe privately owned rights. Reference herein to any specific commercial product, process, or service by trade name, trademark, manufacturer, or otherwise does not necessarily constitute or imply its endorsement, recommendation, or favoring by the United States Government or any agency thereof. The views and opinions of authors expressed herein do not necessarily state or reflect those of the United States Government or any agency thereof. 


\section{DISCLAIMER}

Portions of this document may be illegible in electronic image products. Images are produced from the best available original document. 
MATHEMATICAL MODELING

OF THE VOLOXIDATION PROCESS

FINAL REPORT

June, 1979

T. G. Stanford

UNIVERSITY OF SOUTH CAROLINA

COLLEGE OF ENGINEERING

COLUMBIA, SOUTH CAROLINA 29208

PREPARED FOR THE

DEPARTMENT OF ENERGY

FUEL CYCLE PROGRAM OFFICE

UNDER CONTRACT EY-76-S-09-0944

Form 189 Number 320.03

This report was prepared as an account of work
sponsored by the United States Government Nether the
United States nor the United States Department of
Energy, nor any of their employees, nor any of their
contractors, subcontractors, or their employes, makes
any warranty, express or implied, or assumes any legal
liability or responstblity for the accuracy, completeness
or usefulness of any informatton, apparatus, product or
process disclosed, or represents that its use would not
infrnge privately owned nghts 


\section{ABSTRACT}

A mathematical model of the voloxidization process, a 'head-end' reprocessing step for the removal of volatile fission products from spent nuclear fuel, has been developed. Three types of voloxidizer operation have been considered; cocurrent operation in which the gas and solid streams flow in the same direction, countercurrent operation in which the gas and solid streams flow in opposite directions, and semi-batch operation in which the gas stream passes through the reactor while the solids remain in it and are processed batch wise. Because of the complexity of the physical and chemical processes which occur during the voloxidization process and the lack of currently available kinetic data, a global kinetic model has been adapted for this study.

Test cases for each mode of operation have been simulated using representative values of the model parameters. To process $714 \mathrm{kgm} /$ day of spent nuclear fuel, using an oxidizing atmosphere containing 20 mole percent oxygen, it was found that a reactor $0.7 \mathrm{~m}$ in diameter and $2.49 \mathrm{~m}$ in length would be required for both cocurrent and countercurrent modes of operation while for semibatch operation a $0.3 \mathrm{~m}^{3}$ reactor and an $88200 \mathrm{sec}$ batch processing time would be required. 
LIST OF TABLES iv

LIST OF FIGURES $\quad v$

LIST OF APPENDICES vi

ABSTRACT vii

CHAPTER I AN OVERVIEW OF VOLOXIDATION PROCESS DEVELOPMENT WORK 1

1.1 INTRODUCTION 1

1.2 TRITIUM CONTAINMENT SYSTEMS: VOLOXIDATION

1.2.1 Evolution of the Voloxidation Process 1

1.2.2 Fundamental Development Work 2

1.2.2.1. Preliminary Studies 2

1.2.2.2 0xidation Studies 3

1.2.3 Engineering Development Work 4

1.3 ENGINEERING DESIGN OF THE VOLOXIDATION PROCESS

CHAPTER 2. DEVELOPMENT OF THE REACTOR MODEL 6

2.1 INTRODUCTION 6

2.2 COCURRENT OPERATION 6

2.2.1. Dispersion of Both Gas and Solid Phases 6

2.2.2. Negligible Gas Phase Dispersion 10

2.2.3. Negligible Dispersion of Reactants 11

2.3 COUNTERCURRENT OPERATION 12

2.3.1 Dispersion of Both Gas and Solid Phases 12

2.3.2 Negligible Gas Phase Dispersion 16

$\begin{array}{lll}2.4 & \text { SEMI-BATCH OPERATION } & 19\end{array}$

2.4.1 Dispersion of the Gas Phase and Segregation of the 19 Solid Phase 
2.4.2 Segregation of the Solid Phase with Negligible Dispersion 21 of the Gas Phase

2.4.3 Complete Mixing of the Solids Phase 21

2.4.4 Perfect Mixing of Both Phases 21

2.5 TEMPERATURE EFFECTS AND NON-ISOTHERMAL OPERATION 22

2.6 DISPERSION COEFFICIENTS FOR THE SOLIDS PHASE AND THE GAS 23 PHASE

CHAPTER 3. DEVELOPMENT OF KINETIC EXPRESSIONS FOR THE OXIDATION OF $\mathrm{UO}_{2}$ $\operatorname{AND}(U, \mathrm{Pu}) \mathrm{O}_{2}$

3.1 INTRODUCTION 24

3.2 RATE OF OXIDATION OF UO ${ }_{2}$ AND $(U, P u) O_{2}$

3.2.1 Dependence of the Oxidation Rate Upon Uranium Dioxide 24 Concentration - $\mathrm{UO}_{2}$ Oxidation

3.2.2 Dependence of the Oxidation Rate Upon Metal Oxide 30 Concentration - $(U, \mathrm{Pu}) \mathrm{O}_{2}$ Oxidation

3.2.3 Dependence of the 0xidation Rate Upon 0xygen Concentration - 33 $\mathrm{UO}_{2}$ Oxidation

3.2.4 Dependence of the Reaction Rate Upon the Rotation Speed of the Voloxidizer - $\mathrm{UO}_{2}$ Oxidation

3.3 KINETIC EXPRESSIONS FOR USE IN THE VOLOXIDIZER DESIGN EQUATIONS 36

3.4 CONCLUSIONS 40

CHAPTER 4. DESCRIPTION OF THE VOLOXIDIZER COMPUTER SIMULATION PROGRAMS 42

4.1 INTRODUCTION 42

4.2 COCURRENT OPERATION 42

4.3 COUNTERCURRENT OPERATION 45

4. 4 SEMI-BATCH OPERATION 46

4.5. MODIFICATION OF THE PROGRAMS

4.5.1 Changes in the Reaction Rate Expression 47

4.5.2 Changes in the Equation Describing the Effect of Oxygen 47 Concentration Upon the Reaction Rate 
Page

4.5.3 Changes in the Equation Describing the Effect of Voloxidizer Rotation Speed Upon the Reaction Rate

REFERENCES

NOMENCLATURE

APPENDICES 


\section{LIST OF TABLES}

TABLE

Page

3.1 PARAMETERS IN THE EQUATION DESCRIBING VARIATIONS OF THE FRACTIONAL CONVERSION WITH TIME

4. 1 ENTRIES ON DATA CARDS REQUIRED FOR COMPUTER SIMULATION OF A VOLOXIDATION REACTOR

A. 1 FRACTIONAL CONVERSION OF UO AS A FUNCTION OF TIME DURING ISOTHERMAL OXIDATION AT $400^{\circ} \mathrm{C}$

A. 2 RATE OF CHANGE OF THE FRACTIONAL CONVERSION OF UO AS A FUNCTION OF 1 - X FOR ISOTHERMAL OXIDATION AT $400^{\circ} \mathrm{C}$

A.3 ERROR RESULTING FROM THE USE OF THE KINETIC EQUATIONS TO DESCRIBE $t_{n}$ VERSUS 1 - X BEHAVIOR - ISOTHERMAL OXIDATION OF $\mathrm{UO}_{2}$ AT ${ }^{n} 400^{\circ} \mathrm{C}$

B. 1 EFFECT OF OXYGEN CONCENTRATION UPON THE RATE OF OXIDATION OF $\mathrm{UO}_{\mathrm{W}}$

B.2 EFFECT OF VOLOXIDIZER ROTATION SPEED UPON THE RATE OF 63 OXIDATION OF $\mathrm{UO}_{2}$ 


\section{LIST OF FIGURES}

FIGURE

Page

2.1 MODES OF VOLOXIDIZER OPERATION 7

3.1 ISOTHERMAL OXIDATION OF UO 2 PELLET FRAGMENTS 26

3.2 ISOTHERMAL OXIDATION OF UO 2 PELLET GRAGMENTS 27

3.3 TIME FOR MAXIMUM CONVERSION AS A FUNCTION OF TEMPERATURE 28

3.4 RATE EQUATION CONSTANTS AS A FUNCTION OF TEMPERATURE 31

3.5 BREAK-POINT AS A FUNCTION OF TEMPERATURE 32

3.6 OXIDATION OF STAINLESS-STEEL-CLAD URANIA PELLETS IN A \#-IN-DIAM 34 MINIVOLOXIDIZER WITH THE PARTIAL PRESSURE OF $0_{2}$ AS A PARAMETER

3.7 EFFECT OF OXYGEN CONCENTRATION IN THE GAS STREAM ON THE RATE 35 OF CHANGE OF THE FUEL FRACTIONAL CONVERSION

3.8 OXIDATION OF STAINLESS-STEEL-CLAD URANIA PELLETS IN A 3-IN-DIAM MINIVOLOXIDIZER WITH THE ROTATIONAL SPEED AS A PARAMETER

3.9 EFFECT OF THE VOLOXIDIZER ROTATION SPEED ON THE RATE OF CHANGE OF THE FUEL FRACTIONAL CONVERSION

38

A. 1 FRACTIONAL CONVERSION VERSUS NORMALIZED TIME 56

A.2 ISOTHERMAL REACTION RATE VERSUS FRACTIONAL CONVERSION 58 
APPENDIX A DEPENDENCE OF THE RATE OF OXIDATION UPON URANIUM DIOXIDE CONCENTRATION

A. 1 INTRODUCTION 52

A.2 DESCRIPTION OF THE CALCULATION PROCEDURE 52

A.3 AN EXAMPLE: EQUATION PARAMETERS FOR THE ISOTHERMAL OXIDATION 54 OF URANIUM DIOXIDE AT $400{ }^{\circ} \mathrm{C}$

APPENDIX B DETERMINATION OF THE EFFECT OF OXYGEN CONCENTRATION AND VOLOXIDIZER ROTATION SPEED UPON THE RATE OF OF OXIDATION OF URANIUM DIOXIDE

B.1 OXYGEN CONCENTRATION EFFECTS

B. 2 EFFECTS OF VOLOXIDIZER ROTATION SPEED 62

APPENDIX C EVALUATION OF PARAMETERS FOR THE REACTION RATE EXPRESSION 64

C. 1 DETERMINATION OF THE VOLUME RATIO OF FUEL TO CLADDING IN A FUEL 64 ELEMENT

C. 2 DETERMINATION OF THE SOLIDS DENSITY 64

C. 3 DETERMINATION OF THE INLET MASS FRACTION OF INERT SOLIDS 65

C. 4 DETERMINATION OF THE URANIUM DIOXIDE CONCENTRATION

C.5 DETERMINATION OF THE INLET SOLIDS VOID FRACTION 66

C. 6 DETERMINATION OF THE CROSS-SECTIONAL AREA OCCUPIED BY SOLIDS 67

APPENDIX D COMPUTER PROGRAM LISTINGS

$\begin{array}{lll}\text { D. } 1 \text { COCURRENT VOLOXIDIZER OPERATION } & 70\end{array}$

D.2 COUNTERCURRENT VOLOXIDIZER OPERATION 76

D.3 SEMI-BATCH VOLOXIDIZER OPERATION

$\begin{array}{lll}\text { APPENDIX E SAMPLE PROGRAM OUTPUT } & 87\end{array}$

E. 1 COCURRENT VOLOXIDIZER OPERATION 88

E.2 COUNTERCURRENT VOLOXIDIZER OPERATION 97

$\begin{array}{lll}\text { E. } 3 & \text { SEMI-BATCH VOLOXIDIZER OPERATION } & 106\end{array}$ 


\section{ABSTRACT \\ MATHEMATICAL MODELING OF THE VOLOXIDATION PROCESS}

T. G. Stanford

Voloxidation is a process for the removal of volatile fission products prior to dissolution during spent nuclear fuel reprocessing. Both continuous and batch processes are being evaluated for this task. At the present time, it appears as if the rotary-kiln voloxidizer is the most attractive of the various alternatives which have been evaluated.

A series of computer programs have been written as an aid in the evaluation of processing and design parameters associated with the voloxidation process. Cocurrent, countercurrent, and semi-batch rotary-kiln operation have been simulated. The assumption made in the development of these models is that the release of tritium and other volatile fission products is directly dependent upon the amount of uranium dioxide oxidized to $\mathrm{U}_{3} \mathrm{O}_{8}$ during the voloxidation process. Kinetic expressions have been developed from available data. These are "global" kinetic expressions which take into account all of the physicochemical processes which are occurring. Material bolonies describing the various modes of voloxidizer operation and incorporating appropriate kinetic expression evlolve as first-order nonlinear ordinary differential equations. The computer algorithm used to solve these equations is a 4 th order Runge-Kutta technique. The parameters used for illustrative cases which are presented are those which are felt to be most representative of the actual parameters which will be encountered. 
CHAPTER 1 .

AN OVERVIEW OF VOLOXIDATION

PROCESS DEVELOPMENT WORK

\subsection{INTRODUCTION}

The containment of radioactive wastes from nuclear fuel reprocessing plants has received considerable attention in the recent past. The recovery, entrapment, and disposal of volatile fission products has been the subject of an extensive design and development effort for several years. 1 The EPA (Environmental Protection Agency) and the NRC (Nuclear Regulatory Commission) have issued standards for the emission of krypton-85 and iodine-129, which are expected to take effect in $1983 .{ }^{2}$ Although the EPA does not have sufficient information to propose new release standards for tritium, it does favor development of systems for its control. 2 The work discussed in this report is that associated with the development and design of tritium containment systems; especially the voloxidation process.

\subsection{TRITIUM CONTAINMENT SYSTEMS: VOLOXIDATION}

\subsubsection{Evolution of the Voloxidation Process}

Several alternative processes for containment of tritium emissions from nuclear fuel reprocessing facilities have been proposed. ${ }^{1,3,4,5}$ of these, the voloxidation process has received most of the attention. It has been singled out by the people at Oak Ridge National Laboratory (ORNL) for extensive development work.

Voloxidation is a word derived from two others; "volatilization" and "oxidation." It is a descriptor for a process in which volatile fission products are separated from spent nuclear fuel which has been sheared into small segments. Release of the volitial fission products is facilitated by oxidation of the spent nuclear fuel. This is a "head-end" process step which would be added to a nuclear fuel reprocessing plant flowsheet between the 
shearing and dissolution steps.. It was felt initially that the voloxidation process would provide a means for removing krypton, xenon, iodine, and tritium from spent liquid-metal fast breeder reactor (LMFBR) fuel. Preliminary studies showed that volatilization of the tritium was almost quantitative while about $45 \%$ of the krypton and about $75 \%$ of the iodine were released during oxidation of the fuel. $1,6,8$ Hence, the primary purpose of the voloxidation process is to remove tritium from the fuel before it is dissolved for further processing. The majority of the tritium which is produced in LMFBR's will diffuse through the stainless steel cladding of the fuel elements and appear in the reactor cover gas so the removal of the remaining tritium by voloxidation is not crucial. With light water reactor (LWR) fuels, most of the tritium is retained either in the fuel matrix or in the Zircaloy cladding material. Thus, voloxidation is a necessary process step for these fuels if tritium is to be kept from contaminating the aqueous Purex streams. 1,6,8

\subsubsection{Fundamental Development Work}

Fundamental studies associated with the voloxidation process have been numerous. No attempt will be made here to review all of the pertinent work in this area. Only the results which have significance for the engineering design of the process will be presented. The reader is referred to the reports by Groenier ${ }^{7}$ and Nicholson ${ }^{6}$ for more detailed reviews of these studies.

\subsubsection{Preliminary Studies}

Initial studies were conducted to evaluate the volatile fission product release potential of the voloxidation process. The following observations were made as a result of these studies: $1,6,7$

1. Release of between $88 \%$ and $100 \%$ of the tritium contained in either LWR or LMFBR type fuel can be affected by oxidation of the fuel. 
2. During oxidation, approximately $45 \%$ of the krypton and approximately $75 \%$ of the iodine were released from the fuel samples. Xenon also was not completely released from the fuel.

3. Both heating in an inert atmosphere and vacuum outgassing were found to be much less efficient in removing tritium and other volatile fission products than was voloxidation.

Thus, the voloxidation process now is felt to be the most practical method of tritium isolation even though release of other volatile fission products is less than quantitative.

\subsubsection{Oxidation Studies}

The importance of fuel oxidation was evident when results of the preliminary studies were evaluated. Consequentiy, a program of work was conducted to examine the factors affecting the oxidation of both LWR and LMFBR type fuels. During the course of this work it was found that: ${ }^{1,6,7}$

1. Oxidation of $\mathrm{UO}_{2}$ samples in air occurred between $350^{\circ} \mathrm{C}$ and $550{ }^{\circ} \mathrm{C}$.

2. The maximum rate of oxidation of $\mathrm{UO}_{2}$ occurred at $480^{\circ} \mathrm{C}$; the rate being $21 / 2$ times slower at $450{ }^{\circ} \mathrm{C}$ and 2 times slower at $600{ }^{\circ} \mathrm{C}$.

3. At temperatures above $500^{\circ} \mathrm{C}$, sintering of the $\mathrm{UO}_{2}$ resulted in a hard "crust" which reduced the rate of oxidation of the fuel significantly.

4. All samples of $\mathrm{UO}_{2}$ which were completely oxidized to $\mathrm{U}_{3}{ }_{8}$ also were fragmented.

5. Oxidation of $(U, P \dot{P}) \mathrm{O}_{2}$ samples occurred in a two-step process; a relatively fast oxidation to an oxygen/metal (0/M) molar ratio of approximately 2.3 followed by a much slower oxidation to an $0 / \mathrm{M}$ ration of about 2.57. (This corresponds to a $U_{3} \mathrm{O}_{8}-\mathrm{PuO}_{2}$ mixture for the $20 \%$ Pu samples which were oxidized.) 
6. First-stage oxidation of the mixed-oxide fuels occurred between $350{ }^{\circ} \mathrm{C}$ and $600{ }^{\circ} \mathrm{C}$. No fragmentation of the samples was observed when the $0 / \mathrm{M}$ ratio was less than 2.3 .

7. Complete oxidation of the samples to an $0 / \mathrm{M}$ ratio of about 2.57 occurred at temperatures between $480^{\circ} \mathrm{C}$ and $600{ }^{\circ} \mathrm{C}$. Samples so oxidized were found to have fragmented.

8. Samples containing 0.25 mole percent plutonium could not be oxidized to $0 / M$ ratios greater than about 2.36 even at temperatures as high as $850{ }^{\circ} \mathrm{C}$. It was also ovserved that these samples did not fragment upon oxidation.

Based upon the results of these oxidation studies, the temperature at which the voloxidizer is operated will probably be between $450{ }^{\circ} \mathrm{C}$ and $500{ }^{\circ} \mathrm{C}$. Temperatures within this range are low enough to prevent sintering of the fuel and high enough to allow the oxidation reaction to proceed at a reasonable rate.

\subsubsection{Engineering Development Work}

Several types of equipment have been considered as devices in which the oxidation of spent nuclear fuel could be affected. Among these equipment types are the batch tray reactor, the continuous stirred-bed reactor, and the rotary kiln. 1,8 The engineering development work discussed here will focus upon the rotary-kiln voloxidizer; the device which, at this time, appears to offer operational advantages that the other equipment types do not. It has been determined in initial engineering development studies that: 1,7,8

1. The rate of oxidation of $\mathrm{UO}_{2}$ in a rotary kiln attains a maximum at $480{ }^{\circ} \mathrm{C}$. This reconfirms the results obtained during batch oxidation of $\mathrm{UO}_{2}$.

2. Agitation is essential for the complete oxidation of $\mathrm{UO}_{2}$. This is 
especially true with clad fuel because of the smaller surface area available for oxidation.

3. An increase in the concentration of oxygen in the oxidizing atmosphere increases the rate of oxidation but it also causes sintering of the fuel which reduces the rate of oxidation.

These engineering development studies have established the importance of agitation during fuel oxidation. They also have shown that, while some advantage is to be gained by adjusting the oxygen concentration in the oxidizing atmosphere, air is the most logical oxygen source for this process.

\subsection{ENGINEERING DESIGN OF THE VOLOXIDATION PROCESS}

Engineering development work has produced a great deal of design engineering information. Although it appears at this time that the rotary kiln is the best reactor type for voloxidation, many operational difficulties exist. Because of dust formation and semi-volatile fission product release, many people are encouraging closer studies of batch systems. Ratliff ${ }^{8}$ has reviewed the design aspects of voloxidation in detail. A discussion of both batch and continuous operation is included in his report.

It is important that many design criteria receive careful scrutiny during this period of voloxidation process evaluation. This can best be done using a mathematical model of the process. A mathematical description of the process allows one to examine the effects of various process changes; eliminating some and changing others so that optimum operation is achieved. Although not all of the necessary design data are availableat this time, it is possible to make initial process simulations using the information which has been obtained during fundamental and engineering development studies. The development of a mathematical model of the voloxidation process is discussed in the remainder of this report. 
CHAPTER 2

DEVELOPMENT OF THE REACTOR MODEL

\subsection{INTRODUCTION}

Continuous and semi-batch modes of operation are being considered for the voloxidation process. Sheared fuel segments, approximately one to two inches in length, are to be fed into a cylindrical kiln along with an oxygen rich gas stream. The kiln is equipped with internal mixing flights which enhance mixing and help dislodge the fuel from the cladding by a lift and drop action.

Design of the voloxidizer will be based on the desire to achieve complete oxidation of the fuel which has been found to be closely related to the release of volatile fission products. Thus, for continuous operation, the rotary kiln should be designed for a solids residence time that will allow complete oxidation of the fuel. The design for semi-batch operation should result in a batch processing time which will allow the fuel to be completely oxidized.

\subsection{COCURRENT OPERATION}

The gas feed stream to the reactor is composed of oxygen and an inert diluent such as either nitrogen or helium. The solids feed stream consists of spent nuclear fuel rods which have been chopped into pieces one to two inches in length. In cocurrent operation, the gas and solid phases pass through the reactor in the same direction. (See Figure 2.1).

\subsubsection{Dịspersion of Both Gas and Solid Phases}

The oxygen mass balance for the reactor is

$$
-G \frac{d C_{2}}{d z}+D_{\text {eff }} . \frac{d^{2} \cdot c_{O_{2}}}{d z^{2}}+r_{0_{2}}=0
$$




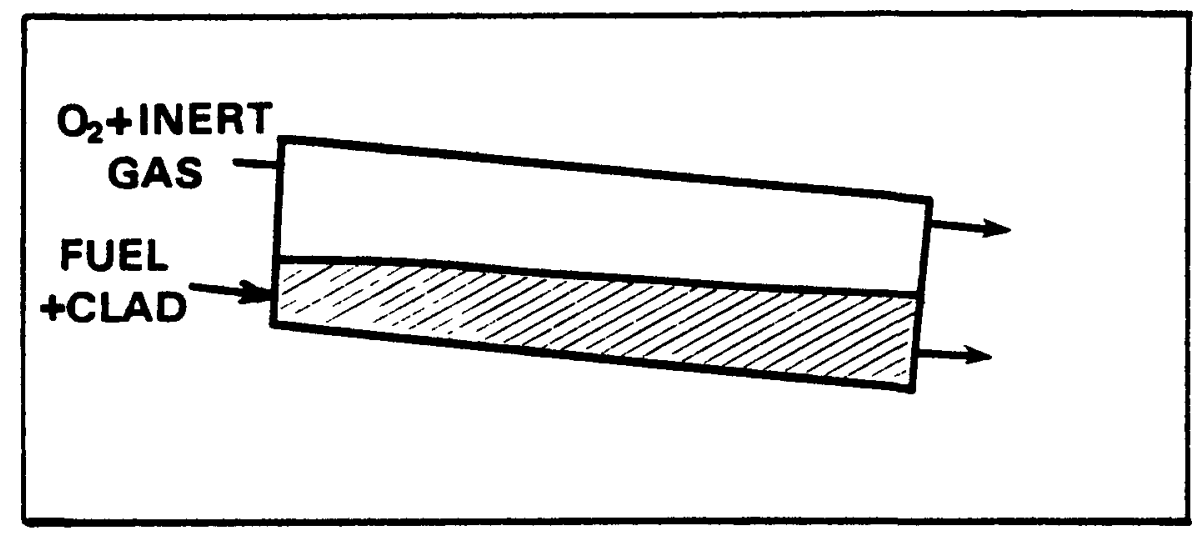

\section{COCURRENT}

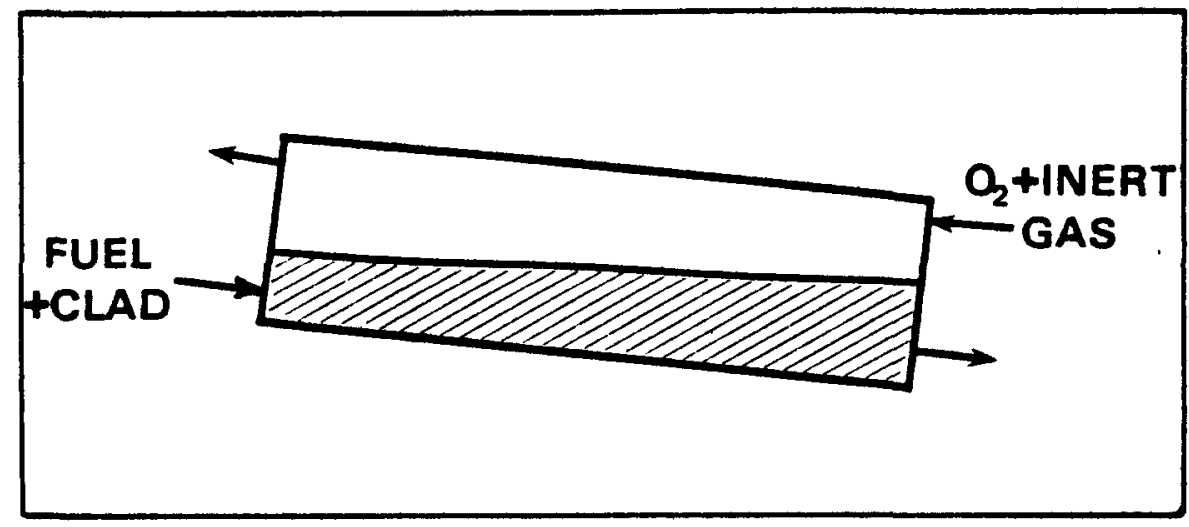

\section{COUNTERCURRENT}

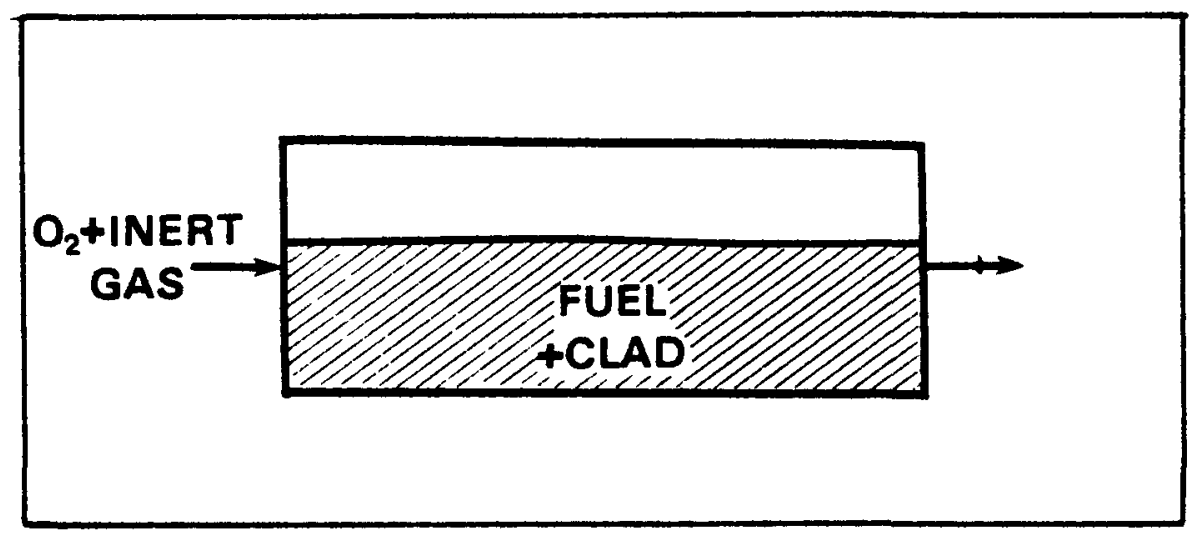

SEMIBATCH

MODES OF VOLOXIDIZER OPERATION

Figure 2.1 
where $G$ is the flux of the inert gas through the reactor, $C_{\mathrm{O}_{2}}$ is the oxygen concentration based on the inert gas present, $D_{\text {eff }}$ is an effective dispersion coefficient for oxygen, and $r_{O_{2}}$ is the volumetric rate of reaction of the oxygen based upon an empty reactor.

The uranium dioxide ${ }^{*}$ mass balance for the reactor is

$$
-S \frac{d C_{\mathrm{wO}_{2}}}{d z}+D_{\text {eff }_{\mathrm{UO}_{2}}} \frac{d^{2} C_{\mathrm{uO}_{2}}}{d z^{2}}+\mathrm{r}_{\mathrm{UO}_{2}}=0
$$

where $S$ is the flux of inert solids (in this case the fuel cladding), $\mathrm{C}_{\mathrm{UO}_{2}}$ is the uranium dioxide concentration based on the inert solids present, $D_{\text {eff }}$ is an effective dispersion coefficient for uranium dioxide, and $\mathrm{ruO}_{2}$ is the rate of reaction of the uranium dioxide based upon an empty reactor.

The boundry conditions for equations (2.1) and (2.2) are. 9-12

$$
\begin{aligned}
& \left(\left.\mathrm{GC}_{0_{2}}\right|_{z=0}\right)=\left(\mathrm{GC}_{0_{2}}-\left.\mathrm{Deff}_{\mathrm{O}_{2}} \frac{\mathrm{dC}_{\mathrm{O}_{2}}}{\mathrm{dz}}\right|_{z=0}\right) \\
& \left(\left.\frac{\mathrm{dC}_{0}}{\mathrm{dz}}\right|_{z=\ell}\right)=0 \\
& \left(\left.\mathrm{SC}_{\mathrm{UO}_{2}}\right|_{\mathrm{z}=0-}\right)=\left(\mathrm{SC}_{\mathrm{UO}_{2}}-\left.\mathrm{Deff}_{\mathrm{UO}_{2}} \frac{\mathrm{dC}_{\mathrm{UO}}}{\mathrm{dz}}\right|_{z=0}\right)
\end{aligned}
$$

* Little is known about the oxidation of mixed oxide fuels. The reactor models are developed for oxidation of $\mathrm{UO}_{2}$ but apply equally to $(\mathrm{U}, \mathrm{Pu})_{2}$ fuels. 


$$
\left(\left.\frac{\mathrm{dC}_{\mathrm{UO}}}{\mathrm{dz}}\right|_{\mathrm{z}=\ell}\right)=0
$$

However, for this system, it is impossible to have dispersion of the reactants at the reactor entrance so equations (2.3) through (2.6) may be replaced by

$$
\left(\left.\frac{c_{0}}{d z}\right|_{z=0}\right)=\left(\left.{ }^{c_{0}}\right|_{z=0}\right)
$$

$$
\left(\left.\frac{\mathrm{dC}_{0_{2}}}{\mathrm{dz}}\right|_{\mathrm{z}=0}\right)=0
$$

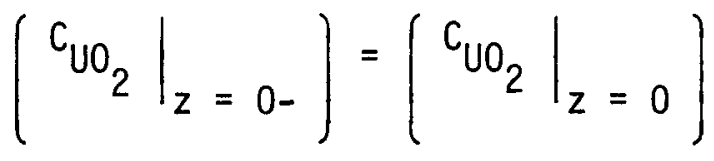

$$
\left(\left.\frac{\mathrm{dC}_{0_{2}}}{\mathrm{dz}}\right|_{\mathrm{z}=0}\right)=0
$$

Equations (2.1), (2.2), and (2.7) through (2.10) may be written as the following equivalent first order system of differential equations. 


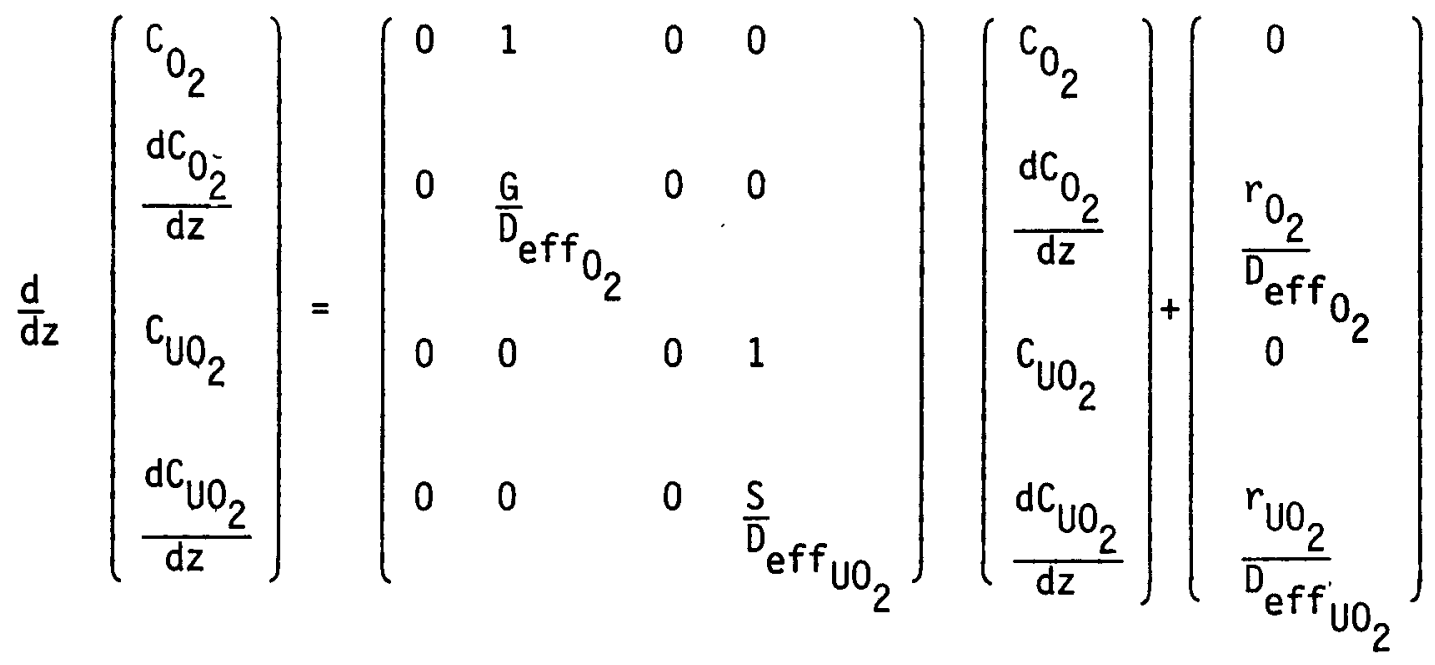

with

$$
\left(\begin{array}{l}
c_{0_{2}} \\
\frac{\mathrm{dc}_{0_{2}}}{\mathrm{dz}} \\
\frac{\mathrm{c}_{\mathrm{uO}_{2}}}{\mathrm{dc} \mathrm{UO}_{2}}
\end{array}\right)=\left(\begin{array}{c}
\left(\left.\mathrm{c}_{0_{2}}\right|_{z}=0\right. \\
0 \\
z=0
\end{array}\right)
$$

\subsubsection{Negligible Gas Phase Dispersion}

It is unlikely that dispersion in the gas phase will be significant.

Thus, $\mathrm{Deff}_{\mathrm{O}_{2}}=0$ and equation (2.1) becomes

$$
-G \frac{d C_{0_{2}}}{d z}+r_{0_{2}}=0
$$

with

$$
c_{0_{2}}=\left({ }^{C_{0_{2}} \mid z=0}\right) \text { at } z=0
$$

at the reactor inlet. 
The equations describing operation of the reactor are equations (2.13), $(2.14),(2.2),(2.9)$, and $(2.10)$. They may be written in the following equivalent form

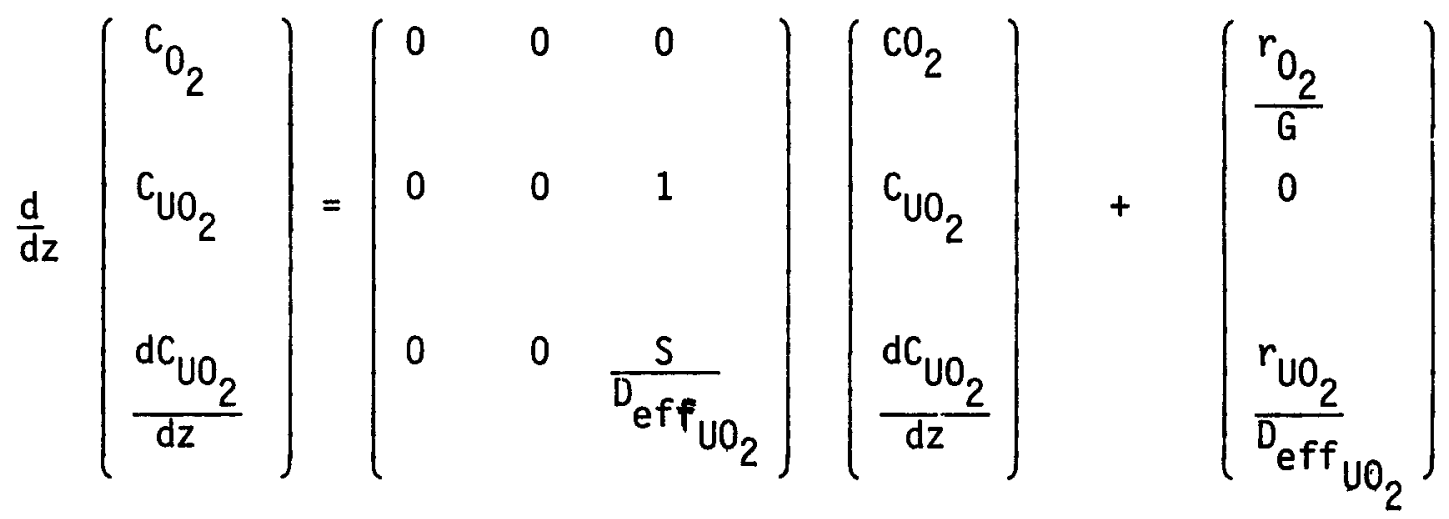

with

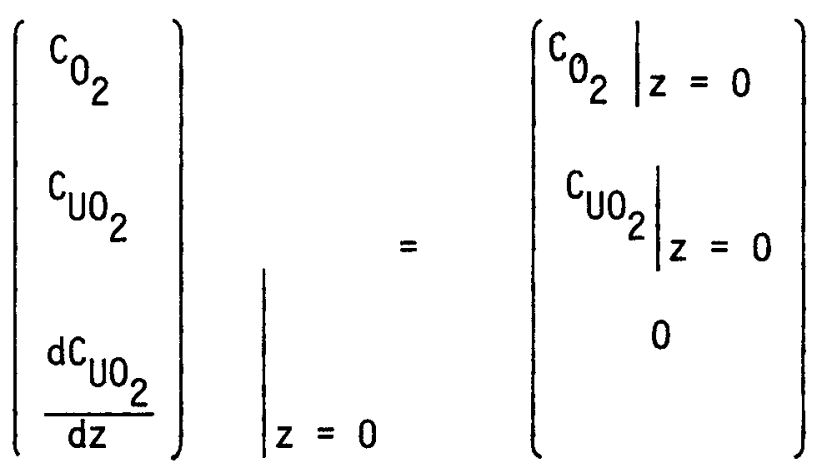

2.2.3 Negligible Dispersion of Reactants

When dispersion of the solid phase is insignificant, equation (2.2) becomes

$$
-S \frac{\mathrm{dC}_{\mathrm{UO}_{2}}}{\mathrm{dz}}+\mathrm{r}_{\mathrm{UO}_{2}}=0
$$

with

$$
C_{\mathrm{UO}_{2}}=\left(\left.\mathrm{CuO}_{2}\right|_{z=0}\right) \text { at } z=0
$$

If both gas phase and solid phase dispersion may be neglected, then reactor operation is described by equations (2.13), (2.14), (2.17), and (2.18) which may be written as 


$$
\frac{d}{d z}\left(\begin{array}{c}
c_{0_{2}} \\
c_{\mathrm{uO}_{2}}
\end{array}\right)=\left(\begin{array}{c}
\frac{r_{0_{2}}}{G} \\
\frac{r_{\mathrm{UO}_{2}}}{S}
\end{array}\right)
$$

with

$$
\left(\left.\begin{array}{l}
c_{0} \\
c_{u_{2}}
\end{array}\right|_{z=0}=\left(\begin{array}{l}
\left.c_{0_{2}}\right|_{z}=0 \\
\left.c_{u_{2}}\right|_{z=0}
\end{array}\right)\right.
$$

\subsection{COUNTERCURRENT OPERATION}

Although it would not be advantageous to operate an oxidation reactor in a countercurrent flow scheme, this case is examined for completeness. The only difference between this case and the case of cocurrent operation is that the gas phase and the solid phase move in opposite directions through the reactor. (See Figure 2..1)

\subsubsection{Dispersion of Both Gas and Solid Phases}

For this mode of reactor operation, the oxygen mass balance is

$$
G \frac{d C_{2}}{d z}+D_{e f f} \frac{d^{2} C_{O_{2}}}{d z^{2}}+r_{O_{2}}=0
$$

while the uranium dioxide mass balance remains unchanged and is

$$
-s \frac{d C_{U 0_{2}}}{d z}+D_{e f f} \frac{d^{2} C_{U O_{2}}}{d z^{2}}+r_{U O_{2}}=0
$$


The boundry conditions for equation (2.21) are

$$
\begin{gathered}
-\left.\mathrm{GC}_{\mathrm{O}_{2}}\right|_{z=\ell+}=\left(-\mathrm{GC}_{\mathrm{O}_{2}}-\left.\mathrm{D}_{\text {eff }} \frac{\mathrm{dC}_{\mathrm{O}_{2}}}{\mathrm{dz}}\right|_{z=\ell}\right) \\
\left.\frac{\mathrm{dC}_{\mathrm{O}_{2}}}{\mathrm{dz}}\right|_{z=0}=0
\end{gathered}
$$

The boundry conditions for equation (2.2) are unchanged.

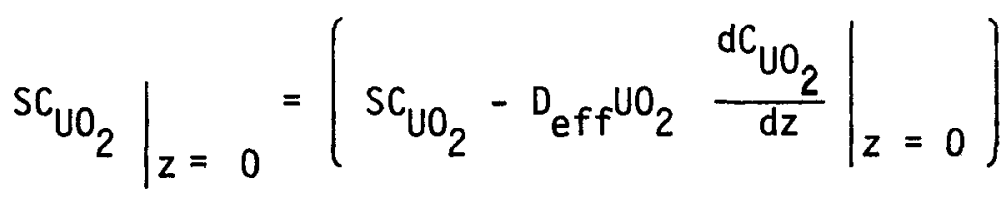

$$
\begin{aligned}
& \left(\left.\frac{\mathrm{dC}_{\mathrm{UO}_{2}}}{\mathrm{dz}}\right|_{z=\ell}\right)=0
\end{aligned}
$$

It is again possible to modify the boundry conditions because of the absence of reactant dispersion at the entrance to the reactor. Thus, equations $(2.20),(2.5)$, and (2.6) become

$$
\begin{gathered}
\left(c_{0_{2}} \mid z=\ell+\right)=\left(c_{0_{2}} \mid z=\ell\right)=0 \\
\left(\left.\frac{d C_{0}}{d z}\right|_{z=\ell}\right)=0
\end{gathered}
$$




$$
\begin{gathered}
\left(\left.{ }^{\mathrm{CuO}_{2}}\right|_{\mathrm{z}=0-}\right)=\left(\left.\mathrm{C}_{\mathrm{UO}}\right|_{\mathrm{z}=0}\right) \\
\left(\left.\frac{\mathrm{dc}_{\mathrm{UO}}}{\mathrm{dz}}\right|_{z=0}\right)=0
\end{gathered}
$$

One would like to formulate this problem as an initial-valve problem rather than a boundry-valve problem so that the problem associated with the numerical solution of boundry-valve problems may be avoided. This requires a knowledge of either $\left(\left.{ }^{C_{0_{2}}}\right|_{z=0}\right)$ or $\left(\left.{ }^{C_{\mathrm{UO}_{2}}}\right|_{z=\ell}\right)$. In this work $\left(\left.\mathrm{C}_{2}\right|_{z}=0\right)$ will be evaluated. An oxygen mass balance for the system provides the required relationship.

$$
\begin{aligned}
& S\left({ }^{\left.C_{2}\right|_{2} \mid z=0}\right)+G\left(C_{0_{2} \mid z=\ell} \mid=S\left(\left.C_{U_{2}}\right|_{z=\ell}\right)+\right. \\
& S\left(C_{U_{3} O_{8} \mid z=\ell}\right)\left(\frac{4 \text { mole } 0_{2}}{\text { mole } U_{3} O_{8}}\right)+G\left(C_{2} \mid z=0\right)
\end{aligned}
$$

The stoichiometry of the reaction is

$$
O_{2}+3 U_{2}+U_{3} O_{8}
$$

If one defines $x$ as the fractional conversion of uranium dioxide, then the oxygen mass balance gives 


$$
\begin{aligned}
& S\left(\left.\mathrm{CuO}_{2}\right|_{z=\ell}\right)^{+S}\left(\left.\mathrm{CuO}_{2}\right|_{z=0}\right)^{-}(1-\mathrm{x}) \\
& S\left(\left.\mathrm{C}_{3} \mathrm{O}_{8}\right|_{z=\ell}\right)=\frac{1}{3} \mathrm{~S}\left(\left.\mathrm{C}_{\mathrm{UO}_{2}}\right|_{z=0}\right) \cdot x
\end{aligned}
$$

and the overall oxygen mass balance becomes, upon rearrangement

$$
\left(\begin{array}{l|l}
C_{0_{2}} \mid z=0
\end{array}\right)=\left(\left.C_{0_{2}}\right|_{z}=\ell\right)^{-\frac{1}{3}} \frac{S}{G} \quad\left(\left.{ }^{C_{u 0_{2}}}\right|_{z=0}\right)
$$

Equations (2.21) and (2.2) may be expressed as an equivalent system of first order differential equations

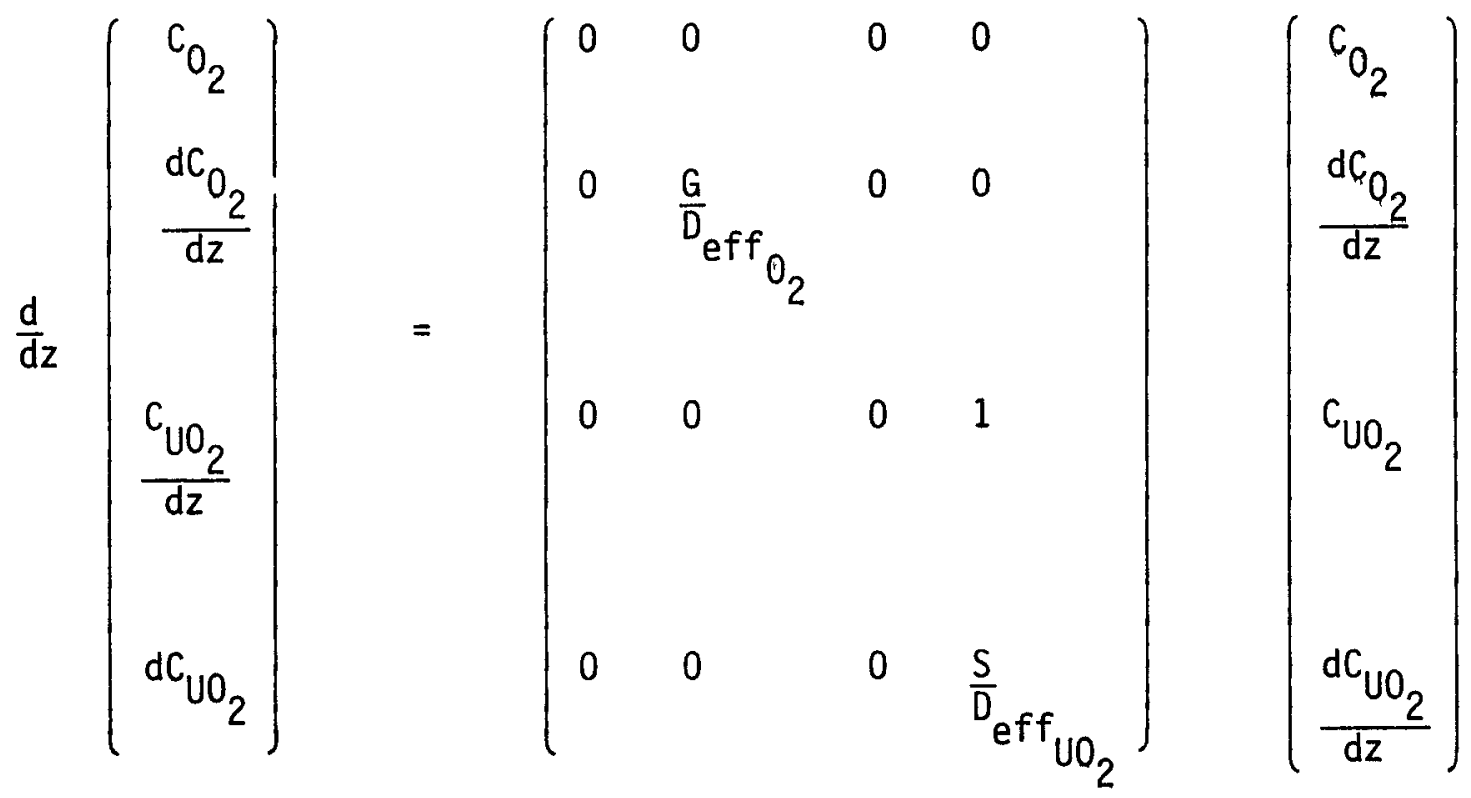

$$
\begin{aligned}
& +\left(\begin{array}{l}
0 \\
-\frac{r_{0_{2}}}{\bar{D}_{\text {eff }}} \\
0 \\
-\frac{r_{\mathrm{UO}_{2}}}{\mathrm{D}_{\text {eff }}}
\end{array}\right)
\end{aligned}
$$


$-1.6-$

with the following boundry conditions

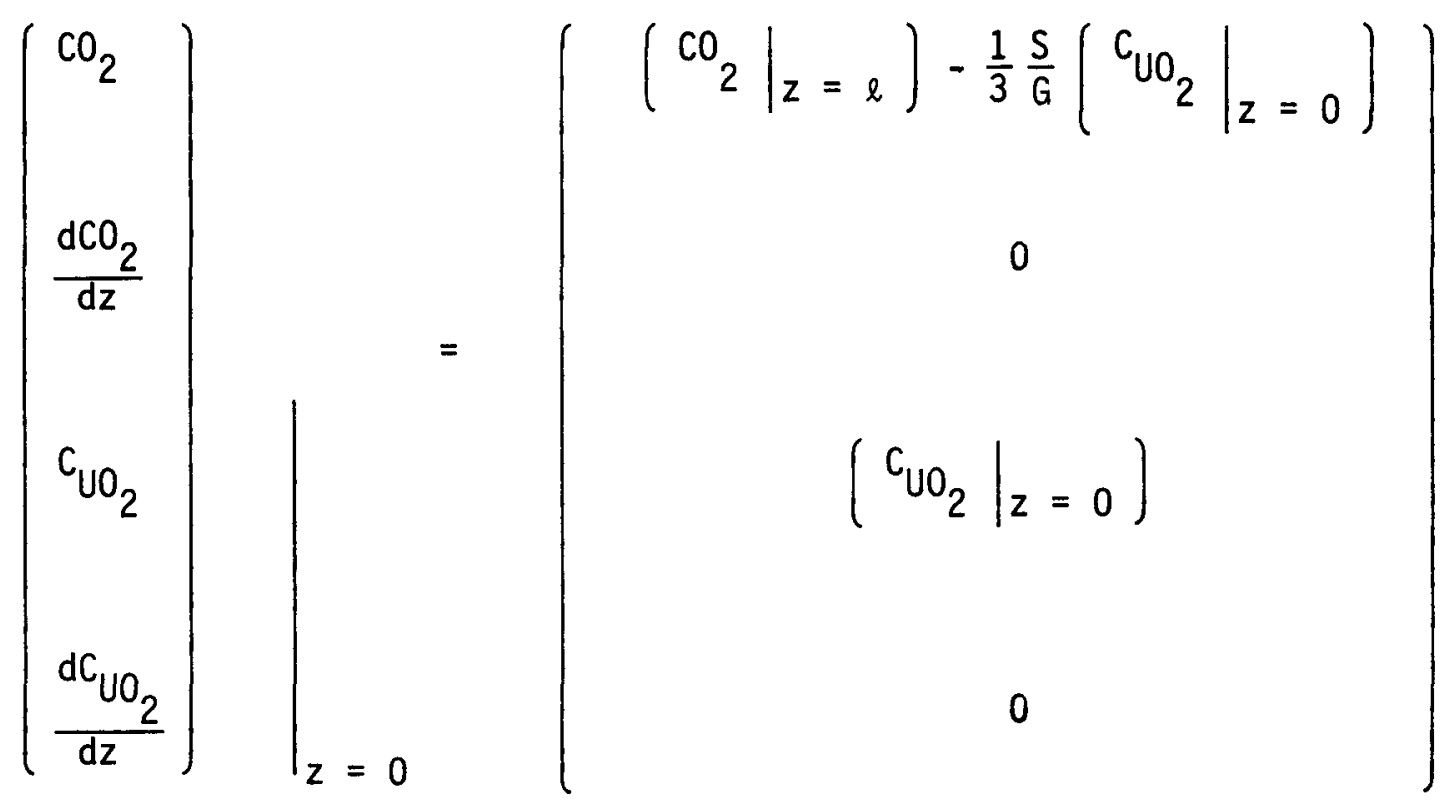

2.3.2 Negligible Gas Phase Dispersion

When there is no significant dispersion in the gas phase, the oxygen mass balance becomes

$$
G \frac{\mathrm{dC}_{\mathrm{O}_{2}}}{\mathrm{dz}}+\mathrm{r}_{\mathrm{O}_{2}}=0
$$

with

$$
C_{\dot{0}_{2}}=\left.C_{0_{2}}\right|_{z}=0 \text { at } z=\ell
$$

As before, the relationship between $\left(\left.\mathrm{C}_{\mathrm{O}_{2}}\right|_{\mathrm{z}}=\right)$ and $\left(\left.\mathrm{C}_{\mathrm{O}_{2}}\right|_{\mathrm{z}=\ell}\right)$ is

$$
\left(\begin{array}{l|l}
C_{0_{2}} & z=0
\end{array}\right)=\left(\begin{array}{l|l}
C_{0_{2}} & z=\ell
\end{array}\right)-\frac{1}{3} \frac{S}{G} \quad\left(C_{U_{2}} \mid z=0\right)
$$


Equations $(2.28),(2.26),(2.2),(2.9)$, and $(2.10)$ describe the steady-state operation of the system. They may be written as the following equivalent first-order system

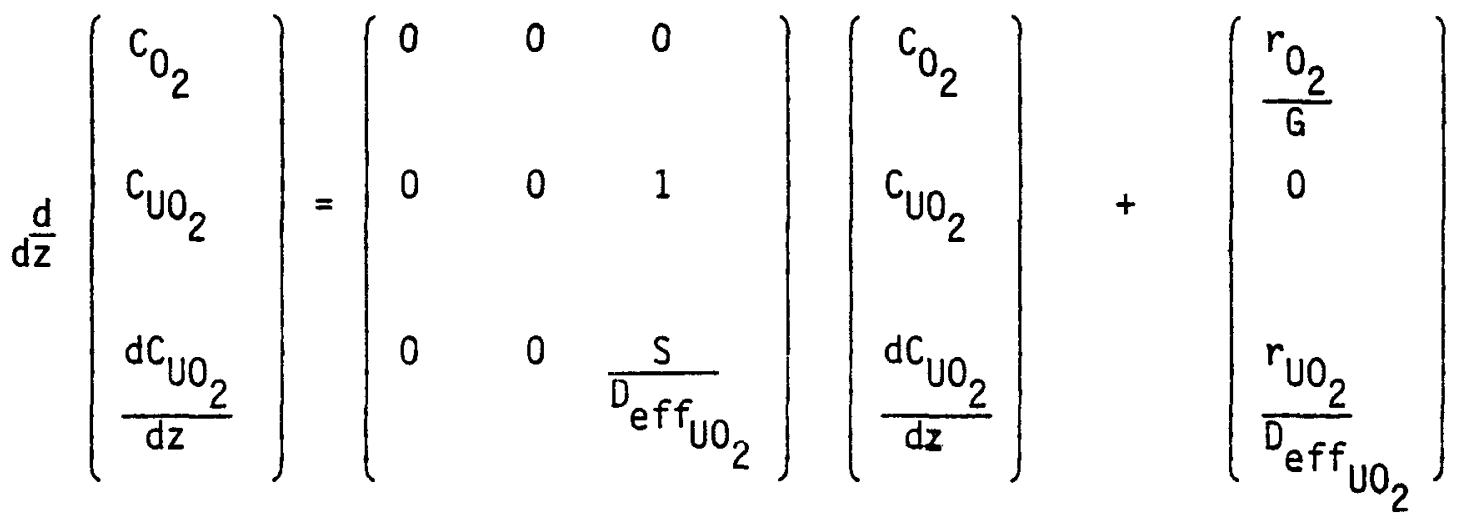

with

$$
\left(\left.\begin{array}{c}
\mathrm{C}_{\mathrm{O}_{2}} \\
\mathrm{C}_{\mathrm{UO}_{2}} \\
\frac{\mathrm{dc} \mathrm{UO}_{2}}{\mathrm{dz}}
\end{array}\right|_{\mathrm{z}=0}=\left(\begin{array}{c}
\left(\left.\mathrm{C}_{\mathrm{O}_{2}}\right|_{\mathrm{z}=\ell}\right)=\frac{1}{3} \frac{\mathrm{s}}{\mathrm{G}}\left(\left.\mathrm{C}_{\mathrm{UO}_{2}}\right|_{\mathrm{z}=0}\right. \\
\left(\left.\mathrm{CuO}_{2}\right|_{\mathrm{z}=0}\right) \\
0
\end{array}\right)\right.
$$


2.3.3 Negligible Dispersion of Reactants

Neglecting the dispersion of the solid phase, one obtains the following uranium dioxide mass balance

$$
-\mathrm{s} \frac{\mathrm{dC}_{\mathrm{UO}_{2}}}{\mathrm{dz}}+\mathrm{r}_{\mathrm{uO}_{2}}=0
$$

with the boundry condition

$$
\mathrm{CuO}_{2}=\left(\left.\mathrm{CuO}_{2}\right|_{z=0}\right) \text { at } z=0
$$

If neither gas phase nor solid phase dispersion is felt to be significant, then operation of the system is described by the following first order non-linear differential equation

$$
\frac{d}{d z}\left(\begin{array}{l}
C_{0_{2}} \\
C_{U_{2}}
\end{array}\right)=\left(\begin{array}{l}
\frac{r_{0_{2}}}{G} \\
\frac{r_{U 0_{2}}}{S}
\end{array}\right)
$$

with the boundry condition

$$
\left(\left.\begin{array}{l}
C_{0_{2}} \\
C_{U_{2}}
\end{array}\right|_{z=0}=\left(\begin{array}{c}
\left(\left.C_{O_{2}}\right|_{z=\ell}\right)-\frac{1}{3} \frac{S}{G}\left(\left.C_{U_{2}}\right|_{z=0}\right) \\
\left(\left.C_{U_{2}}\right|_{z=0}\right)
\end{array}\right)\right.
$$


$-19-$

2.4 SEMI -BATCH OPERATION

Solids are processed batch-wise in semi-batch operation. Spent nuclear fuel rods chopped into pieces one to two inches in length again constitute the solid material to be oxidized. The charge is placed in the kiln, heated to the reaction temperature, and then exposed to an oxidizing atmosphere consisting of oxygen and an inert gas dilutent. (See Figure 2.1)

2.4.1 Dispersion of the Gas Phase and Segregation of the Sol id Phase The oxygen mass balance for the reactor is, in this case,

$$
-G \frac{d C_{2}}{d z}+D_{e f f} \frac{d^{2} C_{O_{2}}}{d z^{2}}+r_{O_{2}}=0
$$

and the uranium dioxide mass balance is

$$
V r_{\mathrm{UO}_{2}}=\bar{s} \frac{\mathrm{dC}_{\mathrm{U0_{2 }}}}{\mathrm{dt}}
$$

where $V$ is the volume of the reactor and $\bar{S}$ is the mass of inert solids changed to the reactor. It is to be noted that

$$
r_{0_{2}}=r_{0_{2}}(z, t)
$$

and

$$
r_{u_{2}}=r_{u_{2}}(z, t)
$$


The boundary conditions for equation (2.33) and equation (2.34) are

$$
\begin{aligned}
& \left(\left.\mathrm{GC}_{\mathrm{O}_{2}}\right|_{\mathrm{z}=0}\right)=\left(\mathrm{GC}_{\mathrm{O}_{2}}-\left.\mathrm{D}_{\text {eff } \mathrm{O}_{2}} \frac{\mathrm{dC_{0_{2 } }}}{\mathrm{dz}}\right|_{\mathrm{z}=0}\right) \\
& \left(\left.\frac{\mathrm{dC}_{0_{2}}}{\mathrm{dz}}\right|_{\mathrm{z}=\ell}\right)=0
\end{aligned}
$$

$$
c_{\mathrm{uO}_{2}}=\left(\left.\mathrm{c}_{\mathrm{uO}_{2}}\right|_{\mathrm{t}=0}\right) \text { at } \mathrm{t}=0
$$

As was done previously, dispersion of the gas phase at the reactor inlet is neglected. Thus, equations (2.3) and (2.4) may be replaced by

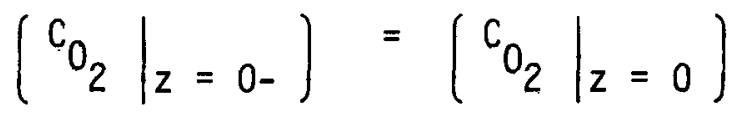

$$
\begin{aligned}
& \left(\left.\frac{\mathrm{dc}_{0}}{\frac{2}{\mathrm{dz}}}\right|_{\mathrm{z}=0}\right)=0
\end{aligned}
$$


2.4.2 Segregation of the Solid Phase with Negligible Dispersion of the Gas Phase

When dispersion in the gas phase is not important, the oxygen mass balance is

$$
-G \frac{d C_{O_{2}}}{d z}+r_{0_{2}}=0
$$

which has the boundry condition

$$
c_{0_{2}}=\left(\left.c_{0_{2}}\right|_{z=0}\right) \text { at } z=0
$$

This mode of reactor operation is described by equations (2.13), (2.14), (2.33), and (2.34).

\subsubsection{Complete Mixing of the Solids Phase}

The mathematical description of the reactor when the solids phase is completely mixed is identical to that of the previous two cases when dispersion in the gas phase is either important or can be neglected. However, when the solids phase is perfectly mixed, the uranium dioxide concentration $\mathrm{C}_{\mathrm{UO}_{2}}$ is no longer a function of axial position in the reactor. This fact must be kept in mind when one solves the equations describing this case.

\subsubsection{Perfect Mixing of Both Phases}

This description of the reactor operations assumes that it is acting like a continuous stirred tank reactor (CSTR). The oxygen mass balance for CSTR operation is

$$
A_{c} G\left(C_{0_{2}} \mid z=0\right)-A_{c} G\left(C_{O_{2}} \mid z=\ell\right)+V r_{O_{2}}=0
$$


where $A_{C}$ is the cross sectional area of the reactor. The uranium dioxide mass balance is

$$
v r_{\mathrm{UO}_{2}}=\bar{s} \frac{d \mathrm{UO}_{2}}{d t}
$$

with the boundry condition

$$
\mathrm{C}_{\mathrm{UO}_{2}}=\left(\left.\mathrm{C}_{\mathrm{UO}_{2}}\right|_{\mathrm{t}=0}\right) \text { at } \mathrm{t}=0
$$

Because the solids phase is completely mixed, the uranium dioxide concentration is a function of time but not of axial position in the reactor. That is

$$
\mathrm{C}_{\mathrm{UO}_{2}}=\mathrm{CuO}_{2}(\mathrm{t})
$$

Reactor operation is thus described mathematically by equations $(2.35),(2.33)$, and (2.34).

\subsection{TEMPERATURE EFFECTS AND NON-ISOTHERMAL OPERATION}

At this time, there is not sufficient data to allow one to consider the consequences of non-isothermal operation. An energy balance for any one of the several cases which have been considered would require knowledge of heat capacities for the spent reactor fuel and its oxidation products as well as a knowledge of heat of combustion data for the fuel. If this information is known, then consideration can be given to problems of start up and to accounting for a solids preheating zone in the reactor. It is important that temperature effects be examined in the voloxidizer design. Thus, it is felt 
that every effort should be made to obtain the necessary data for an accurate energy analysis of the system.

\subsection{DISPERSION COEFFICIENTS FOR THE SOLIDS PHASE AND THE GAS PHASE}

Several of the cases considered in this development require a knowledge of the effective dispersion coefficients for the gas phase and the solids phase. Some work has been done at Oak Ridge National Laboratory (ORNL) 17 in an effort to obtain solids phase dispersion coefficients.

Information about these quantities is very important for the accurate mathematical description of the voloxidizer. Thus, priority should be given to experimental determination of these dispersion coefficients. 


\section{CHAPTER 3}

\section{DEVELOPMENT OF KINETIC EXPRESSIONS FOR}

THE OXIDATION OF $\mathrm{UO}_{2}$ AND $(U, \mathrm{Pu})_{2}$

\subsection{INTRODUCTION}

The goodness of any chemical process simulation depends on the parameters used in it. of course, simulation of systems involving chemical reactions required a knowledge of the reaction kinetics. Voloxidation is a process which involves oxidation of either $\mathrm{UO}_{2}$ or $(\mathrm{U}, \mathrm{Pu}) \mathrm{O}_{2}$. A large proportion of the fundamental work and the engineering development work has been focused on this aspect of the voloxidation process. ${ }^{7}$ It is this work which forms the basis for the kinetic expressions describing the oxidation of both $\mathrm{UO}_{2}$ and $(\mathrm{U}, \mathrm{Pu}) \mathrm{O}_{2}$.

A lack of fundamental physicochemical data and the need for a "simple" description of the complex phemomenia occurring during oxidation of $\mathrm{UO}_{2}$ and $(\mathrm{U}, \mathrm{Pu})_{2}$ make it desirable to develop a "global" kinetic expression for this process. The volumetric rate of oxidation of uranium dioxide is assumed to be represented as

$$
r_{\mathrm{UO}_{2}}=r_{\mathrm{UO}_{2}}\left(\mathrm{C}_{\mathrm{UO}_{2}}, \mathrm{C}_{0_{2}}, \mathrm{~T}, \omega\right)
$$

where $\mathrm{C}_{\mathrm{UO}_{2}}$ is the uranium dioxide based upon the inert solids present, $\mathrm{C}_{2}$ is the oxygen concentration based upon the inert gas present, $T$ is the temperature at which the reaction is occurring, and $\omega$ is the rotational speed of the reactor. These four variables were chosen because they are felt to be the most important factors affecting the rate of oxidation of $\mathrm{UO}_{2}$ and $(\mathrm{U}, \mathrm{Pu}) \mathrm{O}_{2}$.

3.2. RATE OF OXIDATION OF $\mathrm{UO}_{2}$ AND $(U, \mathrm{Pu}) \mathrm{O}_{2}$

3.2.1 Dependence of the Oxidation Rate Upon Uranium Dioxide Concentration $\mathrm{UO}_{2}$ Oxidation

Tennery ${ }^{13}$ made thermogravimetric measurements during the isothermal oxidation of uranium dioxide at several temperatures. The oxygen concentration 
was kept constant at $20 \mathrm{~mol} \%$ by passing $0.8 \mathrm{scfh}$ of "breathing air" through the batch reactor. Results of these experiments are presented as weight gain versus time in Figure 3.1 and Figure 3.2. If it is assumed that the rate of oxidation of uranium dioxide has an $p^{\text {th }}$ order dependence upon uranium dioxide concentration, then one would expect that the time dependence of the fractional conversion of $\mathrm{UO}_{2}$ would be described by the differential equation

$$
d x / d t_{n}=-d(1-x) / d t_{n}=k(1-x)^{p}
$$

where

$$
\mathrm{x}=\left(\mathrm{C}_{\mathrm{UO}}^{\circ}-\mathrm{C}_{-\mathrm{UO}_{2}}^{\circ}\right) / \mathrm{C}^{\circ} \mathrm{UO}_{2}
$$

is the fractional conversion of uranium dioxide and

$$
t_{n}=t / \tau
$$

is a time normalized using $\tau$, the time required for maximum conversion of $\mathrm{UO}_{2}$ to $\mathrm{U}_{3} \mathrm{O}_{8}$ (See Figure 3.3). Equation (3.2) has a solution of the form

$$
t_{n}=-m(1-x)^{n}+b
$$

which may be differentiated to give

$$
d x / d t_{n}=(1-x)^{1-n} / m n=k(1-x)^{p}
$$

with $p=1-n$ and $k=1 / \mathrm{mn}$. Equation (3.5) is used in this work to describe the $t_{n}$ versus $(1-x)$ behavior. It completely determines the fractional conversion, $x$, as a function of the normalized time, $t_{n}$. The procedure used to obtain the parameters in equation (3.5) is described in Appendix A. The calculations associated with the isothermal oxidation at $400{ }^{\circ} \mathrm{C}$ are also presented in this appendix. Table 3.1 presents the equations obtained 


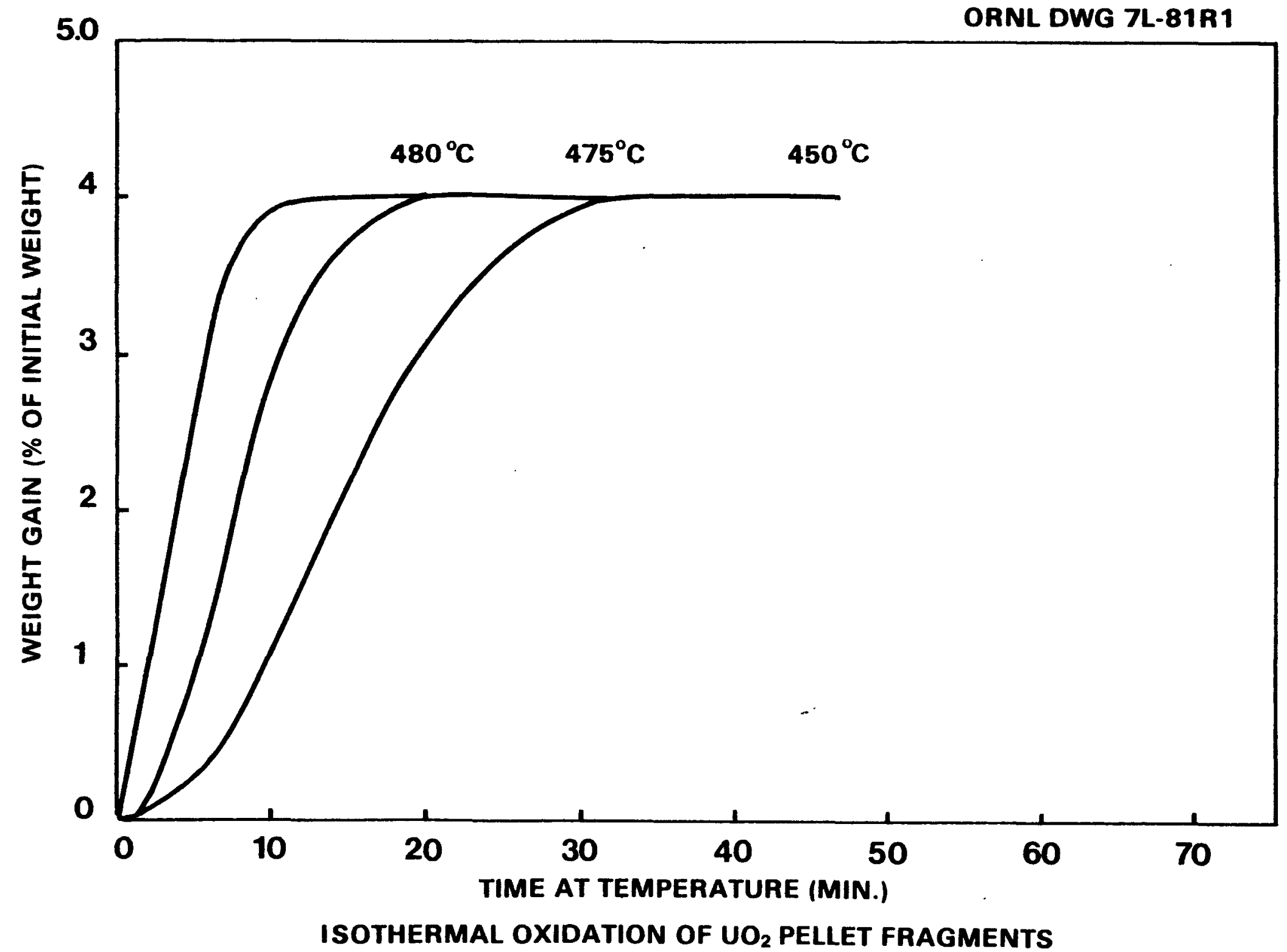

Figure 3.1 


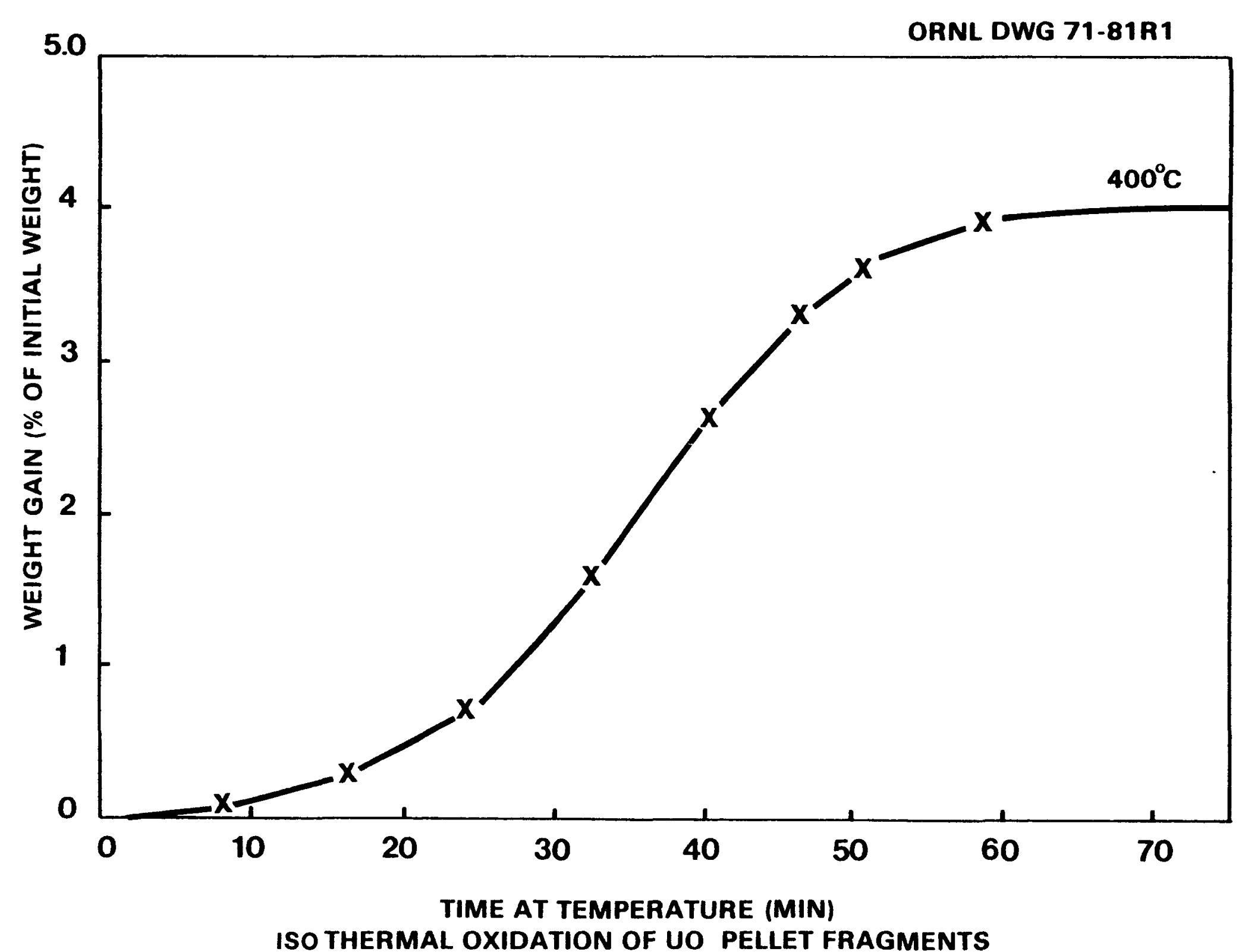

Figure 3.2 ISO THERMAL OXIDATION OF UO PELLET FRAGMENTS 


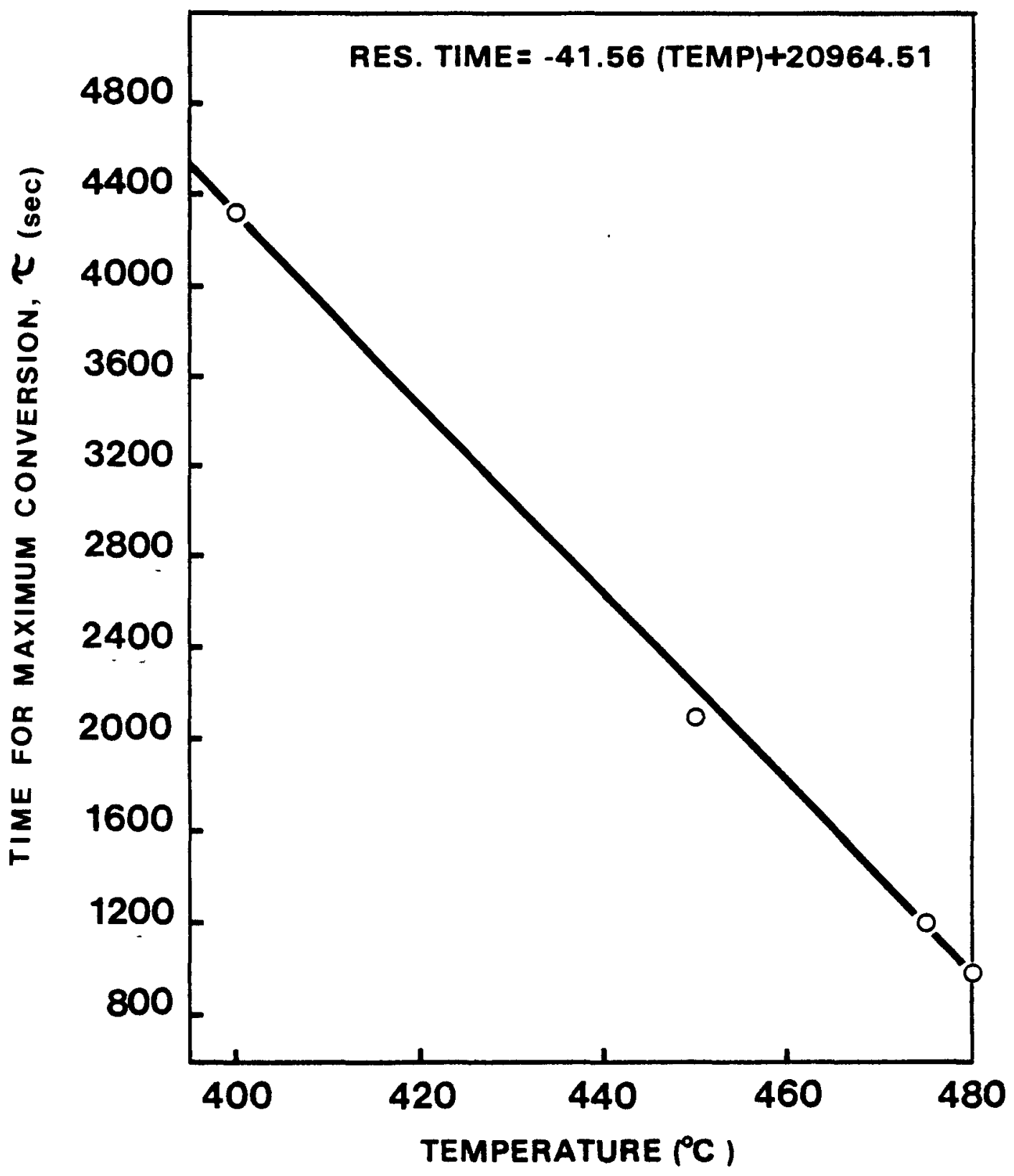

TIME FOR MAXIMUM CONVERSION

AS A FUNCTION OF TEMPERATURE

Figure 3.3 
TABLE 3.1: PARAMETERS IN THE EQUATION DESCRIBING VARIATIONS OF THE FRACTIONAL CONVERSION WITH TIME

\begin{tabular}{|c|c|c|c|}
\hline Temperature & $\begin{array}{l}\text { Break } \\
\text { Point } \\
\text { (BP) }\end{array}$ & $\begin{aligned} & \text { Equation I } \\
< & \mathrm{BP} \quad 0 \quad \mathrm{~B} . \mathrm{P} . \\
& 0.0<(1-x)<\mathrm{BP}\end{aligned}$ & 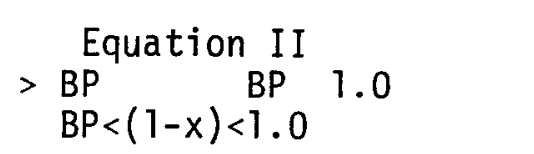 \\
\hline 400 & .6 & $\underline{t}=.934-.582(1-x) .363$ & $\underline{t}=.496-.404(1-x)^{4.245}$ \\
\hline 450 & .8 & $\underline{t}=.903-.754(1-x)^{.528}$ & $\underline{t}=.282-.260(1-x)^{7.518}$ \\
\hline 475 & .62 & $\frac{\tau}{t}=1.003-.805(1-x)^{.346}$ & $\frac{t}{\tau}=.394-.344(1-x)^{3.229}$ \\
\hline 480 & .32 & $\frac{\tau}{\tau}-.302+.495(1-x)^{-.164}$ & $\frac{t}{\tau}=.359-.379(1-x)^{1.541}$ \\
\hline
\end{tabular}


at $400^{\circ} \mathrm{C}, 450{ }^{\circ} \mathrm{C}, 475^{\circ} \mathrm{C}$, and $480^{\circ} \mathrm{C}$. The break-point value of $(1-\mathrm{x})$, where the oxidation reaction changes mechanism, is also listed in this table. Because of the change in the reaction mechanism, there are two equations presented for each temperature. Figure 3.4 shows the temperature dependence of the parameters $m, n$ and $b$ in equation (3.5). Figure 3.5 shows the temperature dependence of the break-point. Since no data were available at intermediate temperatures and no clearly defined "trend" was observed, a linear relationship with temperature is assumed to hold for core parameter at all intermediate temperatures.

3.2.2 Dependence of the 0xidation Rate Upon Metal Oxide Concentration $(\mathrm{U}, \mathrm{Pu})_{2} \mathrm{O}_{2}$ Oxidation

Tennery ${ }^{13}$ also made thermogravimetric measurements during the isothermal oxidation of $(\mathrm{U}, \mathrm{Pu})_{2}$ at several temperatures. The molar rates of uranium to plutonium was varied from infinity (pure uranium dioxide) to 3.0 . The solid solutions were prepared by either mechanical mixing, or coprecipitation, or the "sol-gel" process. The oxidizing atmosphere was kept constant at $20 \mathrm{~mol} \%$ by passing $0.8 \mathrm{scfh}$ of "breathing air" through the batch reactor.

The increased complexity of the reaction mechanism which is associated with the formation of nonstoichmometric compounds, changes in crystal structure, and inhomogenities, makes a kinetic description of the oxidation of mixed uranium, plutonium oxides very difficult. The information obtained from Tennery's work provides only a small glimpse at this complex process.

The only data which could be used to develop a kinetic model for the oxidation of $(\mathrm{U}, \mathrm{Pu}) \mathrm{O}_{2}$ were obtained for coprecipitated $(\mathrm{U}, \mathrm{Pu}) \mathrm{O}_{2}$ with a $\mathrm{U} / \mathrm{Pu}$ molar ration of 4 . Analysis of the information indicates that the oxidation occurs in two stages; each of which is first order with the time dependence of the fractional conversion being described by the equation 

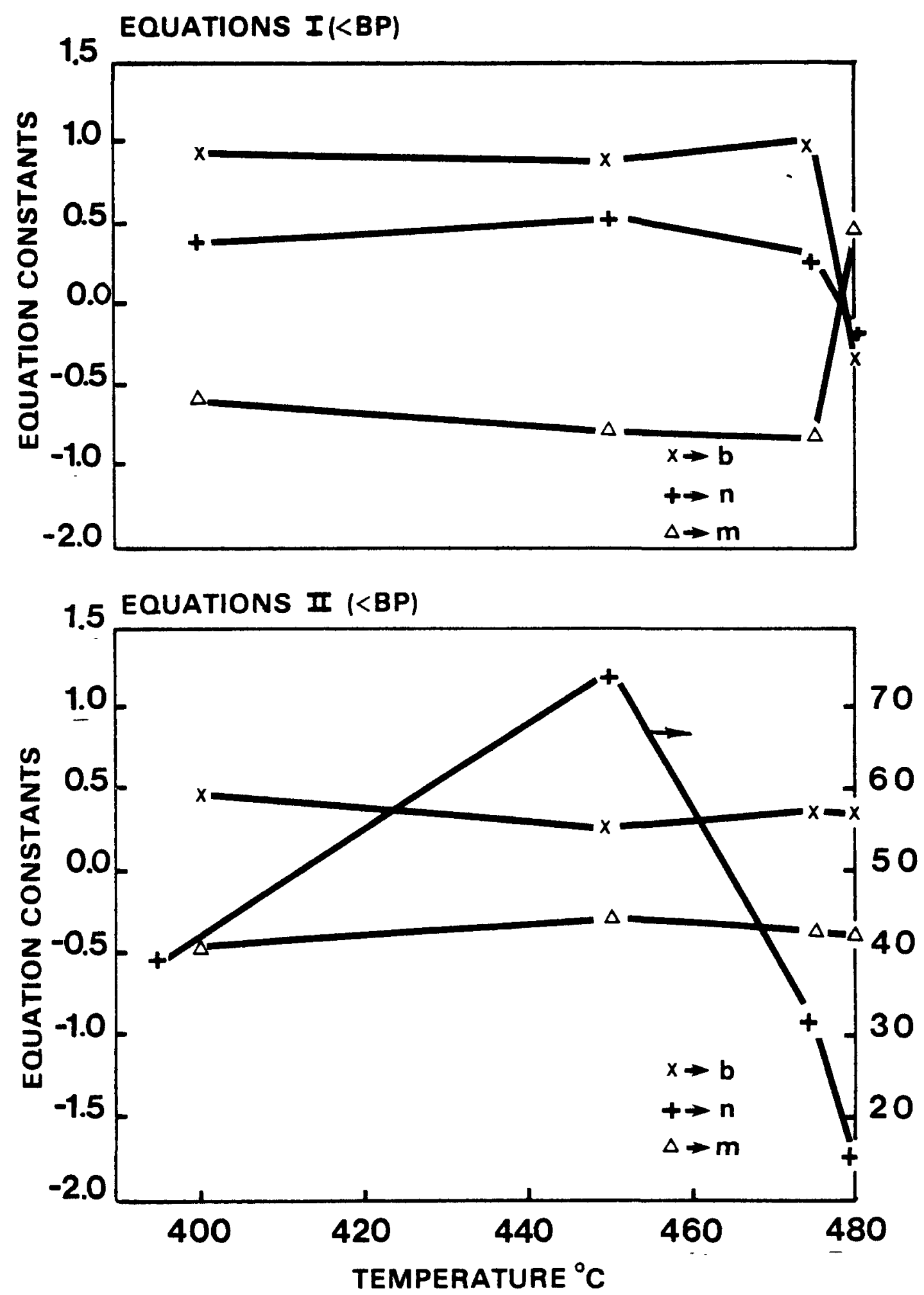

RATE EQUATION CONSTANTS AS A FUNCTION OF TEMPERATURE

F.igure 3.4 


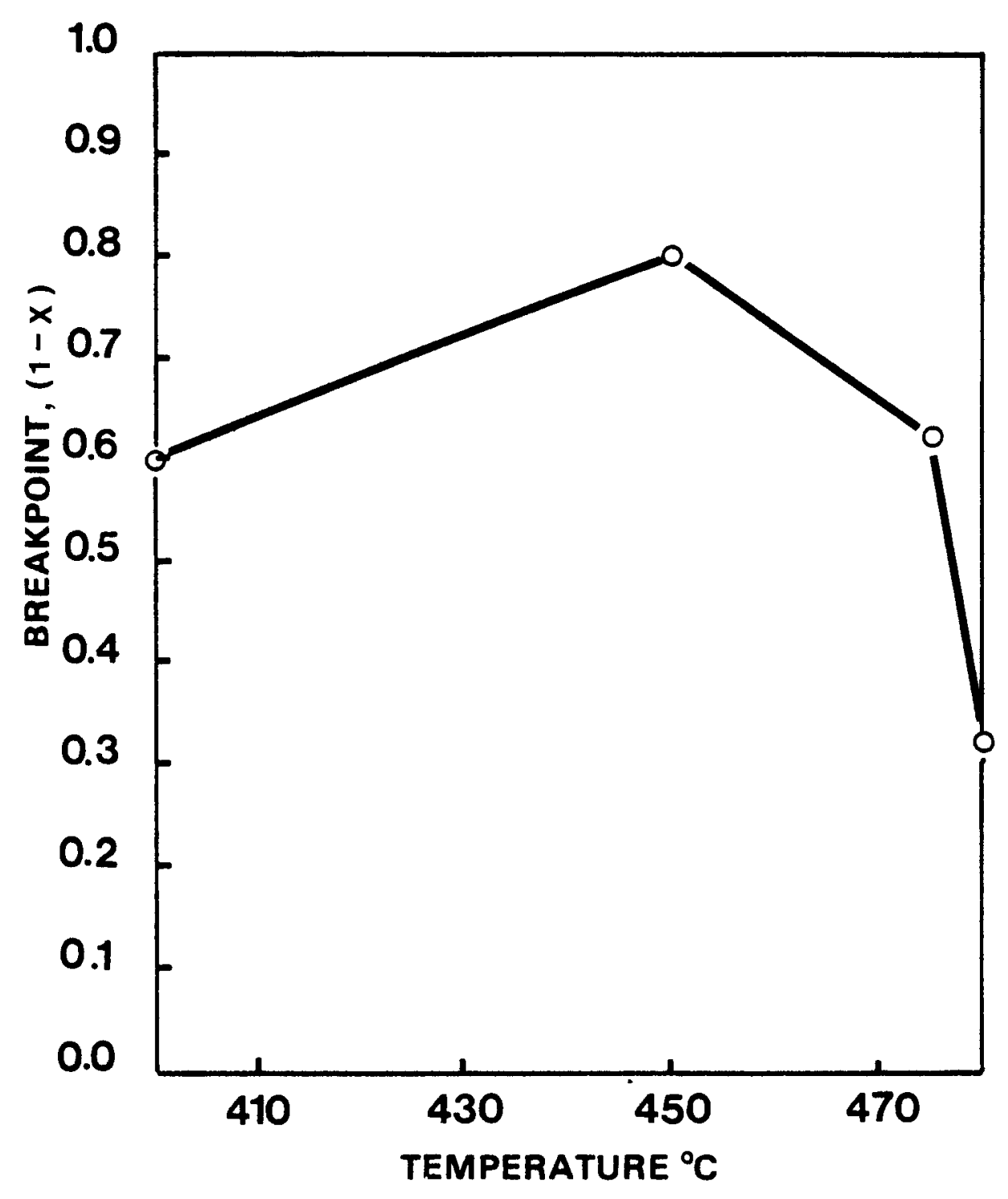

BREAK-POINT AS A FUNCTION

OF TEMPERATURE.

Figure 3.5 


$$
(1-x)=\exp (-k t)
$$

The first stage of the oxidation occurs for fractional conversions up to 0.85 . The rate constant in this case is

$$
k=(143.66 / \mathrm{min}) \exp (-10 \mathrm{~K} \mathrm{cal} / \mathrm{gmol} / \mathrm{RT})
$$

A similar analysis of the second stage of the oxidation proved to be inconclusive. An activatation energy of $41 \mathrm{Kcal} / \mathrm{gmol}$ (cf $10 \mathrm{kcal} / \mathrm{gmol}$ for the first stage) was obtained but the error band on this valve was $40 \%$. 3.2.3 Dependence of the Oxidation Rate Upon Oxygen Concentration - $\mathrm{UO}_{2}$ Oxidation

Watson and $\mathrm{Clinton}{ }^{14}$ oxidized stainless steel clad uranium dioxide pieces in a 3 inch diameter by 2 inch long mini voloxidizer. The oxidation temperature was $480^{\circ} \mathrm{C}$ and the rotation speed of the mini voloxidizer was 12 RPM. Mixtures of oxygen and nitrogen were passed through the reactor at a flow rate of $1.5 \mathrm{scfm}$. 0xygen concentration in the oxidizing atmosphere varied from $20 \mathrm{~mol} \%$ to $100 \mathrm{~mol} \%$. Results of the experiments are presented in Figure 3.6. An analysis of this information led to the development of an equation describing the effect of oxygen concentration on the rate of oxidation of uranium dioxide. This equation is

$$
f\left(Y_{0_{2}}\right)=1.306 \times 10^{4} Y_{0_{2}}^{2}+1.973 \times 10^{-3} Y_{0_{2}}+9.097 \times 10^{-1}
$$

Where $Y_{0_{2}}$ is the molar percentage of oxygen in the gas phase. $f\left(Y_{0_{2}}\right)$ represents a rate enhancement factor; the ratio of the rate of oxidation at an oxygen concentration $\mathrm{Y}_{\mathrm{O}_{2}}$ to the rate of oxidation at an oxygen concentration of $20 \mathrm{~mol} \%$. This equation is shown graphically in Figure 3.7 . Its mathematical development is presented in Appendix B. 


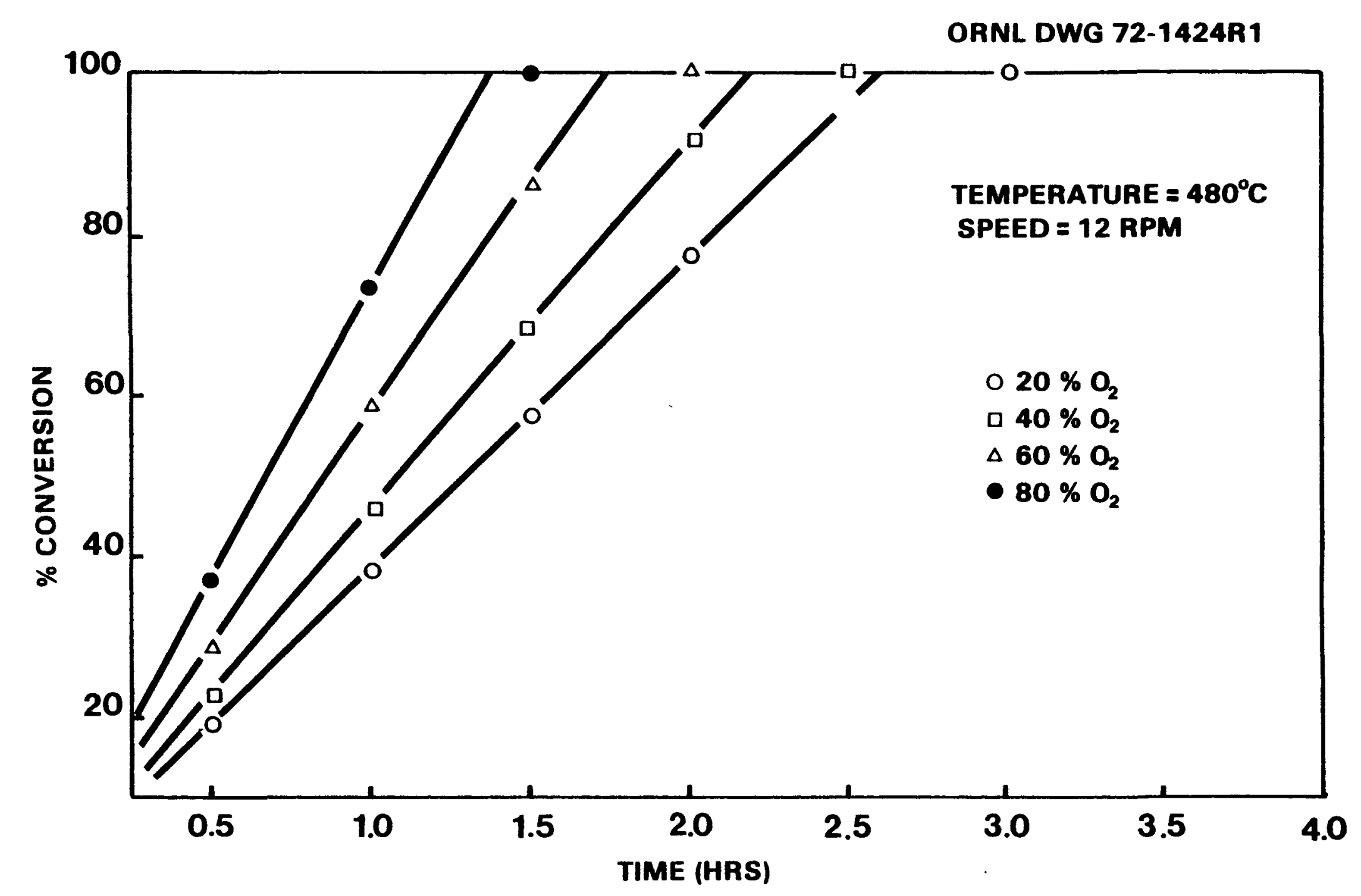




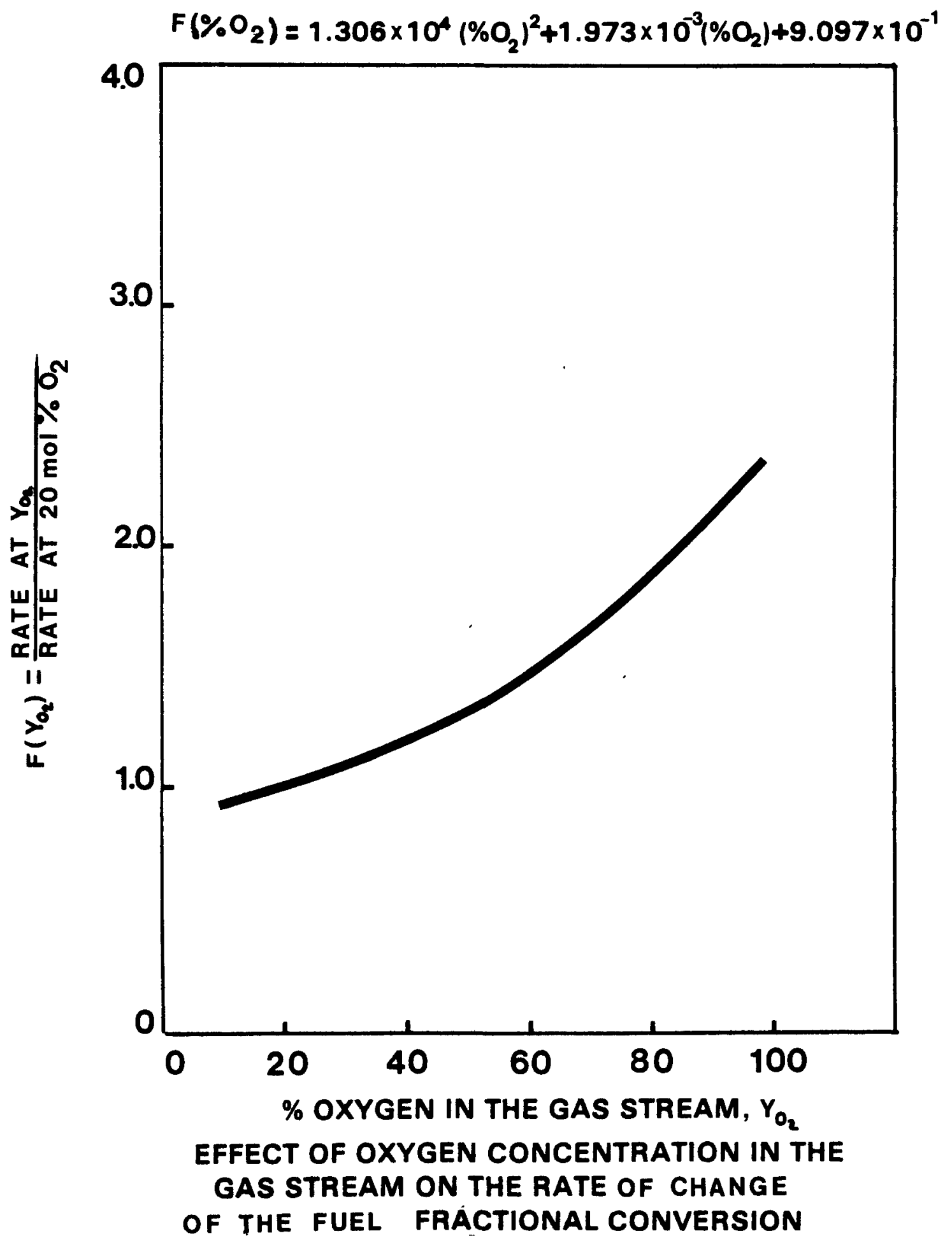

Figure 3.7 
3.2.4 Dependence of the Reaction Rate Upon the Rotation Speed of the Voloxidizer - $\mathrm{UO}_{2}$ Oxidation

The effect of voloxidizer roation speed on the rate of oxidation of stainless steel clad uranium dioxide pieces was studied in a 3 inch diameter by 2 inch long minivoloxidizer. ${ }^{14}$ The oxidizing atmosphere was kept at 20 mol\% oxygen by passing oxygen through the reactor at 0.8 scfh. The rotation speed was varied from 0 to 36 RPM. Results of the experiments are presented in Figure 3.8. These data were used to determine an enhancement factor, $g(\omega)$; the ratio of the oxidation rate at a rotational speed $\omega$ to the oxidation rate at a rotational speed of 12 RPM. The equation for $g(\omega)$ is

$$
g(\omega)=9.509 \times 10^{-4} \omega^{2}+9.238 \times 10^{-3} \omega+7.436 \times 10^{-1}
$$

This equation is shown graphically in Figure 3.9. The mathematical development of it is presented in Appendix B.

3.3 KINETIC EXPRESSIONS FOR USE IN THE VOLOXIDIZER DESIGN EQUATIONS

At this point, it is possible to develop a reaction rate expression for inclusion in the voloxidizer design equations. If one includes the effect of oxygen concentration and voloxidizer rotation speed in a description of the change in the fractional conversion of uranium dioxide* with time then equations (3.6), (3.9) and (3.10) may be combined to give

$$
d x / d t_{n}=(1-x) / m n \cdot f\left(y_{0_{2}}\right) g(\omega)
$$

Equation (3.11) is a dimensionless equation, but an equation describing the rate of production of uranium dioxide per unit reactor volume is required in the voloxidizer design equations. From equation (3.3) one obtains

*At this point the development will focus upon the oxidation of $\mathrm{V}_{2}$. The procedure applies equally to $(\mathrm{U}, \mathrm{Pu}) \mathrm{O}_{2}$. 


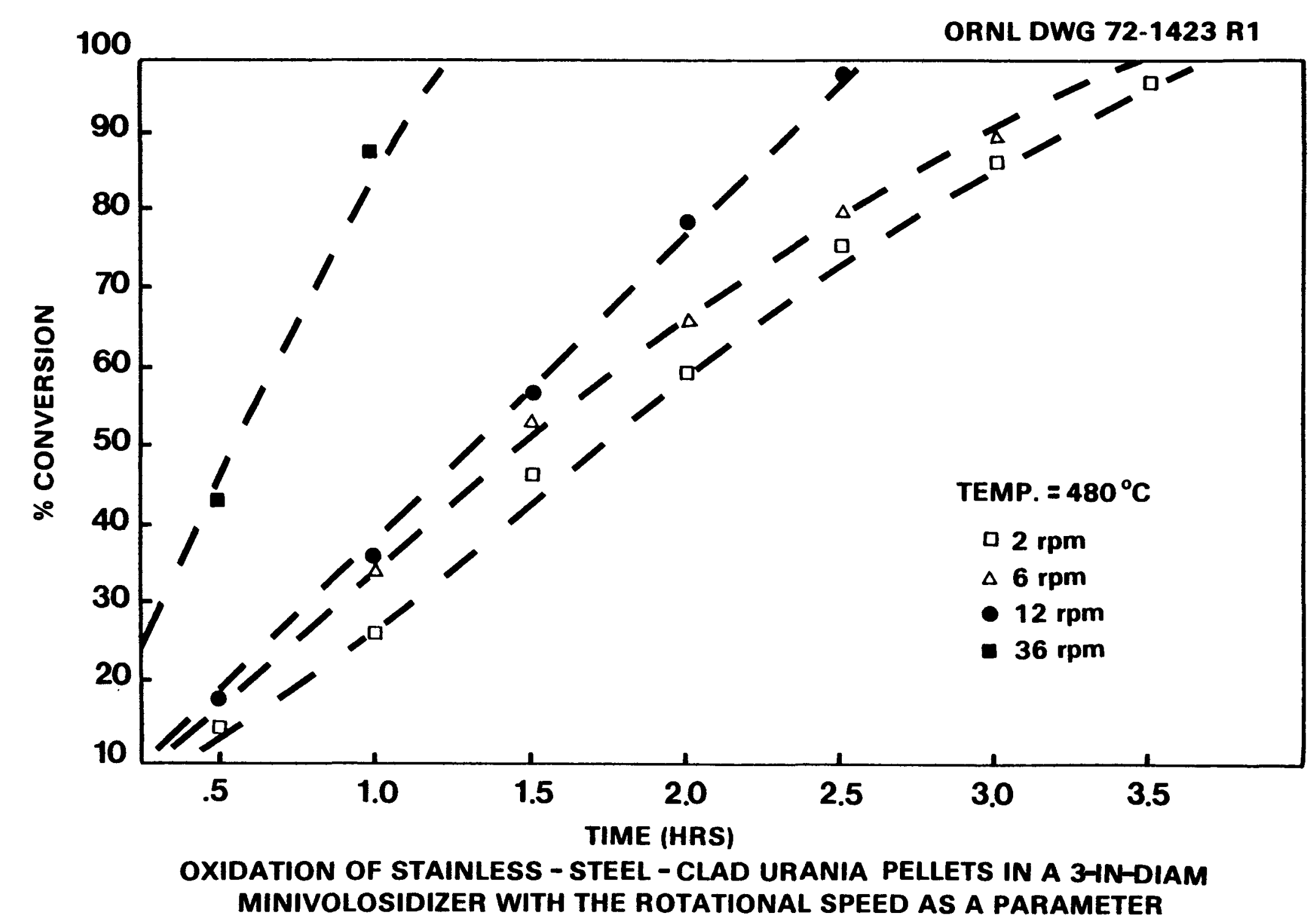

Figure 3.8 


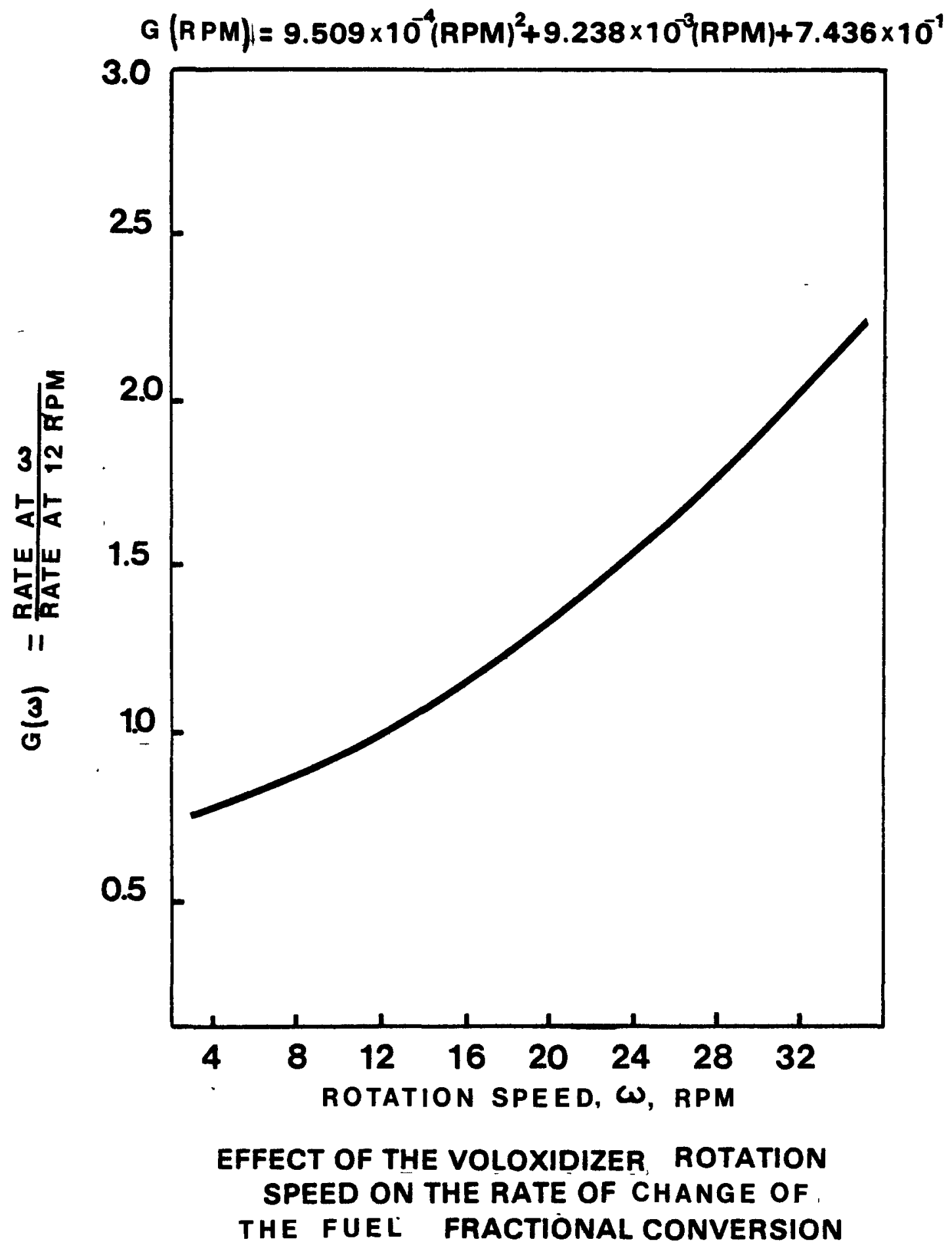

Figure 3.9 


$$
\left.\mathrm{dC}_{\mathrm{UO}_{2}} / \mathrm{dt}=-\mathrm{C}_{\mathrm{UO}_{2}}^{\circ} \mathrm{dx} / \mathrm{dt}=-\mathrm{C}_{\mathrm{UO}_{2}}^{\circ}{ }_{\tau}\right) \mathrm{dx} / \mathrm{dt} \mathrm{n}_{\mathrm{n}}
$$

Equation (3.12) gives the rate of change of uranium dioxide per unit mass of zirconium; the inert solids present in the reactor. The mass of zirconium contained in a unit volume of the reactor at the inlet is

$$
\tilde{\rho}_{\text {Zr }}=\omega_{Z r} \rho_{\text {total }}\left(A_{i n} / A_{C}\right)(1-\varepsilon)
$$

where $\omega_{Z r}$ is the inlet mass fraction of zirconium $\rho_{\text {total }}$ is the total density of solids, $A_{i n}$ is the inlet reactor cross-sectional area occupied by the solids, $A_{C}$ is the cross-sectional area of the reactor, and $\varepsilon$ is the inlet void fraction in that part of the reactor occupied by solids. Since the reacting solids change density, one would like to specify the fraction of the reactor occupied by solids of the outlet. If $\underline{v}$ in and $\underline{v}_{\text {out }}$ are the inlet and outlet solids bulk specific volumes, then

$$
A_{i n} / A_{c}=\underline{V}_{i n} / \underline{V}_{\text {out }}
$$

where $A_{\text {out }}$ is the cross-sectional area occupied by solids at the reactor outlet. Using equation (3.14), equation (3.13) becomes

$$
\tilde{\rho}_{\text {Zr }}=\omega_{\text {Zr }} \rho_{\text {total }}\left(A_{\text {out }} / A_{c}\right)\left(\underline{V}_{\text {in }} / \underline{V}_{\text {out }}\right)(1-\varepsilon)
$$

combining equation (3.12) with equation (3.15), one obtains

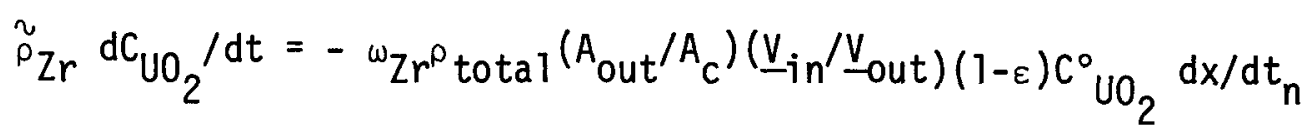

Which is the rate of change of uranium dioxide per unit volume of the reactor. Substituting equation (3.11) into equation (3.16) gives 


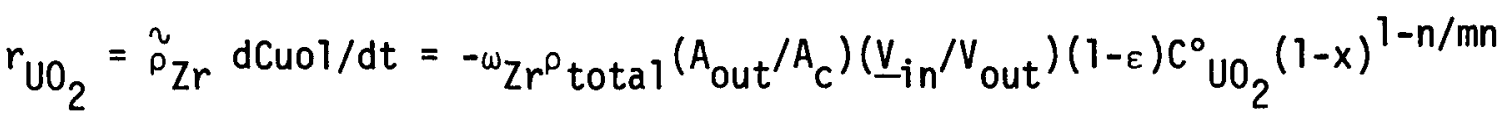

$$
\star f\left(Y_{0_{2}}\right) g(\omega)
$$

Now

$$
Y_{0_{2}}=100 C_{0_{2}} /\left(1+C_{0_{2}}\right)
$$

So equation (3.17) becomes

$r_{U_{2}}=\frac{{ }^{\omega} \mathrm{Zr}^{\rho} \text { total }\left(A_{\text {out }} / A_{c}\right)\left(\underline{V}_{-i n} / \underline{V}_{0}\right)(1-\varepsilon) C^{\circ}{ }_{U 0_{2}}}{\tau} \cdot \frac{(1-x)^{1-n}}{m n} f\left(100 C_{0_{2}} /\left(1+C_{0_{2}}\right)\right) g(\omega)$

Equation (3.19) is the equation which is needed for use in the voloxidizer design equations. A development of the constants found in this equation is presented in Appendix $C$.

\subsection{CONCLUSIONS}

The Kinetics of $\mathrm{UO}_{2}$ and $(\mathrm{U}, \mathrm{Pu}) \mathrm{O}_{2}$ oxidation is complex and not well understood. A better understanding of this phenomenan is required if a mathematical description of the voloxidation process is to be developed. Clearly, an extensive experimental program is needed in order to completely and adequately describe the oxidation of nuclear fuels. Such a program should be given priority as it is an important part of voloxidation process development.

From the initial studies which have been done, it appears as if tritium and other volatile fission products are released during voloxidation. However, the relationship between the release of volatile fission products and the level of oxidation of the metal oxide matrix is not known. All 
design calculations depend on knowledge of this information. Thus, an experimental program to determine those factors which affect the release of volatile fission products should be considered to be an important aspect of voloxidation process development. 


\section{CHAPTER 4 \\ DESCRIPTION OF THE VOLOXIDIZER \\ COMPUTER SIMULATION PROGRAMS}

\subsection{INTRODUCTION}

Computer programs have been written to simulate three modes of voloxidizer operation; cocurrent, countercurrent, and semibatch. The programs are written in level G FORTRAN IV. In each case, solution of the appropriate differential equation provides one with a fractional conversion history, either in space (for cocurrent and countercurrent operation) or in time (for semibatch operation), of the voloxidizer.

\subsection{COCURRENT OPERATION}

The most likely mode of operation for the voloxidizer at this time appears to be a continuous, cocurrent one. The equation describing this operation when solids dispersion is neglected has been shown to be

$$
-\mathrm{S} \mathrm{dC}_{\mathrm{UO}_{2}} / \mathrm{dz}+\mathrm{r}_{\mathrm{UO}_{2}}=0
$$

which can be rewritten in terms of the fractional conversion of uranium dioxide as

$$
\mathrm{dx} / \mathrm{dz}=-\mathrm{r}_{\mathrm{UO}_{2}} / \mathrm{SC}^{\mathrm{o}} \mathrm{uO}_{2}
$$

with

$$
x=0 \text { at } z=0
$$

The reaction rate expression is given by the equation

$$
\begin{aligned}
& r_{U 0_{2}}=-\psi_{z r} \rho_{\text {total }}\left(A_{\text {out }} / A_{C}\right)\left(\underline{V}_{\text {in }} / \underline{V}_{\text {out }}\right)(1-\varepsilon) C^{\circ} \mathrm{UO}_{2}(1-x)^{1-n / \tau m n} \\
& \star f\left[\left(100 c_{0_{2}} /\left(1+c_{0_{2}}\right)\right] g(\omega)\right.
\end{aligned}
$$


The stoichiometry of the reaction and the mass balance for the reactor allow one to relate the oxygen concentration to the fractional conversion of uranium dioxide. This relationship is

$$
C_{0_{2}}=C_{0_{2}}^{\circ}-1 / 3(S / G) C^{\circ}{ }_{00}{ }_{2}^{x}
$$

Equation (4.2) may then be substituted in equation (3.19) to obtain an expression for $\mathrm{r}_{\mathrm{UO}_{2}}$ as a function of the fractional conversion of uranium dioxide and the operating parameters of the reactor. Equations (4.1) and (4.2) along with equations (3.19) and (4.3) constitute a nonlinear first-order ordinary differential equation which describes the fractional conversion of uranium dioxide as function of axial position in the reactor. This set of equations is solved using a 4 th order Renge-Kutta technique. ${ }^{18}$ The computer program used to obtain the solution to the equations is listed in Appendix $D$ and the results of a sample program are listed in Appendix E. Execution of the program requires two DATA dards. The entries on each DATA card are described in Table 4.1 . 
TABLE 4. 1: ENTRIES ON DATA CARDS REQUIRED FOR COMPUTER SIMULATION OF A VOLOXIDATION REACTOR

CARD 1: $X$ initial axial position in the voloxidizer (meters)

$Y$ fractional conversion of uranium dioxide at the initial axial position in the reactor

H Step size used in the differential equation solving algorithm (meters)

NP number of incremental steps taken between values which appear in the plot of the results produced by the program

CARD 2: $E$ solids void fraction

D diameter of the voloxidizer (meters)

DB voloxidizer diameter to fuel bed depth ratio at the reactor outlet

VI inlet specific volume of solids (cubic meters/metric ton)

* V2 outlet specific volume of solids (cubic meters/metric ton)

* Cø2 inlet oxygen concentration (moles $\mathrm{O}_{2}$ /mole diluent gas)

* CU९2 inlet uranium dioxide concentration (moles $\mathrm{UO}_{2} / \mathrm{kg}$ Zirconium)

RPM voloxidizer rotation speed (RPM)

* T operating temperature of the voloxidizer $\left({ }^{\circ} \mathrm{C}\right)$

TG inlet gas temperature $\left({ }^{\circ} \mathrm{C}\right)$

* $\quad \mathrm{P} \quad$ operating pressure of the voloxidizer (atmospheres)

* SS inlet solids flow rate ( $\mathrm{kgm} /$ day)

* Q inlet gas flow rate (cubic meters/minute)

MAX desired final fractional conversion of uranium dioxide $(0.0<x<1.0)$ Entries on each DATA card are in "free" FORMAT. The first entry on a card starts in column 1 and entries are separated by a blank space. The order of the entries is important so it must be followed carefully.

* Only these entries are required on Card 2 in execution of the semi-batch simulator. 


\subsection{COUNTERCURRENT OPERATION}

The differential equation which describes the countercurrent operation of the voloxidizer when solids dispersion is neglected is, once again, equation (2.17)

$$
-\mathrm{S} \mathrm{dC}_{\mathrm{uO}_{2}} / \mathrm{dz}+\mathrm{ruO}_{2}=0
$$

which is rewritten in terms of the fractional conversion of uranium dioxide as

$$
\mathrm{dx} / \mathrm{dz}=\mathrm{ruO}_{2} / \mathrm{SC}^{\circ} \mathrm{UO}
$$

with

$$
x=0 \text { at } z=0
$$

The reaction rate expression in this case is

$$
\begin{gathered}
r_{U_{2}}=-\omega_{\text {Zr }}{ }^{\rho} \text { total } \\
\left(A_{\text {out }} / A_{c}\right)\left(\underline{V}_{\text {in }} / \underline{V}_{\text {out }}\right)(1-\varepsilon) C^{\circ}{ }_{U 0_{2}}(1-x)^{1-n / \tau n m} \\
f\left[100^{\circ} C_{O_{2}} /\left(1+C_{0_{2}}\right)\right] \cdot g(\omega)
\end{gathered}
$$

As in the previous case, one must obtain a relationship between $\mathrm{C}_{\mathrm{O}_{2}}$ and the fractional conversion of uranium dioxide in the reactor. For the counter current mode of operation, this relationship is

$$
\mathrm{C}_{\mathrm{O}_{2}}=\mathrm{C}_{\mathrm{O}_{2}}^{\circ}+1 / 3 \mathrm{~S} / \mathrm{G} \mathrm{C} \mathrm{UO}_{2}\left(\mathrm{x}-\mathrm{x}_{\max }\right)
$$

Where $x_{\max }$ is the maximum fractional conversion of uranium dioxide obtained in the reactor. Equations $(4.1),(4.2)(3.19)$, and (4.4) constitute a nonlinear first-order ordinary differential equation which describes the fractional conversion of uranium dioxide as a function of axial position in the reactor. A 4th order Runge-Kutta technique is used to solve this set of equations. The computer program used to obtain the solution to the equations is listed in Appendix $D$ and the results of a sample program are listed in 
Appendix E. This program has as input two BATA cards which have the entries described in Table 4.1.

Table 4.I.

\subsection{SEMI-BATCH OPERATION}

The differential equation describing semi-batch operation of the voloxidizer assuming perfect mixing of the solids phase is

$$
\mathrm{Vr}_{\mathrm{UO}_{2}}=\overline{\mathrm{s}} \mathrm{dC}_{\mathrm{UO}_{2}} / \mathrm{dt}
$$

Equation (2.33) can be written as an equation describing changes in the fractional conversion of uranium dioxide.

$$
\mathrm{dx} / \mathrm{dt}=-\mathrm{Vr}_{\mathrm{uO}_{2}} / \overline{\mathrm{SC}} \mathrm{uO}_{2}
$$

with

$$
x=0 \text { at } t=0
$$

If the gas phase is also perfectly mixed, then the oxygen concentration in the reactor is given by the equation

$$
A_{C} G C^{\circ} 0_{2}-A_{C} G+(V / 3) r_{U 0_{2}}=0
$$

The reacton rate expression in this case is given by the equation

$$
r_{\mathrm{UO}_{2}}=-\mathrm{c}_{\mathrm{UO}_{2}}^{\circ} / \tau \cdot(1-x)^{l-n / m n} \mathrm{f}\left[100 \cdot \mathrm{c}_{0_{2}} /\left(1+\mathrm{C}_{0_{2}}\right)\right] g(\omega)
$$

Equations $(2.33),(4.5),(2.35)$, and (3.20) constitute a nonlinear first order ordinary differential equation which is solved using a 4 th order RengeKutta technique. Appendix $D$ contains a listing of the computer program and Appendix E lists results of a sample program. Two DATA cards are required for execution of the program. The entries on these cards are described in Table A. 1 . 


\subsection{MODIFICATION OF THE PROGRAMS}

The computer programs used to simulate cocurrent, countercurrent, and semi-batch operation of the reactor incorporate information about the factors affecting the oxidation of uranium dioxide. If new experimental results indicate that changes in this information are warranted, then the programs are easily modified

\subsubsection{Changes in the Reaction Rate Expression}

A reactor rate expression of the form

$$
d x / d t=(1-x)^{1-n} / m n=k(1-x)^{P}
$$

is used to describe the dependence of the fractional conversion on the normalized time. The constants in this equation can easily be updated by replacement of the appropriate statements for the parameters which are found at the beginning of the program.

\subsubsection{Changes in the Equation Describing the Effect of Oxygen Concentration} Upon the Reaction Rate

The effect of oxygen concentration in included in the calculation of the reaction rate term. This is an ARITHMETIC FUNCTION STATEMENT for $R(X, Y, M, N)$, which is found at the beginning of the program. This function contains in it the equation describing changes in the reaction rate with oxygen concentration which is

$$
f\left(Y_{0_{2}}\right)=1.306 \times 10^{-4} Y_{0_{2}}^{2}+1.943 \times 10^{-3} Y_{0_{2}}+9.097 \times 10^{-1}
$$

Either changes in the constant coefficients of this equation can be made or the equation can be replaced with one which describes more accurately the effect which the oxygen concentration has on the reaction rate. 
4.5.3 Changes in the Equation Describing the Effect of Voloxidizer Rotation Speed Upon the Reaction Rate.

The variable REV in the programs is the value of $g(\omega)$ which has been determined for a particular voloxidizer rotational speed, $\omega$. The effect of the voloxidizer rotational speed on the reaction rate was found to be

$$
g(\omega)=9.509 \times 10^{-4} \omega^{2}+9.238 \times 10^{-3} \mathrm{CO}+7.436 \times 10^{-1}
$$

Replacement of this correlation with another in the programs is effected by replacing the card which defines REV with another which contains the updated information. 


\section{REFERENCES}

1. Groenier, W. S., Current Position and Status of the Voloxidation process at ORNL, ORNL/CF - 77/67 (Apri1, 1977)

2. 40 CFR-190, Environmental Radiation Protection for Nuclear Power Operations, Proposed Standards, Supplementary Information, U. S. EPA (January, 1976!.

3. Finney, B. C., et al., Correlation of Radioactive Waste Treatment Costs and the Environmental Import of Waste Effluents in the Nuclear Fuel Cycle for Use in Establishing "As Low as Practicable" Guides - Nuclear Fuel Reprocessing, U. S. ERDA Report, DRNL/TM - 4901 (May, 1975).

4. North, E. D. and R. L. Booth, Fission Product Gas Retention Study Final Report, ORNL/TM-4409 (August, 1973).

5. Murbach, E. W., Fission Product Gas Retention Process and Equipment Design Study, ORNL/TM-4560 (May, 1974).

6. Nicholson, E. L., A Critical Review of the Voloxidation Development Program, ORNL/CF -76/65 (February, 1976).

7. Good, J. H., ed., Voloxidation - Removal of Volatile Fission Products from Spen LMFBR Fuels, ORNL/TM-3723 (January, 1973).

8. Ratcliff, J. T., Technical Data Summary: Tritium Removal Process LWR Fuel Recycle, DPSTD - LWR - 76-6

9. Hill, C. G., An Introduction to Chemical Engineering Kinetics and Reactor Design, John Wiley \& Sons, New York, 1977.

10. Holland, C. D. and R. G. Anthony, Fundamentals of Chemical Reactor Engineering, Prentice-Ha11, Inc., Englewood Cliffs, N. J., 1979.

11. Rase, H. F., Chemical Reactor Design for Process Plants, Volume One: Principles and Techniques, John Wiley \& Sons, New York, 1977.

12. Carbery, J. J., Chemical and Catalytic Reaction Engineering, McGraw-Hill Book Company, Inc. New York, 1976.

13. Tennery, V. J., The Oxidation of $\mathrm{UO}_{2}$ and $(\mathrm{U}, \mathrm{Pu}) \mathrm{O}_{2}-\mathrm{A}$ Thermogravimetric and X-Ray Diffraction Study, in Good, J. H., ed., Voloxidation - Removal of Volatile Fission Products from Spend LMFBR Fuels, ORNL/TM - 3723 (January, 1973).

14. Watson, C. D. and S. D. Clinton, Engineering Data, in Good, J. H., ed., Voloxidation - Removal of the Volatile Fission Products from Spent LMFBR Fuels, ORNL/TM - 3723 (January, 1973).

15. Ratliff, J. T., Personal Communication, March, 1977.

16. Brown, 6.6 et a1., Unit Operations, John Wiley \& Sons, Inc., New York, 1950. 
17. Whatley, M., ORNL, Personal Communication, 1977.

18. Carnohan, B., H. A. Luther, and J. 0. Wilkes, Applied Numerical Methods, John Wiley and Sons, Inc., New York, 1969. 


\section{NOMENCLATURE}

$A_{c} \quad=$ empty cross-sectional area of the reactor

$A_{\text {in }}=$ cross-sectional area of the reactor occupied by solids at the inlet $A_{\text {out }}=$ cross-sectional area of the reactor occupied by solids at the outlet $\mathrm{CO}_{2}=$ uranium dioxide concentration based upon the inert solids present $\mathrm{C}_{\mathrm{UO}_{2}}=$ uranium dioxide concentration based upon the inert solids present $\mathrm{D}_{\text {eff }}=$ effective dispersion coefficient for uranium dioxide G

$\mathrm{K}=$ reaction rate constant

$\ell \quad=$ reactor length

$\mathrm{P} \quad=$ reaction order

$r_{0_{2}} \quad=$ rate of production of oxygen per unit reactor volume

$\mathrm{R}_{\mathrm{UO}_{2}}=$ rate of production of uranium dioxide per unit reactor volume

$S=$ flux of inert solids through the reactor

$\bar{S}=$ mass of inert solids in the reactor (semi-batch operation)

$\mathrm{V} \quad=$ reactor volume

$\underline{V}_{\text {in }} \quad=$ solids specific volume at the reactor inlet

$\underline{v}_{\text {out }}=$ solids specific volume at the reactor outlet

$\mathrm{Y}_{\mathrm{O}_{2}} \quad=$ oxygen concentration in mole percent

$z \quad=$ axial distance in the reactor

$x=$ fractional conversion of uranium dioxide in the reactor

$\varepsilon \quad=$ solids void fraction

$\omega \quad=$ voloxidizer rotation speed

${ }^{\omega} z_{r} \quad=$ weight fraction of zirconium in the inlet solids

$\rho_{\text {total }}=$ solids density

$\tilde{\rho}_{\text {Tr }} \quad=$ density of zirconium based upon unit reactor volume

$\tau=$ time for maximum conversion of uranium dioxide to $\mathrm{U}_{3} \mathrm{O}_{8}$ 


\section{APPENDIX A \\ DEPENDENCE OF THE RATE OF OXIDATION \\ UPON URANIUM DIOXIDE CONCENTRATION}

\section{A. 1 INTRODUCTION}

The rate of oxidation of uranium dioxide is assume to have a pth order dependence upon uranium dioxide concentration. Thus,

$$
-d(1-x) / t_{n}=k(1-x)^{p}
$$

Where $x$ is the fractional conversion of uranium dioxide and $t_{n}$ is a time normalized using $\tau$, the time required for maximum conversion of $\mathrm{UO}_{2}$ to $\mathrm{U}_{3} \mathrm{O}_{8}$. This equation has a solution of the form

$$
t_{n}=-m(1-x)^{n}+b
$$

where

$$
P=1-n
$$

and

$$
k=1 / m n
$$

\section{A.2 DESCRIPTION OF THE CALCULATION PROCEDURE}

The parameters in equation (3.2) and equation (3.5) are obtained using the following procedure.

1. Plot $(1-x)$ versus $t_{n}$ for a given temperature $T$.

2. Obtain the slope of the curve, $d(1-x) / d t_{n}$, as a function of $t_{n}$ by graphical differentiation.

3. Plot $\log \left(-d(1-x) / d t_{n}\right)$ versus $\ln (1-x)$ and determine the slope of the best line segment which can be drawn through the data. This should be a linear graph with slope $p$ since equation (3.2) can be written as 


$$
\log \left(-d(1-x) / d t_{n}\right)=\ln (k)+p \ln (1-x)
$$

4. Determine the point of intersection between the left most two straight line segments in the plot. (Such points are defined as break-points and indicate a change in the reaction mechanism. (See Figure 3.5.))

5. Solve equation (3.2) using the initial condition

$$
(1-x)=0.0 \text { at } t_{n}=1.0
$$

to obtain the constants $\mathrm{bl}, \mathrm{ml}$, and $\mathrm{nl}$ in equation (3.5). This equation describes the time dependence of the fractional conversion for

$$
0.0<(1-x)<B P 1
$$

where BPI is the first break-point value of $(1-x)$.

6. Repeat step 5 using the initial condition

$$
(1-x)=\text { BP1 at } t_{n}=t_{n} 1
$$

to obtain the constants in the equation

$$
t_{n}=m 2(1-x)^{n 2}+b 2
$$

which holds for

$$
B P^{7}<(1-x)<\mathrm{BP}^{2}
$$

7. For the $\ell$ th line segment, repeat step 5 using the initial condition

$$
(1-x)=B P l \text { at } t_{n}=t_{n} l
$$

to obtain constants in the equation

$$
t_{n}=m e(1-x)^{n \ell}+b^{2}
$$

which holds for

$$
B P(1-\ell)<(1-x)<B P \ell
$$


8. Repeat steps 1 through 7 for each temperature.

A.3 AN EXAMPLE: EQUATION PARAMETERS FOR THE ISOTHERMAL OXIDATION OF URANIUM DIOXIDE AT $400{ }^{\circ} \mathrm{C}$

The following example illustrates the procedure used to obtain the parameters in equation (3.5). Data for the isothermal oxidation of uranium dioxide at $400{ }^{\circ} \mathrm{C}$ are taken from Figure 3.2. The fractional conversion and normalized times are presented in Table A.I and plotted in Figure A.l. Slopes of the curve shown in Figure A.1 are given in Table A.2 and shown in Figure A.2 as functions of $1-x$,

The values of $-d(1-x) / d t_{n}$ can be correlated with values of $(1-x)$ using two straight lines, the equations of which are

$$
\log \left(-d(1-x) / d t_{n}\right)=0.637 \log (1-x)+0.675
$$

for

$$
0.0<(1-x)<0.6
$$

and

$$
\log \left(-d(1-x) / d t_{n}\right)=-3.245 \log (1-x)-0.234
$$

for

$$
0.6<(1-x)<1.0
$$

Equation (A.5) is solved with the initial condition

$$
1-x=0.0 \text { at } t_{n}=1.0
$$

to give

$$
t_{n}=-m 1(1-x)^{n 1}+b 2=-0.582(1-x)^{0.363+0.134}
$$

and equation (A.6) is solved with the initial condition 
TABLE A1: FRACTIONAL CONVERSION OF $\mathrm{UO}_{2}$ AS A FUNCTION OF TIME DURING ISOTHERMAL OXIDATION AT $400{ }^{\circ} \mathrm{C}$

\begin{tabular}{|c|c|c|c|c|}
\hline Time, $t(\mathrm{sec})^{\star}$ & $\tau(\mathrm{sec})^{+}$ & $\begin{array}{l}\text { Normalized } \\
\text { time } \\
t / \tau\end{array}$ & $\begin{array}{l}\text { Fractional } \\
\text { Conversion, } X^{*}\end{array}$ & $(1-x)$ \\
\hline 20.2 & 182.5 & 111 & .015 & .985 \\
\hline 30.6 & 182.5 & .168 & .035 & .965 \\
\hline 40.8 & 182.5 & .224 & .060 & .940 \\
\hline 50.9 & 182.5 & .279 & .102 & .898 \\
\hline 61.1 & 182.5 & .335 & .174 & .826 \\
\hline 71.3 & 182.5 & .391 & .269 & .731 \\
\hline 81.4 & 182.5 & .446 & .389 & .611 \\
\hline 91.8 & 182.5 & .503 & .528 & .472 \\
\hline 102.0 & 182.5 & .559 & .664 & .336 \\
\hline 112.1 & 182.5 & .614 & .775 & .225 \\
\hline 117.1 & 182.5 & .642 & .823 & .177 \\
\hline 122.2 & 182.5 & .670 & .857 & .143 \\
\hline 127.4 & 182.5 & .698 & .894 & .106 \\
\hline 137.4 & 182.5 & .753 & .940 & .060 \\
\hline 147.6 & 182.5 & .809 & .970 & .030 \\
\hline 162.4 & 182.5 & .890 & .993 & .007 \\
\hline 182.5 & 182.5 & 1.000 & 1.000 & 0.000 \\
\hline
\end{tabular}

*Values taken from Figure 3.2

+Value taken from Figure 3.3 


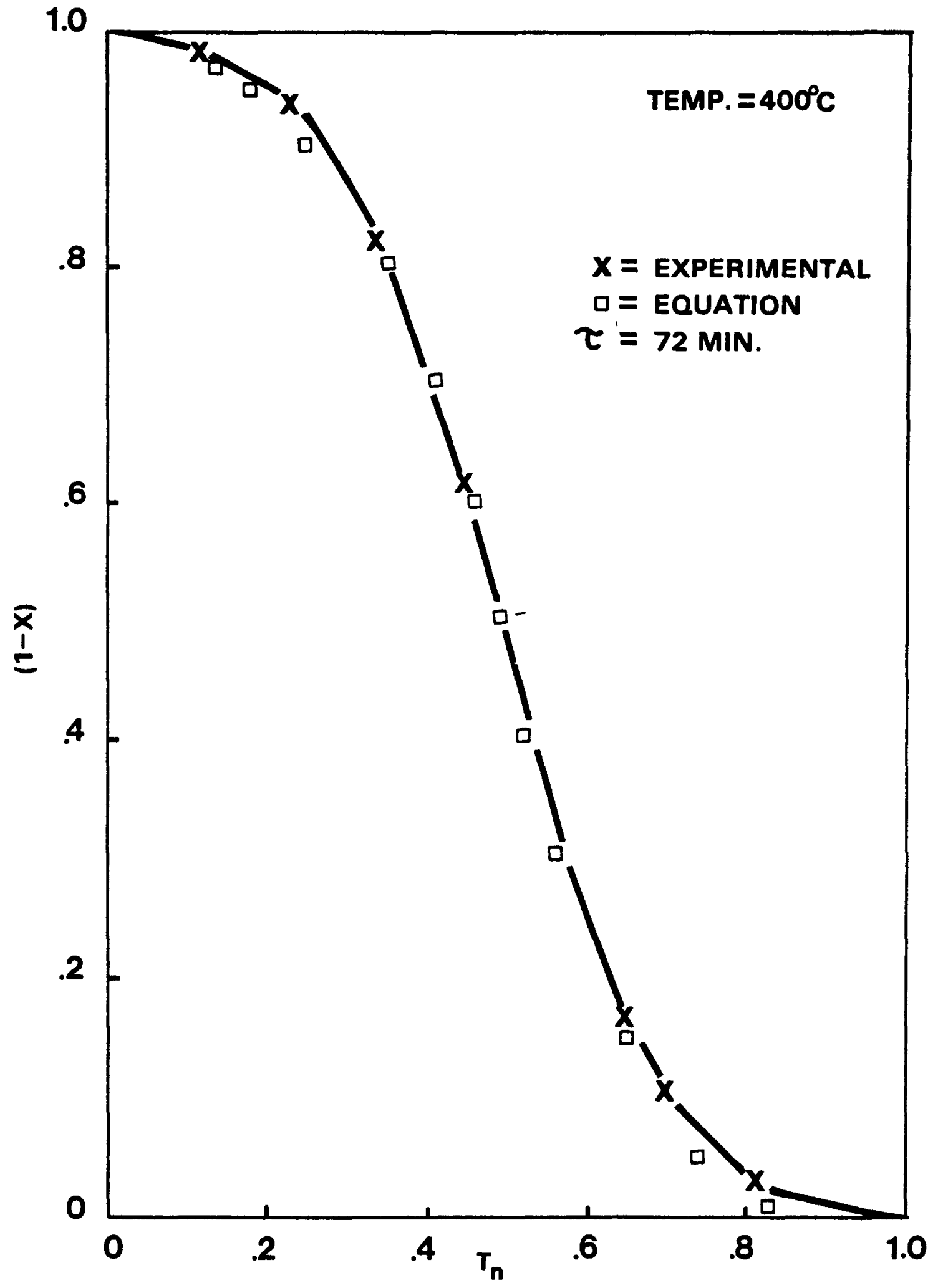

FRACTIONAL CONVERSION VERSUS NORMALIZED TIME

Figure A.1 
TABLE A.2: RATE OF CHANGE OF THE FRACTIONAL CONVERSION OF $\mathrm{UO}_{2}$ AS A FUNCTION OF 1-X FOR ISOTHERMAL OXIDATION

\begin{tabular}{c|c|c|c}
$(1-x)^{*}$ & $\log (1-x)$ & $\left(\Delta(1-x) / \Delta t_{n}\right)$ & $\log \left(-\Delta(1-x) / \Delta t_{n}\right)$ \\
\hline .025 & -1.602 & .427 & -.370 \\
.05 & -1.301 & .725 & -.140 \\
.10 & -1.00 & 1.190 & .076 \\
.20 & -.699 & 1.667 & .272 \\
.30 & -.523 & 2.083 & .319 \\
.40 & -.398 & 2.778 & .444 \\
.50 & -.301 & 2.941 & .468 \\
.60 & -.222 & 2.381 & .377 \\
.70 & -.155 & 2.174 & .337 \\
.80 & -.097 & 1.613 & .208 \\
.85 & -.071 & 1.163 & .066 \\
.90 & -.046 & .806 & -.094 \\
.95 & -.022 & .490 & -.310
\end{tabular}

*Values of $(1-x)$ at which $-\Delta(1-x) / \Delta t_{n}$ is determined by graphical differentiation of Figure A. 1 . 


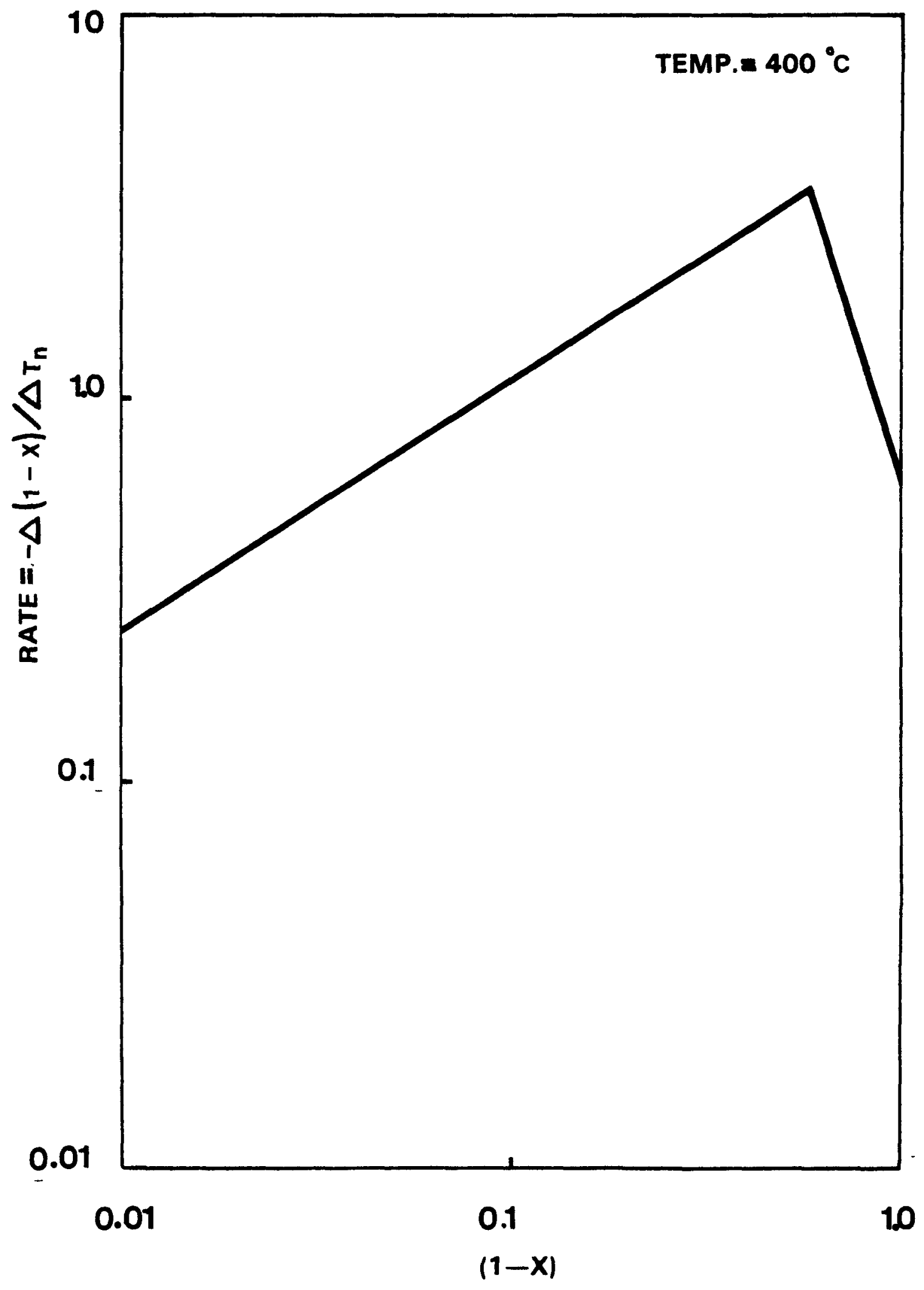

F.igure A.2 


$$
1-x=0.6 \text { at } t_{n}=0.45
$$

for

$$
0.6<(1-x)<1.0
$$

Table A.3 presents the errors incurred when equation (A.9) and equation (A.11) are used to describe the $t_{n}$ versus $(1-x)$ behavior. 
TABLE A.3: ERROR RESULTING FROM THE USE OF

EqUATION (A.9) AND EQUATION (A.11) TO DESCRIBE THE $t_{n}$ VERSUS $(1-x)$ BEHAVIOR - ISOTHERMAL OXIDATION OF UO 2 AT $400^{\circ} \mathrm{C}$

\begin{tabular}{|c|c|c|c|}
\hline $1-x$ & $t_{n}$ & $\stackrel{t_{n}}{\text { Derived Equations }}$ & $\begin{array}{c}\% \\
\text { Error }\end{array}$ \\
\hline .01 & .867 & .825 & 4.84 \\
\hline .025 & .817 & .781 & 4.41 \\
\hline .05 & .761 & .738 & 3.02 \\
\hline .10 & .700 & .682 & 2.57 \\
\hline .15 & .661 & .642 & 2.87 \\
\hline .20 & .628 & .610 & 2.87 \\
\hline .25 & .597 & .582 & 2.51 \\
\hline .30 & .572 & .558 & 2.45 \\
\hline .35 & .542 & .536 & 1.11 \\
\hline .40 & .528 & .517 & 2.08 \\
\hline .45 & .508 & .498 & 1.97 \\
\hline .50 & .483 & .481 & .41 \\
\hline .55 & .469 & .466 & .64 \\
\hline .60 & .450 & .451 & -.22 \\
\hline .65 & .428 & .431 & -.70 \\
\hline .70 & .406 & .407 & -.25 \\
\hline .75 & .378 & .377 & .26 \\
\hline .80 & .350 & .339 & 3.14 \\
\hline .85 & .317 & .293 & 7.57 \\
\hline .90 & .271 & .238 & 12.18 \\
\hline .95 & .194 & .171 & 11.86 \\
\hline .975 & .139 & .133 & 4.32 \\
\hline
\end{tabular}




\section{APPENDIX B \\ DETERMINATION OF THE EFFECT OF OXYGEN CONCENTRATION \\ AND VOLOXIDIZER ROTATION SPEED UPON THE RATE \\ OF OXIDATION OF URANIUM DIOXIDE}

\section{B. 1 OXYGEN CONCENTRATION EFFECTS}

The data presented in Figure 3.6 were used to determine the effect of concentration upon the rate of oxidation of uranium dioxide. If the rate of oxidation when the oxidizing atmosphere contains 20 mol\% oxygen, then it is assumed that the rate of oxidation at some other oxygen concentration is given by the relationship

$$
f\left(Y_{0_{2}}\right)=r_{U O_{2}}\left(Y_{0_{2}}\right) / r_{U 0_{2}}\left(Y_{0_{2}}=20 \mathrm{~mol} \% 0_{2}\right)=t_{m}\left(Y_{0_{2}}=20 \mathrm{~mol} \%\right) t_{m}\left(Y_{0_{2}}\right)
$$

$\mathrm{Y}_{\mathrm{O}_{2}}$ is the mole perant oxygen in the gas phase, where $\mathrm{r}_{\mathrm{UO}_{2}}$ is the volumetric rate of formation of uranium dioxide, and $t_{m}$ is the time required for $100 \%$ conversion of the uranium dioxide, and $t_{m}$ is the time form of $f$ is assumed to be

$$
f\left(Y_{\mathrm{O}_{2}}\right)=a Y_{\mathrm{O}_{2}}^{2}+b \mathrm{O}_{2}+c
$$

Using the "least-squares" criterion for determination of the constants $a, b$, and $c$, one must minimize the objective function I given by the equation

$$
I=\sum_{i=i}^{N}\left[f_{i}-\left(a Y_{0_{2} i}^{2}+b Y_{0_{i} i}+C\right)\right]^{2}
$$

This procedure yields the following relationship for $f$

$$
f\left(Y_{0_{2}}\right)=1.306 \times 10^{-4} Y_{0_{2}}^{2}+1.943 \times 10^{-3} Y_{0_{2}}+9.097 \times 10^{-1}
$$

The values of the $f_{i}$ and the $Y_{0_{2}}$ used in the calculation are given in Table B. 1 . 


\section{B.2 EFFECTS OF VOLOXIDIZER ROTATION SPEED}

The data presented in Figure 3.8 were used to determine the effect of the voloxidizer rotation speed upon the rate of oxidation of uranium dioxide. Using the rate of oxidation when the rotational speed is 12 RPM as a basis, the rate of oxidation at some other rotational speed can be assumed to be given by the relationship

$$
g(\omega)=r_{U_{2}}(\omega) / r_{U_{O_{2}}}(\omega=12 R P M)=t_{m}(\omega)
$$

where wis the rotation speed of the voloxidizer in RPM, $r_{U_{O_{2}}}$ is the volumetric rate of formation of uranium dioxide, and $t_{m}$ is the time required for $100 \%$ conversion of the uranium dioxide to $U_{3} \mathrm{O}_{8}$. If the functional form of $\mathrm{g}$ is assumed to be

$$
g(\omega)=a \omega^{2}+b \omega+c
$$

then the "least-squares" criterion for determining the constants $a, b$, and $c$ gives the objective function

$$
\sum_{i=1}^{N}\left[\left[g_{i}-\left(a \omega_{i}^{2}+b \omega_{i}+c\right)\right]^{2}\right.
$$

Which must be minimized with respect to the constants $a, b$, and $c$. This leads to the following relationship for $\mathrm{g}$

$$
g(\omega)=9.509 \times 10^{-4} \omega^{2}+9.238 \times 10^{-3} \omega+7.436 \times 10^{-1}
$$

The values of the $g_{i}$ and the $\omega_{i}$ used in the calculation are given in Table B. 2. 
TABLE B. 1 EFFECT OF OXYGEN CONCENTRATION UPON THE RATE OF OXIDATION OF $\mathrm{UO}_{2}$

\begin{tabular}{|c|c|c|}
$\%$ Oxygen in the Gas Phase & $\begin{array}{c}\text { Time Required for 100\% } \\
\text { Conversion of } \mathrm{UO}_{2} \\
\mathrm{t}_{\mathrm{m}} \text { (hours) }\end{array}$ & $f_{i}=t_{\mathrm{m}}\left(\mathrm{Y}_{0_{2}}=20 \mathrm{~mol} \%\right) /\left(\mathrm{Y}_{0_{2}}\right)$ \\
\hline $\mathrm{Y}_{2 i}$ & 2.583 & 1.000 \\
20 & 2.155 & 1.199 \\
40 & 1.729 & 1.494 \\
60 & 1.358 & 1.902 \\
\hline
\end{tabular}

TABLE B. 2 EFFECT OF VOLOXIDIZER ROTATION SPEED UPON THE RATE OF OXIDATION OF $\mathrm{UO}_{2}$

\begin{tabular}{|c|c|c|}
$\begin{array}{c}\text { Rotational Speed } \\
\omega \text { (RPM) }\end{array}$ & $\begin{array}{c}\text { Time Required for } 100 \% \\
\text { Convers ion of U0 } \\
t_{m} \text { (hours) }\end{array}$ \\
\hline 2 & 3.648 & $g_{i}=t_{m}(\omega=12 R P M) / t_{m}(\omega)$ \\
6 & 3.464 & 1.000 \\
12 & 2.829 & 1.053 \\
36 & 1.226 & 2.990 \\
\hline
\end{tabular}




\section{APPENDIX C}

EVALUATION OF PARAMETERS FOR THE REACTION RATE EXPRESSION

C. 1 DETERMINATION OF THE VOLUME RATIO OF FUEL TO CLADDING IN A FUEL ELEMENT The volume ratio of fuel to cladding in a fuel element is given by the equation

$$
v_{\text {fue } 1} / V_{\text {clad }}=\frac{\pi}{4} D_{I}^{2} L / \frac{\pi}{4}\left[\left(D_{I}+2 t\right)^{2}-D_{I}^{2}\right] L=D_{I}^{2} / 4\left(D_{I} t+t^{2}\right)
$$

where $D_{I}$ is the inside diameter of the cladding and $t$ is the cladding thickness. If

$$
D_{I}=1 / 2 \text { inch }=1.27 \times 10^{-2} \mathrm{~m}
$$

and

$$
t=0.02 \text { inch }=5.08 \times 10^{-4} \mathrm{~m}
$$

then

$$
\begin{aligned}
v_{\text {fuel }} / V_{\text {clad }} & =\left(1.27 \times 10^{-2} \mathrm{~m}\right)^{2} / 4\left[\left(1.27 \times 10^{-2} \mathrm{~m}\right)\left(5.08 \times 10^{-4} \mathrm{~m}\right)^{2}\right]\left(5.08 \times 10^{-4} \mathrm{~m}\right) \\
& =6.0
\end{aligned}
$$

This is expected to be a typical fuel to cladding volume ratio based upon current nuclear fuel fabrifaction practices.

\section{C.2 DETERMINATION OF THE SOLIDS DENSITY}

The total mass of solids (fuel plus cladding) is

$$
m_{\text {total }}=m_{\text {fuel }}+m_{\text {cl adding }}=v_{\text {fuel }} \rho_{\text {fuel }}+v_{\text {clad }} \rho_{\text {clad }}
$$

Division of this equation by the total volume of the solids gives

$$
\rho_{\text {total }}=m_{\text {total }} / v_{\text {total }}=\left(v_{\text {fuel }} \rho_{\text {fuel }}+v_{\text {clad }} \rho_{\text {clad }} / v_{\text {total }}\right.
$$

Which can be simplified using equation (C.2) to yield

$$
\rho_{\text {total }}=6 / 7 \rho_{\text {fuel }}+1 / 7 \rho_{\text {clad }}
$$


The density of the fue 1 is $10500 \mathrm{kgm} / \mathrm{m}^{3}$ and the density of zirconium is 6440 $\mathrm{kgm} / \mathrm{m}^{3}$ so equation (C.5) can be used to obtain the total solids density

$$
\begin{aligned}
\rho_{\text {total }}=6 / 7\left(10500 \mathrm{kgm} / \mathrm{m}^{3}\right)+1 / 7\left(6440 \mathrm{kgm} / \mathrm{m}^{3}\right) \\
=9920 \mathrm{kgm} / \mathrm{m}^{3} \\
\simeq 9900 \mathrm{kgm} / \mathrm{m}^{3}
\end{aligned}
$$

C. 3 DETERMINATION OF THE INLET MASS FRACTION OF INERT SOLIDS

The mass fraction of inert solids (cladding) at the inlet is

$$
\begin{gathered}
{ }^{\omega}{ }_{c l a d}=m_{c l a d} / m_{\text {total }}=m_{c l a d} /\left(m_{c l a d}+m_{\text {fuel })}\right) \\
=v_{c l a d} \rho_{c l a d} /\left(v_{c l a d} \rho_{c l a d}+v_{\text {fuel }} \rho_{\text {fgel }}\right) \\
=\rho_{c l a d} /\left[\rho_{c l a d} f\left(v_{\text {fuel }} / V_{c l a d}\right) \rho_{c l a d}\right]
\end{gathered}
$$

This equation can be simplified using equation (C.2) to give

$$
{ }^{\omega} \text { clad }=\rho_{\text {clad }} / \rho_{\text {clad }}+6 \rho_{\text {fuel }}
$$

For zirconium clad fuel

$$
\rho_{\text {fuel }}=10500 \mathrm{kgm} / \mathrm{m}^{3}
$$

and

$$
P_{\text {clad }}=6440 \mathrm{kgm} / \mathrm{m}^{3}
$$

Hence, equation (C.7) may be evaluated as

$$
\begin{gathered}
\omega_{\text {clad }}=\left(6440 \mathrm{kgm} / \mathrm{m}^{3}\right) /\left(6440 \mathrm{kgm} / \mathrm{m}^{3}\right)+6\left(10500 \mathrm{kgm} / \mathrm{m}^{3}\right) \\
=0.09274 \mathrm{kgmZr} / \mathrm{kgm} \text { total }
\end{gathered}
$$

\section{C.4 DETERMINATION OF THE URANIUM DIOXIDE CONCENTRATION}

The concentration of uranium dioxide is based on the inert solids (cladding material) present. Hence, 


$$
\mathrm{C}_{\mathrm{UO}_{2}}^{\circ}=\mathrm{m}_{\mathrm{UO}_{2}} / \mathrm{m}_{\mathrm{Zr}}=\mathrm{m}_{\text {fuel }} / \mathrm{m}_{\mathrm{clad}}=v_{\text {fuel }} \rho_{\text {fuel }} / \mathrm{v}_{\mathrm{clad}} \rho_{\mathrm{clad}}
$$

Using equation (C.2), this equation becomes

$$
\mathrm{C}^{\circ} \mathrm{UO}_{2}=6 \cdot \rho_{\text {fuel }} / \mathrm{\rho} \mathrm{clad}
$$

As noted in the section C.2

$$
\rho_{\text {fuel }}=10500 \mathrm{kgm} / \mathrm{m}^{3}
$$

and

$$
\rho_{\mathrm{clad}}=6440 \mathrm{kgm} / \mathrm{m}^{3}
$$

so

$\mathrm{C}_{\mathrm{UO}_{2}}^{\mathrm{O}}=6 \cdot\left(10500 \mathrm{kgm} / \mathrm{m}^{3}\right) /\left(6440 \mathrm{kgm} / \mathrm{m}^{3}\right)=\left(9.783 \mathrm{kgm} \mathrm{UO} \mathrm{O}_{2} / \mathrm{kgm}^{2} \mathrm{r}\right)\left(\mathrm{kgmol} 1 \mathrm{UO}_{2} / 267 \mathrm{kgm}\right)$

$$
=0.0366 \mathrm{kgmol} 1 \mathrm{UO}_{2} / \mathrm{kg} \mathrm{Zr}
$$

\section{5 DETERMINATION OF THE INLET SOLIDS VOID FRACTION}

The void fraction for randomly packed right cylinders is calculated using a correlation presented in Unit Operations by G. G. Brown et el. 16 The correlation is based upon the sphericity, $\psi$, defined by the equation

$$
\psi=A_{s p} / A_{p} \frac{\text { Surface area of a sphere with } V=V_{r}}{\text { Surface Area of Particle }}
$$

For a right cylinder with Diameter $D_{p}$ and length $L$

$$
A_{p}=\pi D_{p}^{2} / 2
$$

and

$$
v_{p}=\pi D_{p}^{e} L / 4
$$

Thus,

$$
A_{s p}=\pi\left(6 V_{p} / \pi\right)^{2 / 3}
$$


so

$$
\psi=A_{s p} / A_{p}=\left(3 / 2 D_{p}^{2} L / 2\right)^{2 / 3} /\left(D_{p}^{2} / 2+D_{p} L\right)
$$

Assuming that the length of the sheared fuel segments is $2.54 \times 10^{-2} \mathrm{~m}$ and that their diameter is $1.3208 \times 10^{-2} \mathrm{~m}$, equation (C.10) yields

$$
\begin{gathered}
\psi=\left[3 / 2\left(1.3208 \times 10^{-2} \mathrm{~m}\right)^{2}\left(2.54 \times 10^{-2} \mathrm{~m}\right)\right]^{2 / 3 /} \\
{\left[1 / 2\left(1.3208 \times 10^{-2} \mathrm{~m}\right)^{2}+\left(1.3408 \times 10^{-2} \mathrm{~m}\right)\left(2.54 \times 10^{-2} \mathrm{~m}\right)\right]=0.8363}
\end{gathered}
$$

This value of $\psi$ gives a porosity, $\varepsilon$ of 0.42 .

\section{6 DETERMINATION OF THE CROSS SECTIONAL AREA OCCUPIED BY SOLIDS}

Solids will not occupy the entire volume of the voloxidizer. Specification of the fuel bed depth to kiln diameter ratio at the outlet from the reactor, $D / b_{\text {out }}$ is a task required of the design engineer. The currently accepted value of $D / b_{\text {out }}$ is 5.6. Although values of $D / b_{\text {out }}$ will be design specifications, the cross sectional area occupied by the solids is required in the reaction rate expression. This is easily determined once $D / b$ has been fixed. The angle $\theta$ associated with the cord drawn a perpendicular distance $b$ from the edge of a circle is

$$
\begin{gathered}
\theta=2 \cos ^{-1}(c / R) \\
=2 \cos ^{-1}[(D / 2-b) / D / 2] \\
=2 \cos ^{-1}[(D-2 b) / D]
\end{gathered}
$$

The angle $\theta$ forms a sector of area 


$$
\begin{aligned}
A_{\text {sec }} & =R^{2} \theta / 2 \\
& =D^{2} \theta / 8 \\
& =[(D-2 b) / D] / 4
\end{aligned}
$$

The angle $\theta$ also has associated with it a triagle formed by the cord and two radi $i$ which have an included angle of $\theta$. This triangle has an area

$$
\begin{aligned}
A_{\text {tri }} & =C\left(R^{2}-c^{2}\right) \\
& =(D / 2-b)\left[D^{2} / 4-(D / 2-b)^{2}\right]^{1 / 2} \\
& =(D-2 b / 2)\left(D b-b^{2}\right)^{1 / 2}
\end{aligned}
$$

Thus, the area of the segment is

$$
A_{\text {seg }}=A_{\text {sec }}-A_{\text {tri }}=D^{2} \cos ^{-1}[(D-2 b) / 2] / 4-[(D-2 b) / 2]\left(D b-b^{2}\right)^{1 / 2}
$$

This is the cross sectional area occupied by the solids in the rotary-kiln reactor.

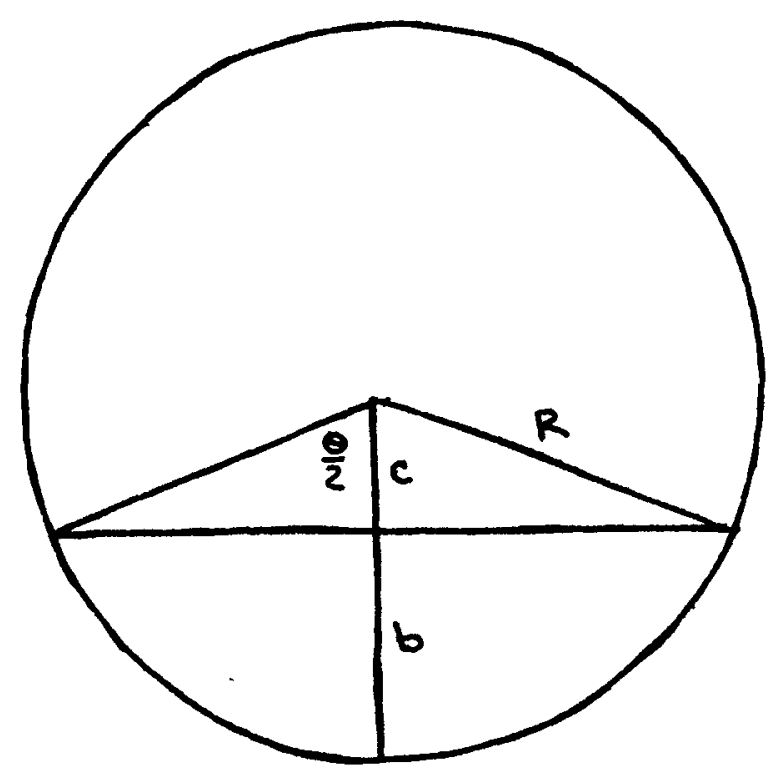


APPENDIX D

COMPUTER PROGRAM LISTINGS

$-69-$ 
FORTËAN IV RI PELFASE 2.0

THIS PROIJTAM IS A MAIHIMATICAL MUDEL OF THE HEAD-ENU TREATMENT PROCESS (VOLUXIUATIUN) OF SPENT NUCLEAH WASTE.

CACF I:CURURKFNT

THF hIINTE-KUTTA r UURITH UHDEH ACCURACY IS USEU TO SOLVE THE FULI OWING DIFFERENTIAL EUIJAIION ;

DXUOL/OZ $=-G(K+H) *(11-E) * A(O, B) / A C *(V I N / V O U T)) *(10 Z R /(S * T A U)$

WHF DF $((N * M)) *(1-X(1 \cup Z) *(1-N) * F(02))$

DXUUCAOZ=RATE UF CONVERSION OF VOZ U3OH WITH RESPECT TO VULOXIUILTH LENGTH

G(RPH) =A HULTIPLICATIVE FACIOH WHICH IS A FUNCTION OF THE VOLUXIOI/EH'S ROTATIOH

$A(D, t)=$ CKOSS SECTIONAL AREA OF VOLOXIUIZER THAT IS FILLEO

VIT IVUUTIIHATIO UF INPUT TO OUTHUT UF THE SHECIFIC VOLUME OF SOLIDS

F(OP) = FUNCTIUN OF UXYGFN CONCENTHATION

NOTF. THAT THIS PRUGRAM USHS A RATE EOUATION OF THE FORM

$T / T A U=13-11 *(1-X U(15) * \$ N$

Al, WHERE THE KATE UF REACTION $R$ IS DEF INES HY

$H=0(X \cup U 2) / D(T / T A U)$

AL\U,

B,M.IN ARE EQUATION CONSTANTS, FUNCTION OF TEMPERATURE

DEFFHITIUIN OF TERAS ANU THEIR RESPFCTIVE UNITS

WHFAt 
ADH = CKUSS SECTIORAL AHEA OF SOLIUS IN VOLOXIOILEH IM**21 H $(1,2)=$ ACONSTANT IN THE RATE EQUATION $F(T)$

BP= BREAK POINT. CUNOIIION TO CHANGE RAIE EQUATION

COZ = INLET OXYGEN CONCENTRATION (MOLES OZ/MOLES DILUENT GASI - DILUENT GAS SHUULO BE INERT, IN THIS CASE ITS NITHOGEN

CUOZ= UPANIUH DIUXIUE_CONGENTRATION (MOLES UOZ/ KG ZIRCONIUM)

$D=$ UIAME TEK OF VULUXIOIZLE (M)

OH = DIAIETEK TO FULL DENTH RATIO

$D O=$ CUNSTANT $(1 / 1$,

$F=$ VUIU FRACTIUN IUNITLESS)

$G=$ FLUX OF DILUENT GAS (MOLES N2, (SEC*M*"?))

GI= GAS FLOW RATE (MULES, MINUTE)

GASP = MULE FHACTIUN OF DILUENT GAS

$G()=$ IINHUT GAS FLUW HATE (M* J/MINUTE)

$N(1,2)=$ A CONSIANT I'N THE RATE F(NUATION $F(T)$

MAX $=$ UESIHEU CONVERSION (RANGE: 0.0 TO 1.0)

$A(1,2)=$ A CONSTANT IM THE RATE EOUATION $F(T)$

NP = FRE JUENCY OF DATA POINT SELECTION

$N=$ PHESSUHE OF SYSIEM (ATM)
O

$P=$ PRESSUAE OF SYSTEM (ATM)
$D=$ RELATING UOZ TO NL (MOLES

$O=$ RELATING UOZ TO N2 (MULES UO2/ MOLES N2)

$\overline{R E V}=$ MULTIPLICATIVE FACTOR, FINCIION OF VOLOXIOIZER ROTATION

RHM = HOTATIUNS PEH MINUTE OF VOLOXIOILER

$S=$ LIMCONIUM FLOW RATE (KG ZR / (SEC*M*Z2))

$S S=$ ANOUUNT OF SUI IUS TO BE PROCESSEU (KG / DAY)

$T=$ IF HWERATURE OF VOLOXIUIZER (C)

TAU = RESIUEINCE TIIE (SECONUS)

$T G=$ GAS INLET TENPERATURE (C)

$V I=$ INLET P PECIFIC VOLUME OF SOLIDS (M\#\#3, METRIC TON)

$V>=$ OUTLET SPECIFIC VOLUME OF SOLIOS (M*3, METRIC TON)

PLEAST NOTE

HIEASF $X(=)$ STANUS FUR VOLOXIOILFR LENGTH

-..- $Y(=)$ STAIUUS FUR COIJVERSIUN

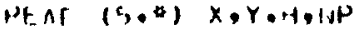




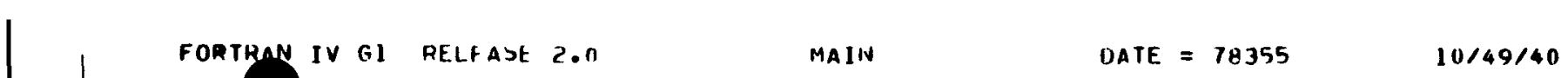

PAGE 0004

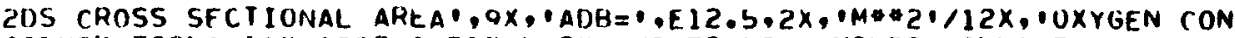

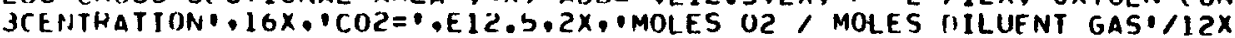

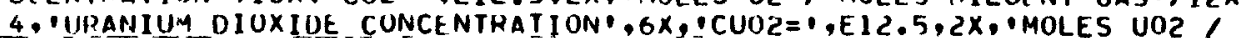

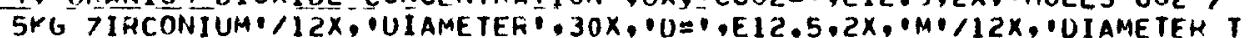

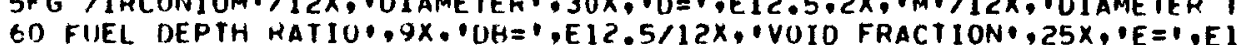

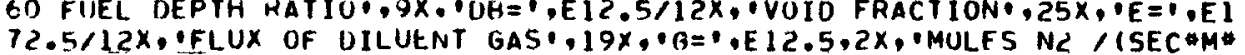

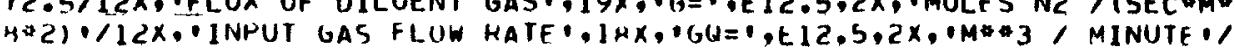

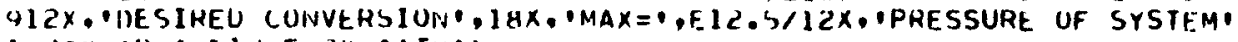

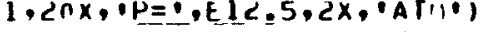

0055
0056
120 FOITE $(h, 120)$ HPM,S,SS, T, TAU,TG,VI,V2

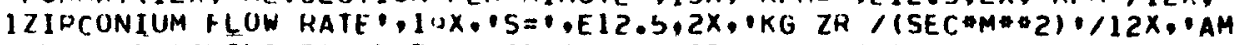

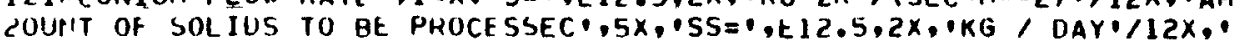

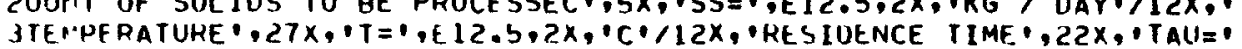

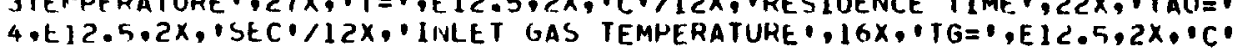

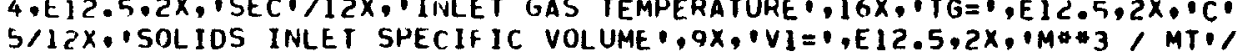

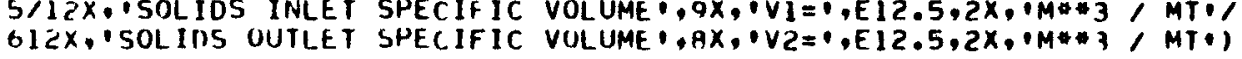

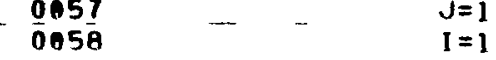

INTFGRATION IS DUNE USING THE RUNGE-KUTTA FOURTH ORDER ACCURACY

60 CUNTINUT

$A l=H * F(X, Y, H Z, N 2)$

$A Z=H=F(X+H / 2, Y Y+A) / 2, C, C, N C)$

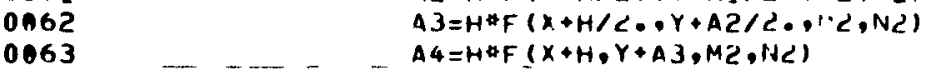

$0064 \quad Y=Y+(A I+2 . * A \bar{C}+2 . * A 3+A 4) / 6$.

0665

$C$ - CHECK FOR AKE AK-PUINT

0066 It $\quad$ I7ZAP .LE BP) GU 10 11)

$0067 \quad x=I * H$

0068

IF (MOD (1.NP). NE. O) $60 \quad$ TO 65

0069

$35 x \times(7)=x$

$r Y(J)=r$

- n $\quad$ -

0071

CALCULATE THE OUTLET OXYGFN CONCENTHATION CC(J)

0072

0073

0074

0076

0,77

0078

0079

$C(1, J)=(1) 2-(j * y$

$J=J+1$

65 CUn.TINUT

$I=1+1$

i, to on

70 $x=x-4$

$L=1$

WHITE $(6,130) J$

IJ FURMAT (///,I2X, DUATA PUINTS PHIOR $70 \mathrm{H.P.}=1.112$ )

OดคO

OดA

C INTEGRATIING THF SECUINU PAHT OF THE PATE EUUATION

$0 \theta 82$

0083

0.84

0085

gU CUITINUE

$A L=H * F(X, Y, H I, N I)$

$A C=H \& F(x+H / 2, Y Y+A 1 / 2, \ldots+1, T N 1)$

$A J=H * F(X+H / 3 \cdots Y+A 2 / 2, B, 1, N 1)$

$\left.A 4=H^{*} F()+H, Y+A 3,(4), H 1\right)$

$Y=Y+(A)+? \cdot A C+2 \cdot A B+A 4) / 6$ 


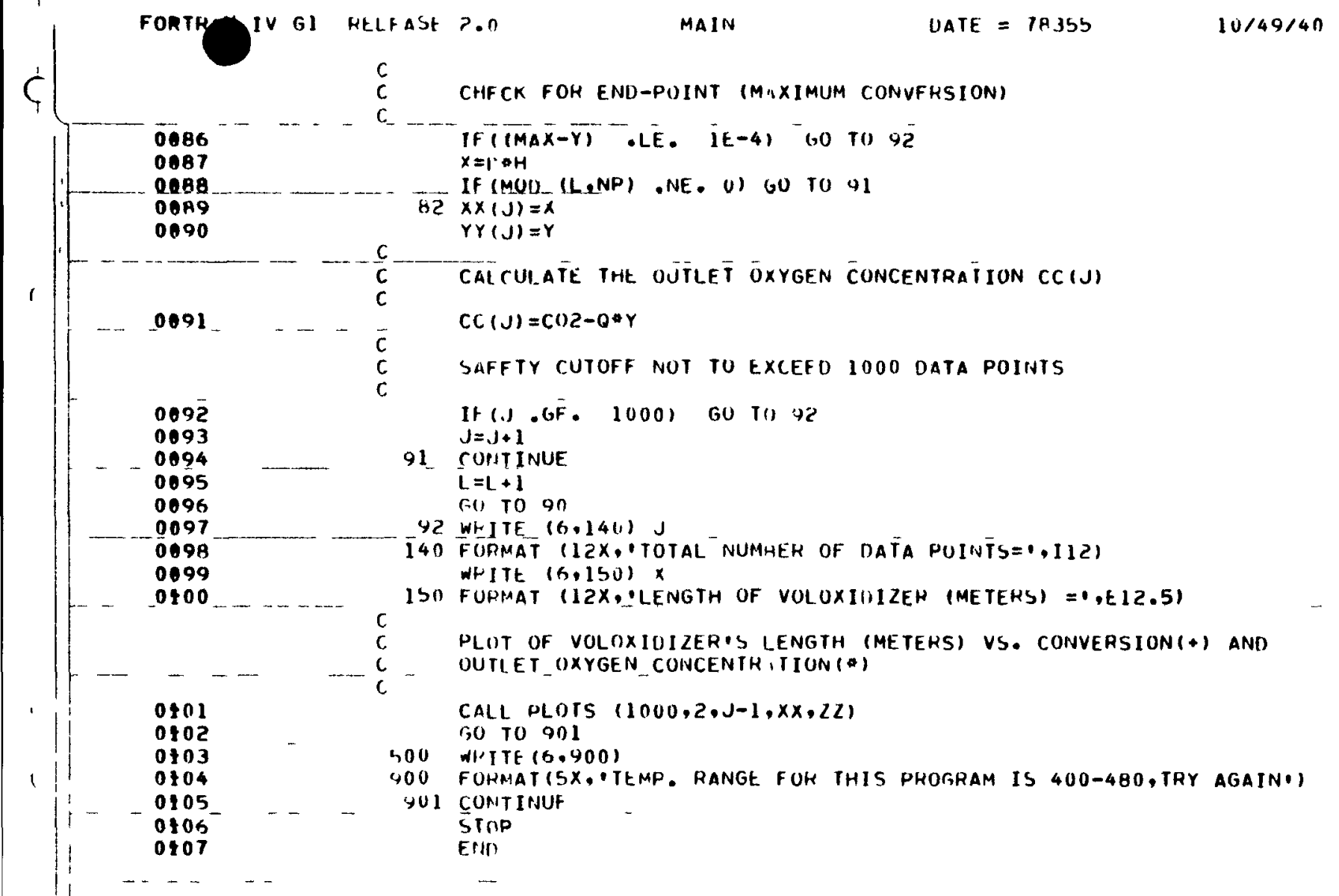

C CHFCK FOR END-PUINT (M $C X I M U M$ CONVFHSION) 
SUIPOUTINE PLOTS (NOIM,NC,NL, $X, Y$ )

DIMFNSION X (NL), Y (NUIM,NC), IN (5), D(5), MT (S), P (132)

DATA U,W,P,D/S*3,1HI,132*1H, IH*, IH*,1H\#,IHI,IHX/

0002

0.04
0005

WHITE $(6, S 0)(D(K), K=1, N C)$

0007 WIITE $(6,32)$

0,0 O

000 B

(1) FURMAT $(/ 9 x, h(A) 2)$

$0010 \ldots \ldots-C=0$.

0011 DO $10 \mathrm{~L}=1$. NL

$0012 \ldots$ - $\quad 0010 \mathrm{~J}=1, \mathrm{NC}$

$C=A N A X I(Y(L, J), C$

0014

10 $T=A M I N I(Y(L, J), I)$

$B=A M I N I((M I(N C)-C) /(C-1), 50, / A M A X I(C,-T))$

$\begin{array}{ll}0.16 & T=-T H A+P \\ 0.17 & 110>0 \quad K=1 . N L\end{array}$

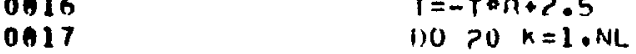

0 (1)

DO $25 \quad J=1 . N C$

0019

$P(N(J))=P(1)$
$P(T)=W$

0020

0021
-0021
0022

$M=T$.

$0023 \quad N(J)=Y(K, J) * B+$

$0024 \ldots P(N I(J))=0(J)$

$0025-65 \mathrm{M}=N \wedge \times 0(N(J), M)$

0026

0026

IF (IC.E 0,1$)$ WR I TE $(0,31) \times(K),(Y(K, J), J=1, N C),(P(J), J=1, M)$

0027

IF $(N C, E 0.2)$ WHI IE $(6,32) \times(K),(Y(K, J), J=1, N C),(P(J), J=1, M)$

0028

IF (NC.E(O.3) WHI IE $(6, J 3) \times(K),(Y(K, J), J=1, N C),(P(J), J=1, M)$

0029

IF $(N C, E 0.4)$ wK I TE $(6,34) \times(K),(Y(K, J), J=1, N C),(P(J), J=1, M$

0 Q 30

20 It (IIC,EQ, 5) WRITE $(6,3 \zeta) \times(K),(Y(K, J), J=1, N C),(P(J), J=1, M)$

0031 J1 FUPMAT $(611.3 \cdot 612,4,2 x, 106 A 1)$

0032 32 FORMAT $(611.3 .2612 .4 \cdot 2 x, 44 A 1)$

0033 33 FURI AT (611.3.3G12.4.2X.8CA1)

On34 J4 FURATIGI1.3.4G12.4.2X,70A1

0035 IS FUFMAT(G11.3.5GI2.4.2X.5HAI)

0036

DATA MT $/ 106,94,82,70,5 A /$

$P(T)=P(1)$

0037

Hit TIITH

0039 F(II) 


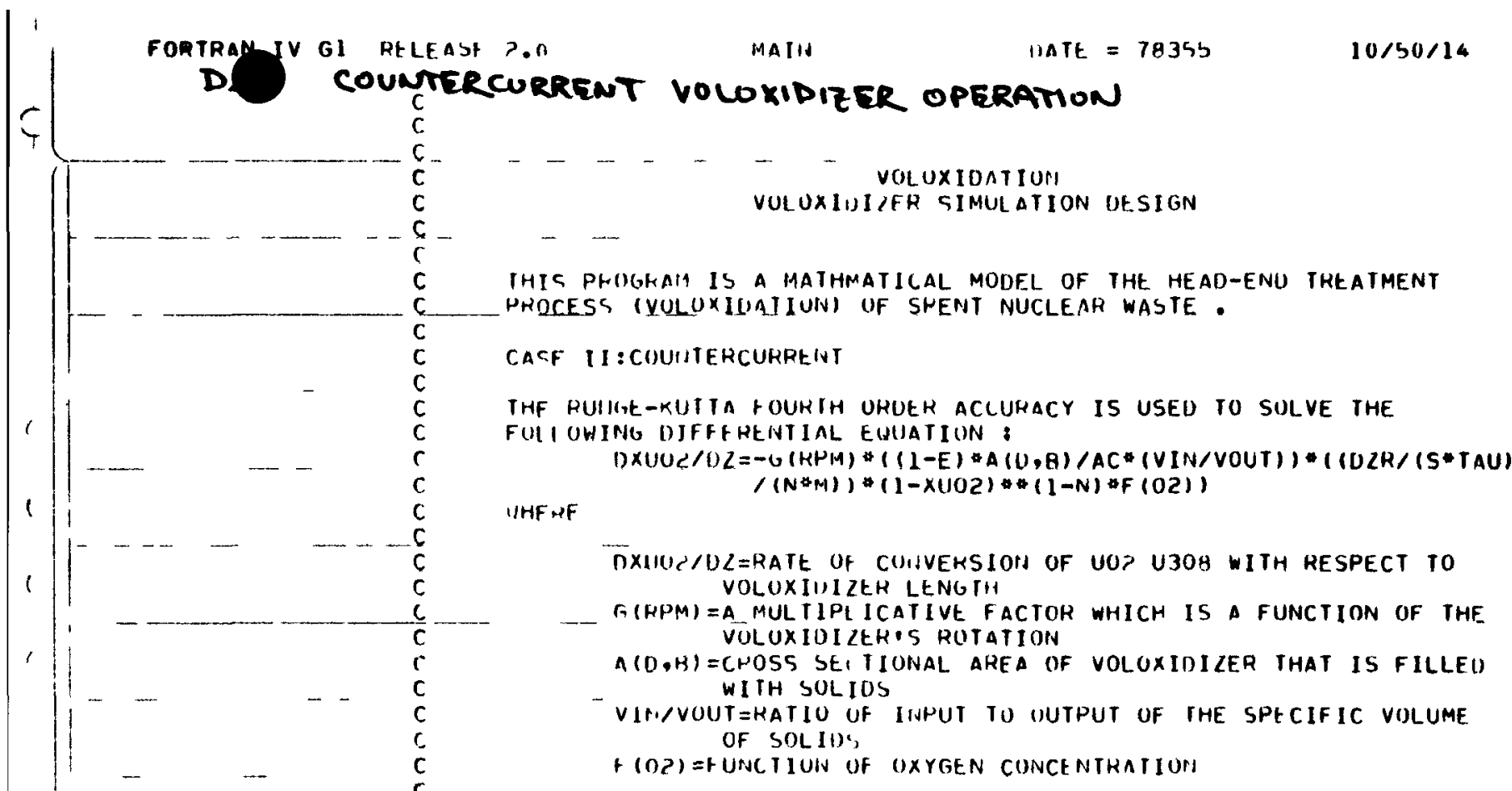

Page 0001

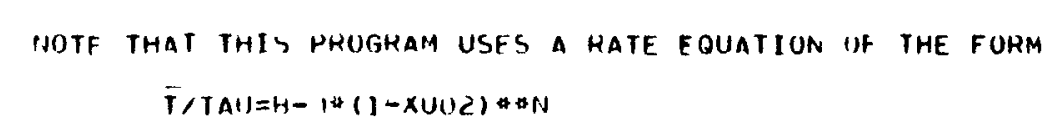

ANO WHFHE THE HATE Ut HEACTIOH $R$ IS DEFINED iY

ALCO, R=O(XUUZ) /D(T/TAU)

H.M.H ARE GQUATIUN CONSTANTS, FUNCTION OF TEIAPERATURE

DEFFNITION OF TENWS AINI THEIR HE SPFCTIVE UI ITS WhF'E 
P(1.2) = ACONSTANT IN THE HATE EMUATIUN F(T)

HP = BHEAK PUINT, CONUITION TO CHANGE RAIE EMUATION

COP = INLET UXYGEN CUNCENTRATION (MULES OZ/MOLES UILUENT GAS)

- OILUENT GAS SHOULD BE INERT. IN THIS CASE ITS NITHOGEN

CUOZ = UKANIUM DIOXIUE CUNCENTHATION (MOLES UOZ, KG ZIRCONIUM) $\mathrm{D}=$ DIAME IEH OF VOLOXIDIZER (M)
$\mathrm{UH}=$ DIAMETER TU FUEL UEPTH RATIO $D D=$ CONSTANT $(1 / \cdots)$

$E=$ VIIU FHACIIUIV (UNITLESS)

$G=$ FLUX JF DILUENT GAS (MOLES NE, ISEC MMOZ);

$G I=$ GAS FLOW RATE (MOLES, MINUTE)

GAS? = MULE FHACTIUN OF OILUENT GAS

GO= INPUT GAS FLOW RATF (MW B/MINUTE)

$M(1.2)=$ A CONSTANT II) IHE RAIE EQUATION F (T)

MAX $=$ DESIHEU CUNVEHSION (RANGE: 0.0 TO 1.0 )

MAXY = EXTFNT OF HEACTION (TERH USED ONLY IN COUNTERCURRENT CASE)

M! $(1.2)=$ A CONSTANT IU THE RATE FUUATIUN F(T)

NH = FPEIUUENCY UF DATA POINT SELECTION

$P=$ PRESSURE UT SYSIF.M (AIM)

$\theta=$ PFLATING UOZ TO NZ (MOLFS UOC/ MOLFS N2)

$H=$ RAUIUS UF VULOXIDIZEK (M)

RE $\bar{V}=$ MULTIPLICATIVE FACTUR, FUNCTION OF VOLOXIDIZER ROTATION

RPIN= RUTATIUIVS PER MINUTE OF VOLOXIDIZEH

$S=$ ZIRCONIUM HLUW HATE (KG LR, (SEC MON2))

$S S=$ AMOUINT UF SUL IUS IO RE PHOCESSEU (KG, DAY)

$T=$ TEMPEKATUHE OF VOI OXIUIZER (C)

TAU = RESIUE NUCE IIIAE (SECONUS)

TGE GAS INLET TEMPEHATURE ICI

$V I=$ INLET SHECIFIC VOLUME OF SOLIOS (M\#3/ METRIC TON)

$V Z=$ OUTLET SPECIFIC VOLUME OF SOLIDS (M\$3, METKIC TON)

PLFÁSE NUTE

$X(\Rightarrow)$ STAINUS FUR VOLOXIOIZEH LENGTH

$-----Y(=)$ STAINOS FUR CUIVVERSIUN

HEA NI,MI, NC,MR,XX(1000), YY $(1000), C C(1000), 2 L(1001,2), M A X, M, N$ EUI!TYALENCE $(Y Y(1), \angle 2(1,1)),(C C(1), Z Z(1,2))$

0001

0002

0003

0004

0005

0006

0007

000
EU!TVALENCE TYY (X)

1 $3 .-M A X Y)) * Z *+1.443 E-j *(C U Z *(S / G) *(C U U Z \# Y / 3 .-M A X Y))+.90971 /(N * A)$

REAT $(5, D) x, Y, H, H P$

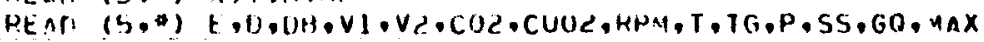

1)? $P=6440$.

$T H=T(i+213.15$

$T A 1 I=-41.66 * T+211464 \cdot 31$ 


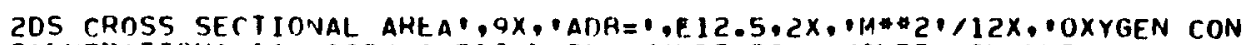

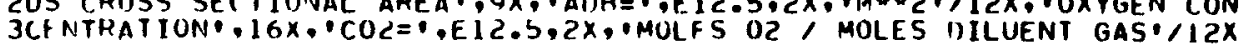

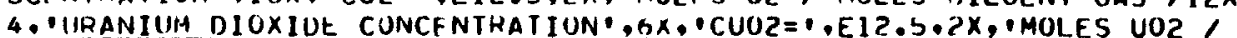

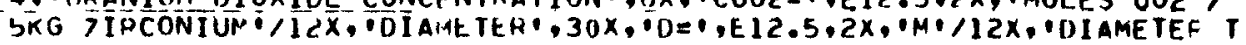

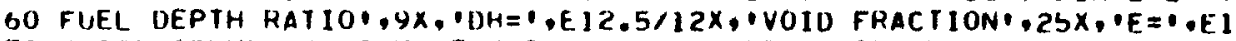

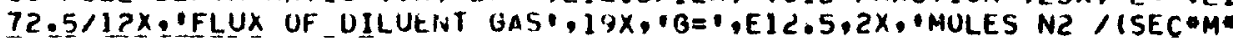

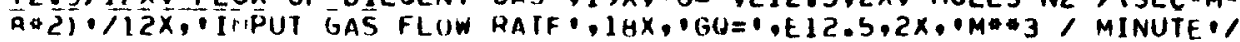

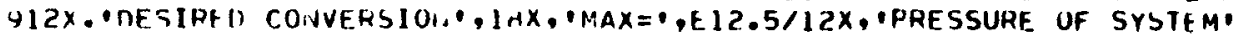
$\left.1,211 \times, \cdot P=\cdot, t 12 \cdot 5,2 x_{, 1}, A T, 1\right)$

0056 WRTTE $(H, 120) \mathrm{KPM}, \mathrm{S}, \mathrm{SS}, \mathrm{T}, \mathrm{TAU}, \overline{\mathrm{T} G}, \mathrm{~V} 1, V Z$

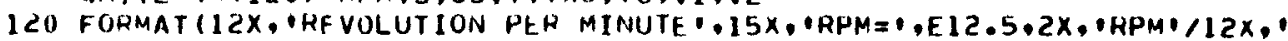

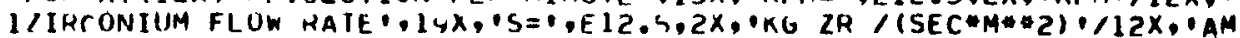

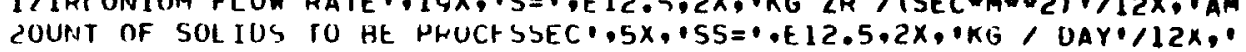

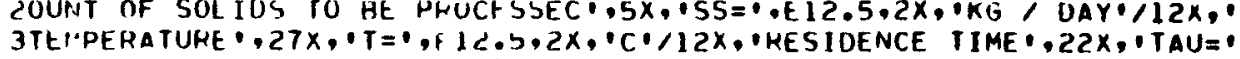

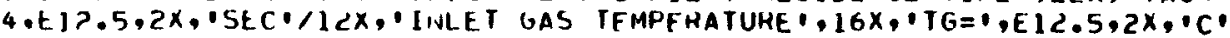
$5 / 1>x$, , SOLIDS INLET SPECIF IC VOLUME $\cdot 9 x, \cdot V 1=0, E 12.5,2 x, \cdot M * * 3 / M T$ M,

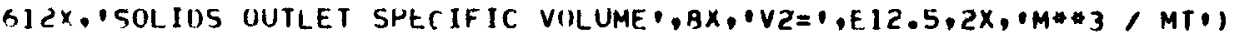

0058 $\begin{aligned} \mathrm{J} & =1 \\ \mathrm{I} & =1\end{aligned}$
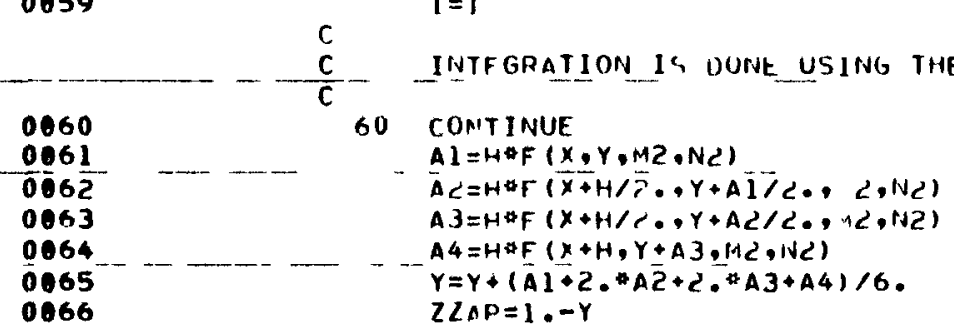


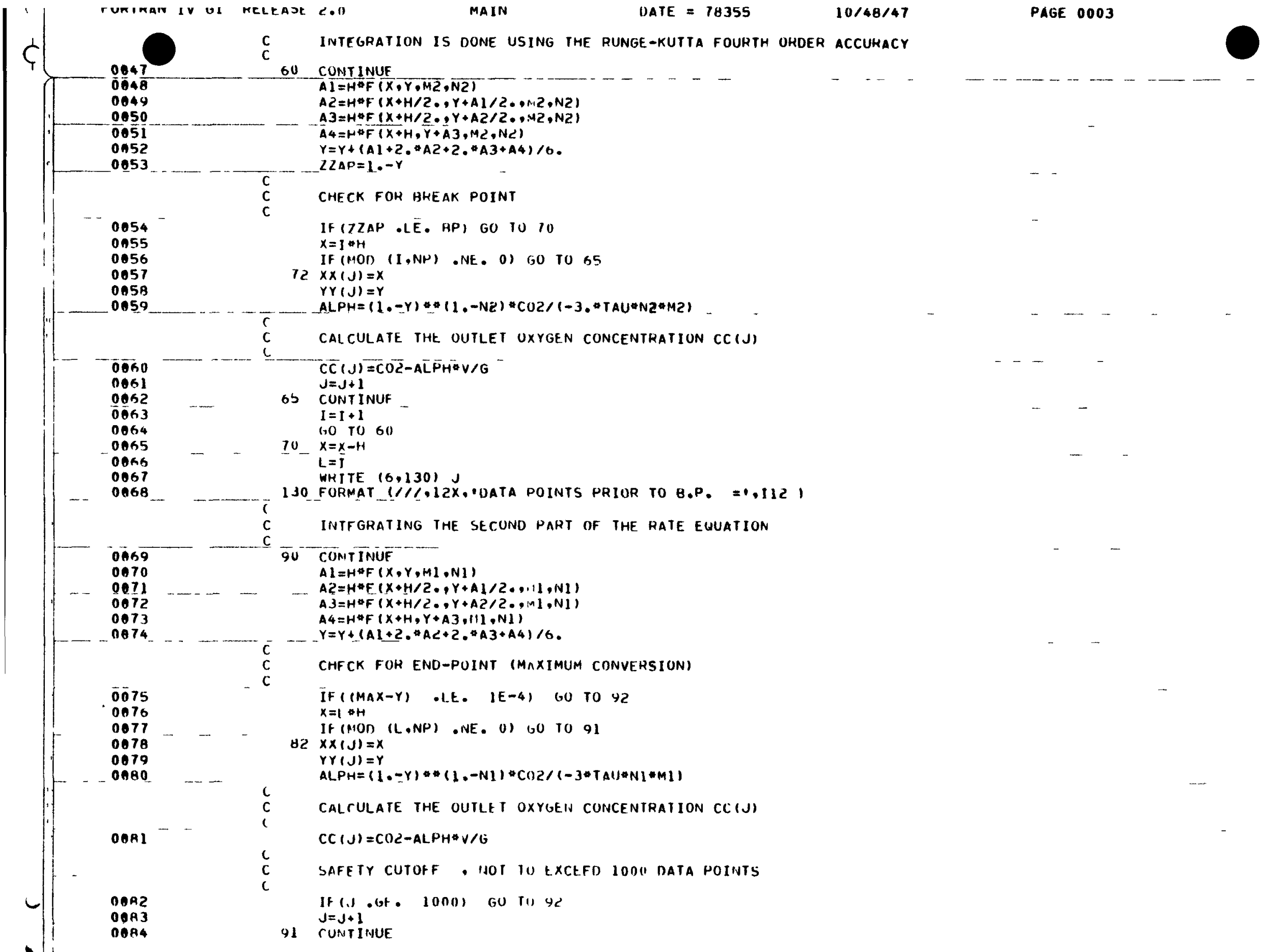




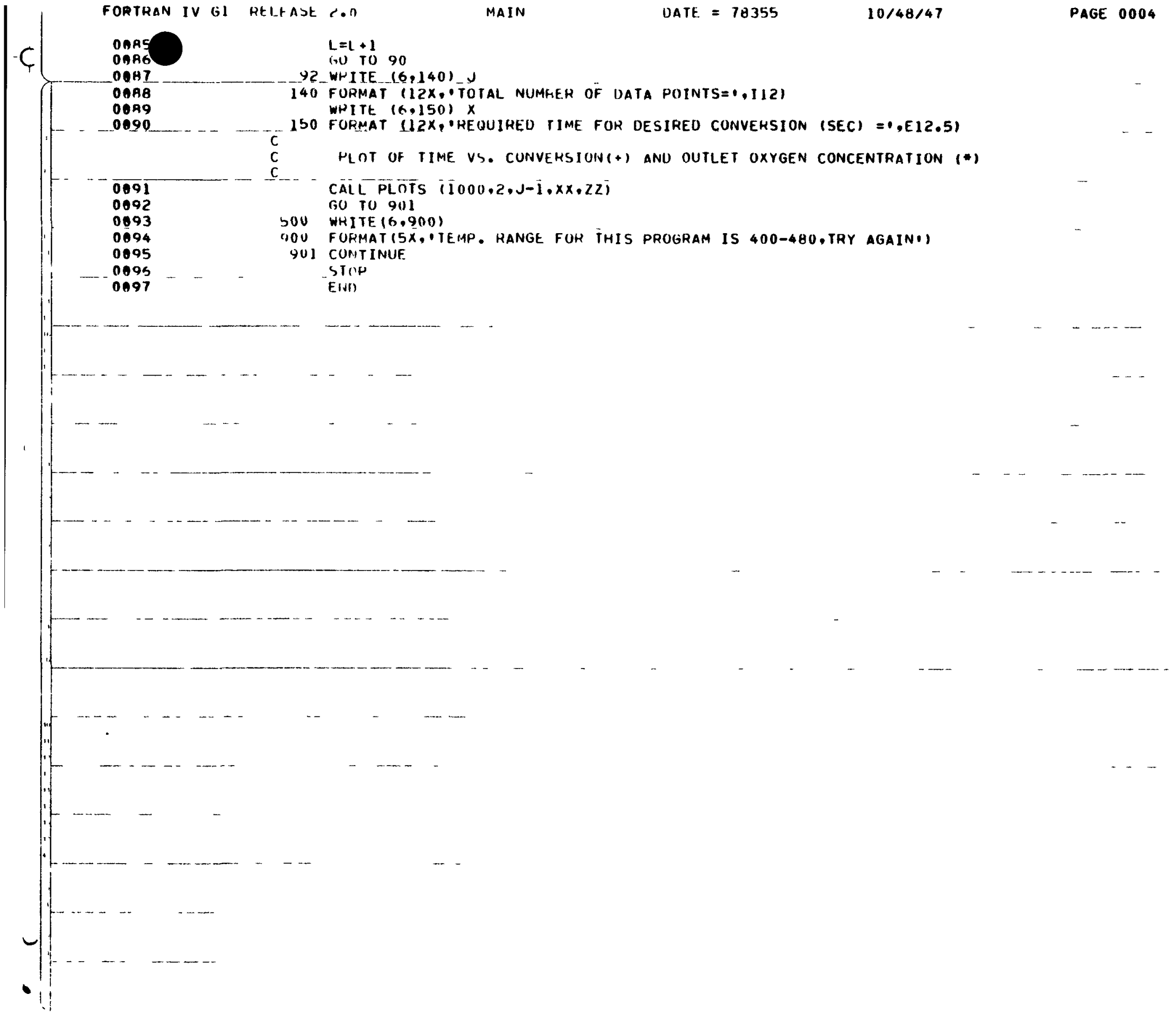




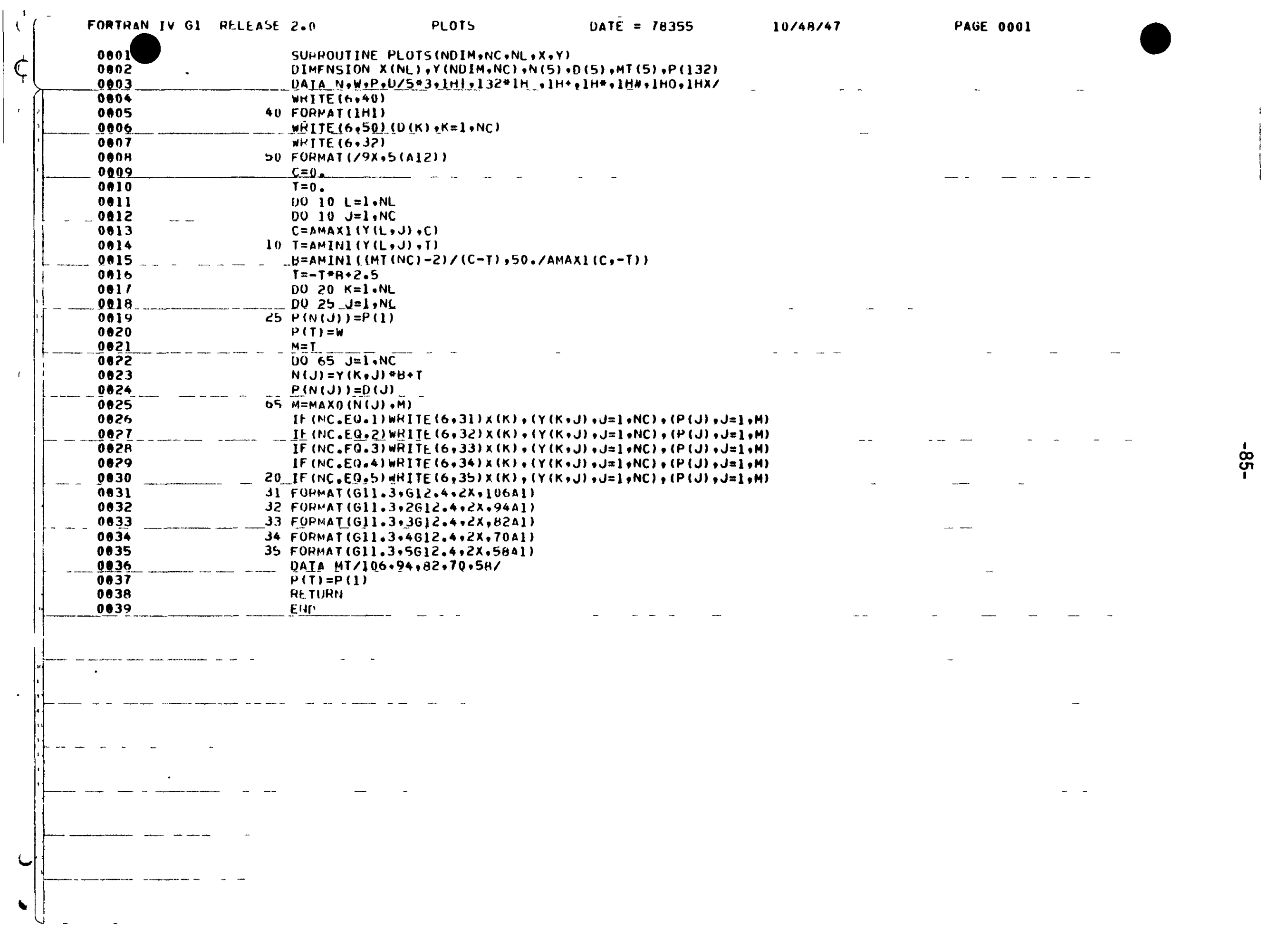


OONA bU FURMAT $(19 \times, 5(112))$

oeng 드. $\quad C=n$.

0010

0011

DO $10 \mathrm{~L}=1 \cdot \mathrm{NL}$

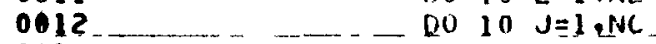

$0013 \quad C=A P A X I(Y(L, J), C)$

0014

$10 T=A M I N I(Y(L \cdot J), T)$

0015

$a=A M I N I((M) T(N C)-C) /(C-T), b)$. /AMAXI $(C,-T))$

$0016 \quad T=-T * H+2 . S$

$0011 \quad$ HU $>0 \mathrm{~K}=1$.NL

0018

DO $25, \mathrm{~J}=1, \mathrm{NL}$

010

2 P $P(N(J))=p(1)$

$0020 \quad P(T)=$

0021

0022

$M=T$

DO $05 \bar{J}=1 \cdot \overline{N C}$

$N(J)=Y(K, J) * H+T$

0024

$P(N(J))=0(J)$

0025

0026

0027

b) $M=M A \times \cap(N(J), M)$

IF (NC.EO, 1$)$ WHITE $(6,31) \times(K),(Y(K, J), J=1, N C),(P(J), J=1, M)$

0027 IF (NC OF $(2,2)$ \&

0028 IF $(N C, E(1,3)$ WKITE $(6,33) \times(K),(Y(K, J), J=1, N C),(P(J), J=1, M)$

0029 IF (NC.F Q.4) WHITE $(6,34) \times(K),(Y(K, J), J=1, N C),(P(J), J=1, M)$

$0030 \ldots \quad 20$ IF (NC,EU.S)WRITE $(0,35) \times(K),(Y(K, J), J=1, N C),(P(J), J=1, M)$

0031 JI FORMATIG11.3.1212.4.2X,106A1)

$\begin{array}{ll}0032 & 32 \text { FURPATT (GI } 1.3,2612.4,2 X, 94 A 1) \\ 0033 & 33 \text { FUHMAT }(G) 1.3,3612.4,2 x, 42 A 1)\end{array}$

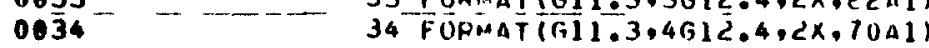

0035 J5 FOPHAT (G11.3.5612.4, $2 x, 54 A 1)$

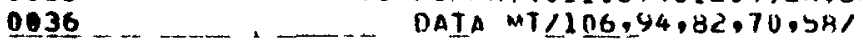

$0037 \cdots \cdots(T)=P(1)$

0038 RF TIIRII

0039 Eun 
APPENDIX E

SAMPLE PROGRAM OUTPUT

$-87-$ 


\section{' E.1 COCURRENT VOLOXIDIZER OPERATION \\ C OCURHE IT}

RAIE EOUATION CONSIANTS

B1 $=-0+30199 t+00$
$M 1=0.44500 t+00$

$M 1=0244500 t+00$
$N 1=-0+16399 t+00$

$A 2=0.35900 t+0 n$

$M 2=-0.37700 t+00$

$N 2=0.15410 t \cdot 01$

$\overline{P P}=\overline{0} . \overline{3200} \overline{1 E+00}$

RFACTOR PARANETËPS

- - - - - - - -

- $\ldots+\cdots$

-

CROSS SECTIONAL AREA

SOLIDS CROSS SECTIONAL AREA

OXYGEN CONCENTRATION

URASIUTA DIOXIUE CONCENTHATIOI.

OIAMETEN

$A C=0.38484 E-02 \quad M * 2$

$\triangle D B=0.96733 E-03 \quad M * 42$

$C U 2=0.25000 E+00$ MOLES O2, MOLES OILUENT GAS

CUUZ $=0.13700 E-01$ MOLES UD2 / KG ZIRCONIUM

$\mathrm{U}=0.10000 \mathrm{E}-01 \quad \mathrm{M}$

DIAMETER TO FUEL DEPTH RATIO

$B=0.62500 E+01$

$E=0.74000 E+00$

$\begin{aligned} \text { FLIIX OF DILUENT GAS } & G=0.57284 E+00 \\ \text { INPUT GAS FLOW RATE } & G U=0.37900 F+01\end{aligned}$

MOLES N2 / (SECAM**2)

INPUT GAS FLOW RATE

DESIRED CONVFRSION

PRESSURE OF SYSTEM

REVOLUTIUN PEH MTHUTE

7 IRCONIUAN FLON RATE

AMOUNI OF SULIOS TO BE PHOCESSEC

TEMPERA IURE

RESIDENCE TIME

INLET GAS TLMPEHATURE

INLE GAS TLMPERATURE

SOLIUS NUTLET SPFCIFIC VULUME

$A X=0.99400 E+00$

$P=0.100000^{\circ}+01$

$A P=0.10000 E+01$
$A P M=0.12000 E+02$

$S=0.79384 t+00 \quad K G$ ZR / (SEC*M**2)

$S=0.71400 E+03$ KG / DAY

$I=0.4 \mathrm{AOOOH}+03 \mathrm{C}$

$T A U=0.96771 E+03 \quad S E C$

$T_{U}=0.3731 \mathrm{SE}+03 \quad \mathrm{C}$

$V I=0.74000 F+00 \quad M * 3, \mu T$

$V 2=0.79000 E+00 M * 3, M T$

$\begin{array}{ll}\text { DATA POIITS PKIUK TO H.P. }= & 127 \\ \text { TOTAL NUAAER OF OATA POINTS } & 499\end{array}$

LENGTH OF VULOXINILER (METERS) $=0.24910 \mathrm{O}+01$ 


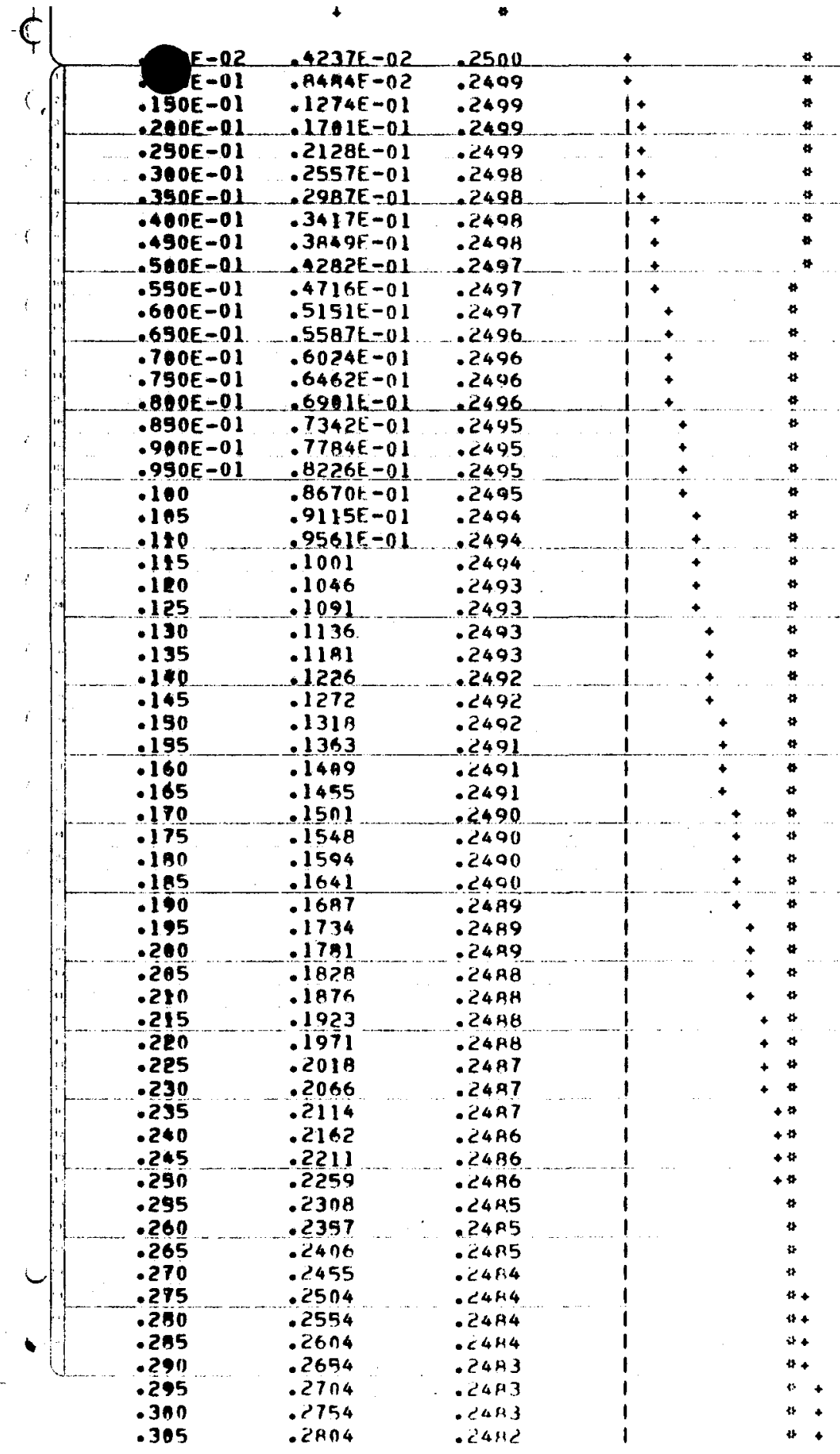




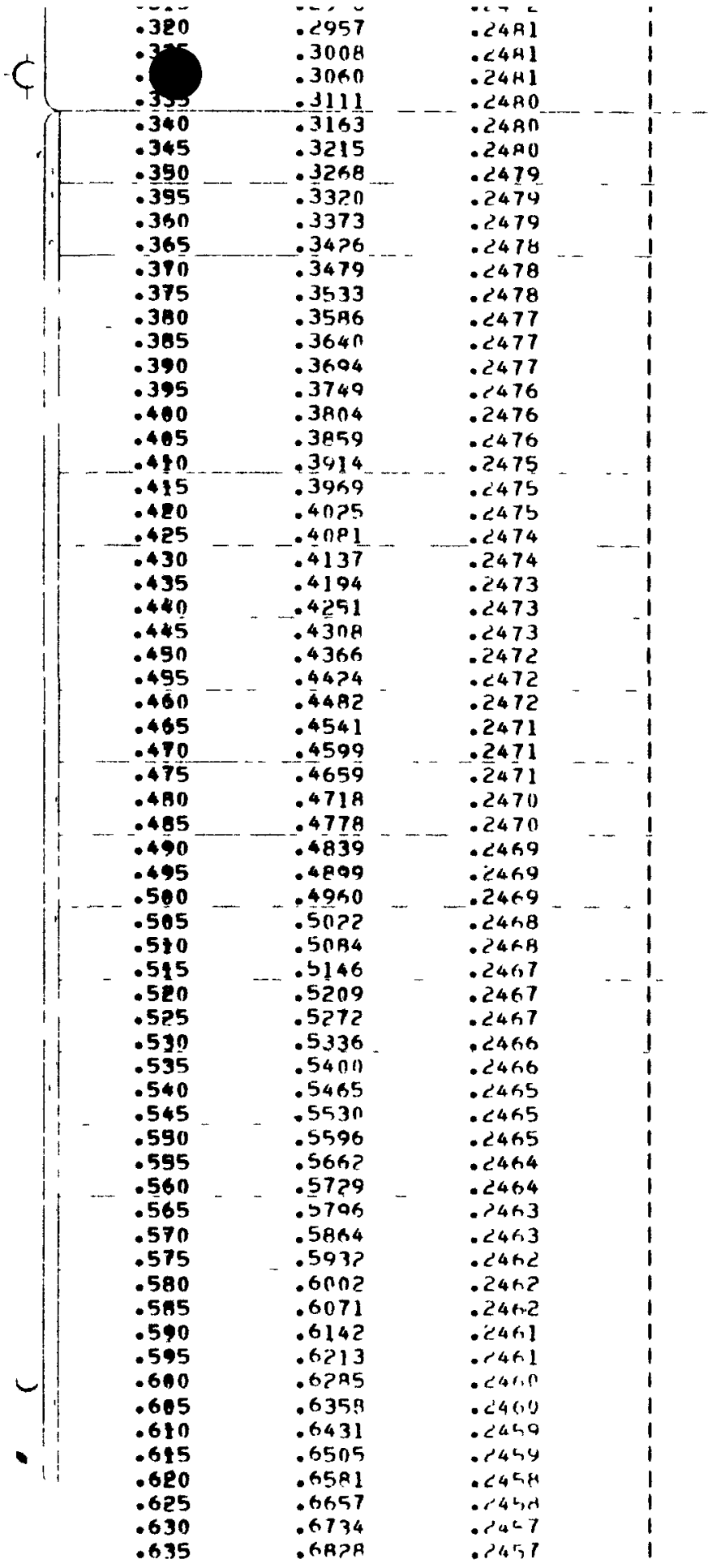




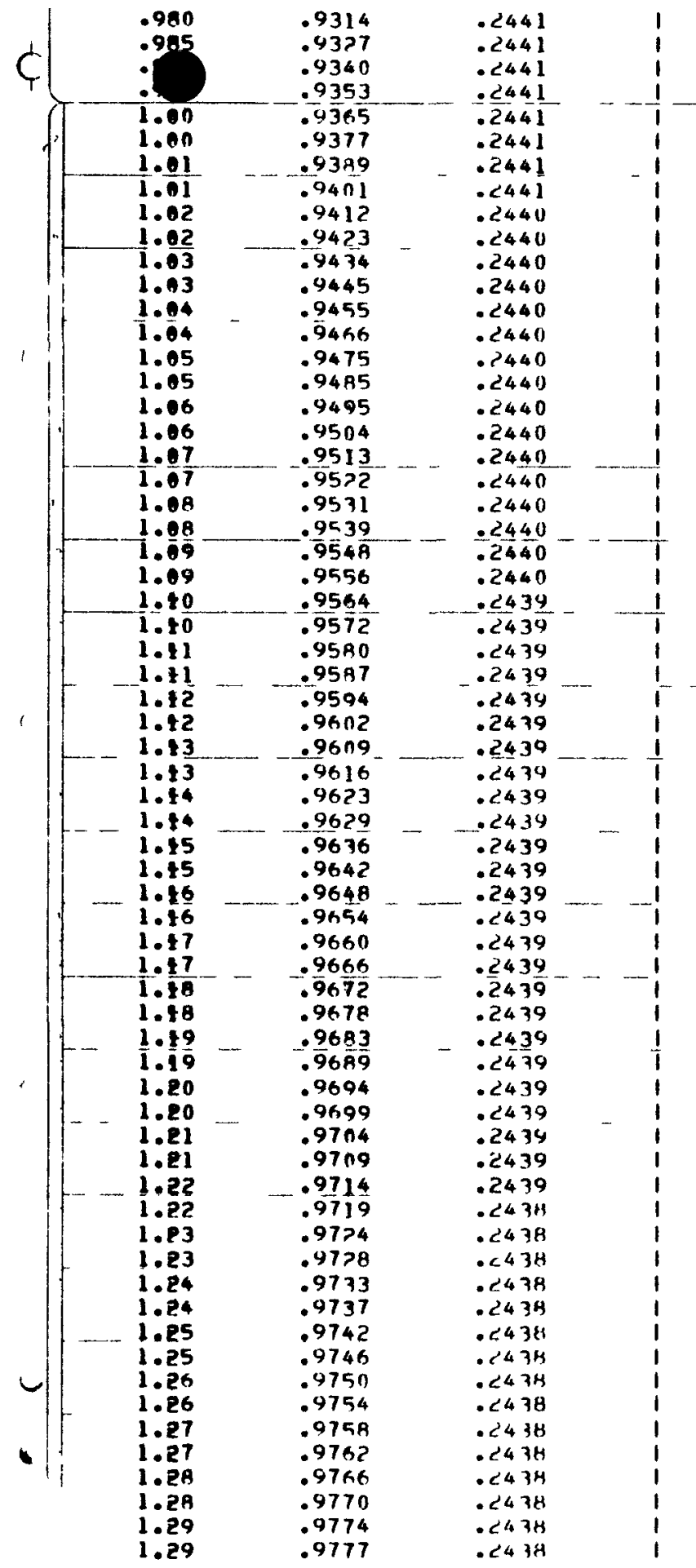




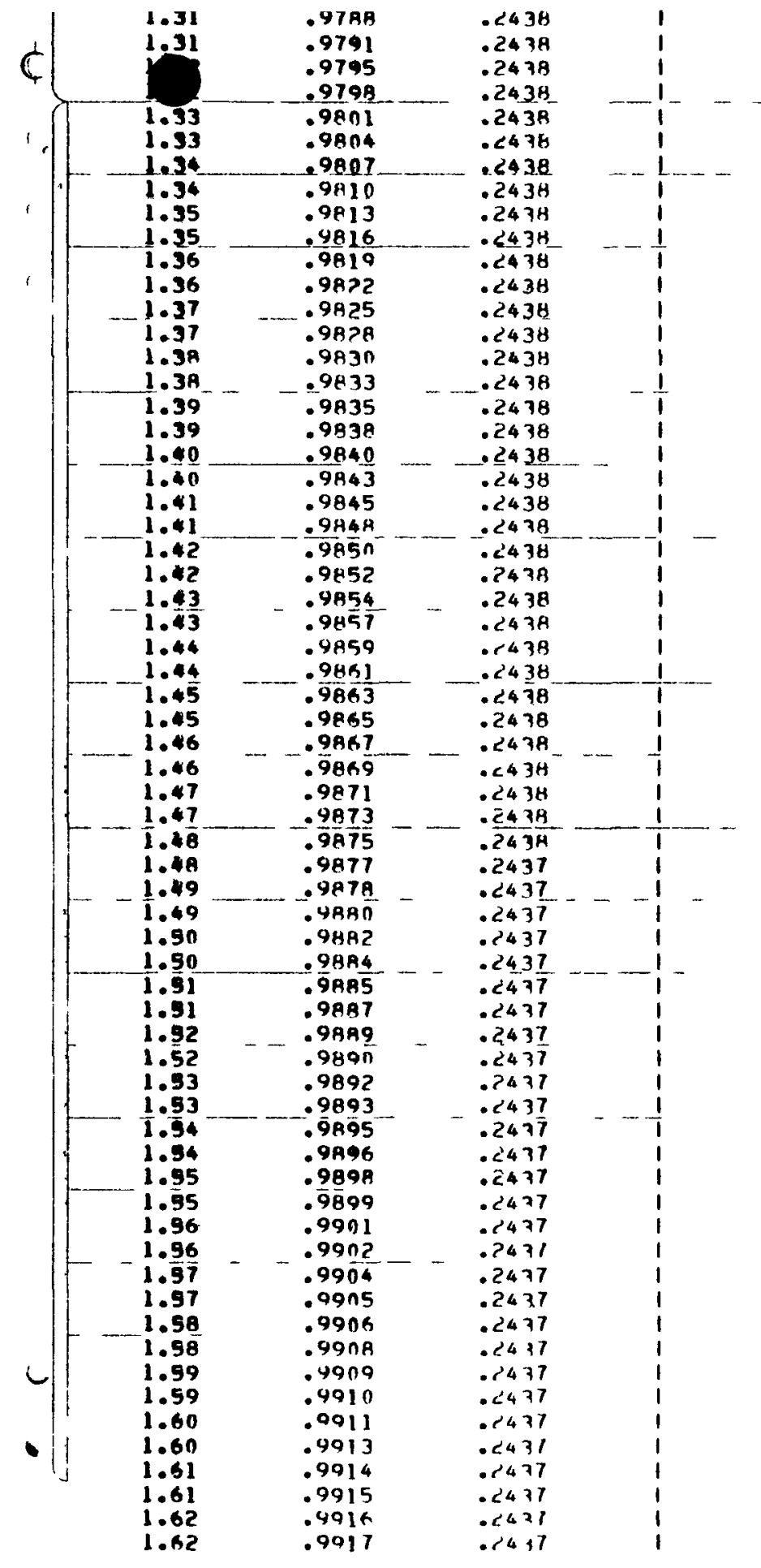



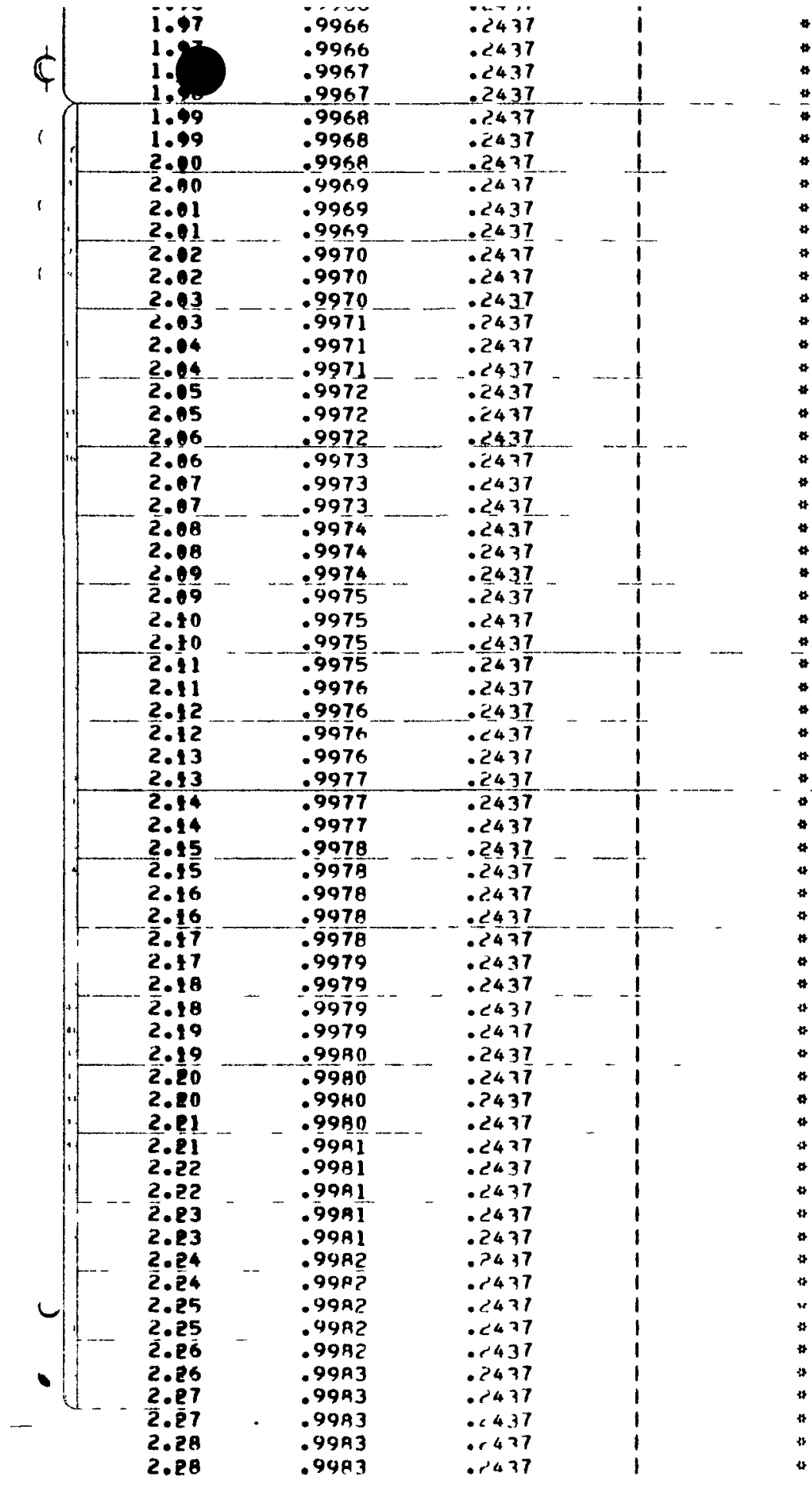


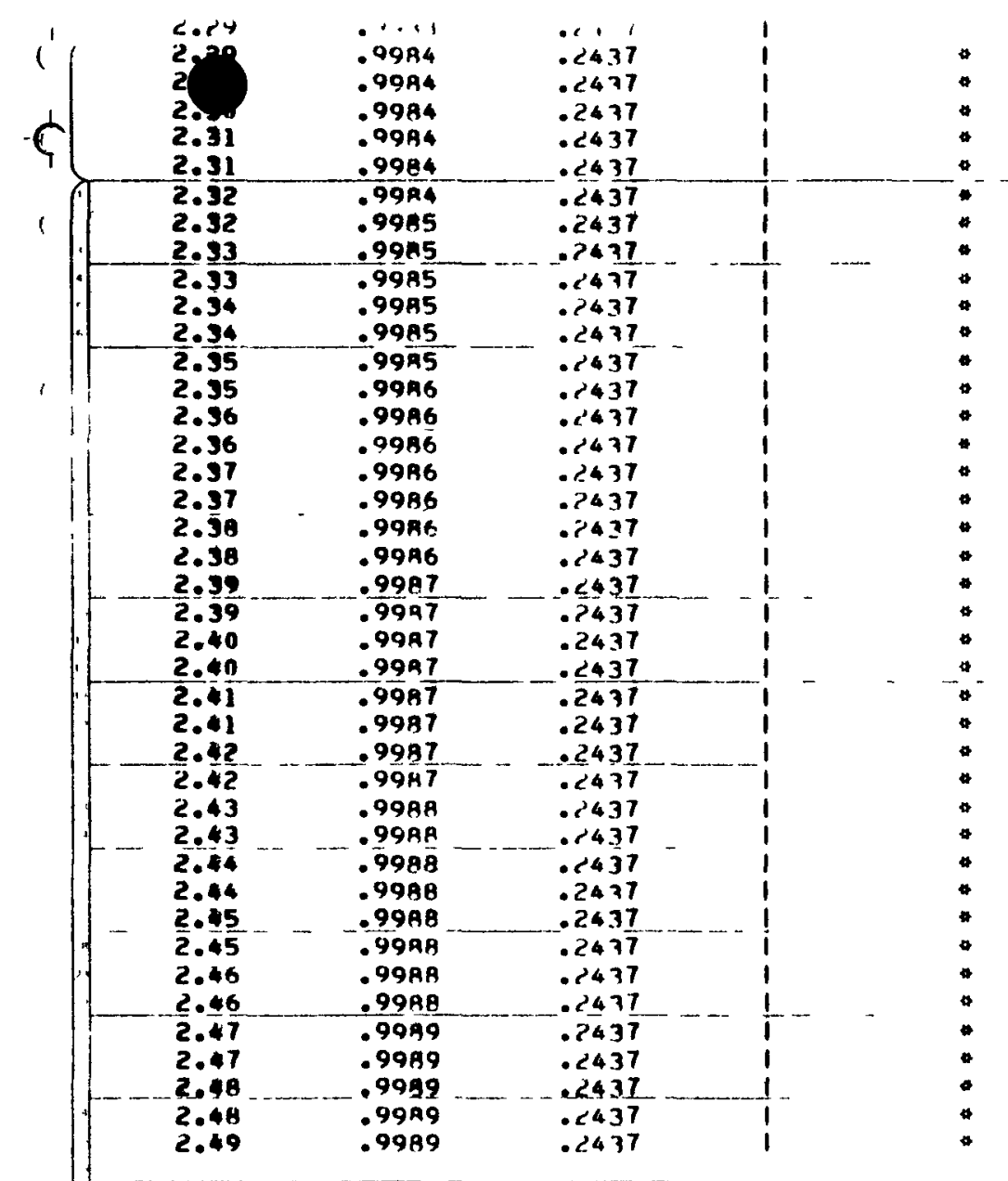




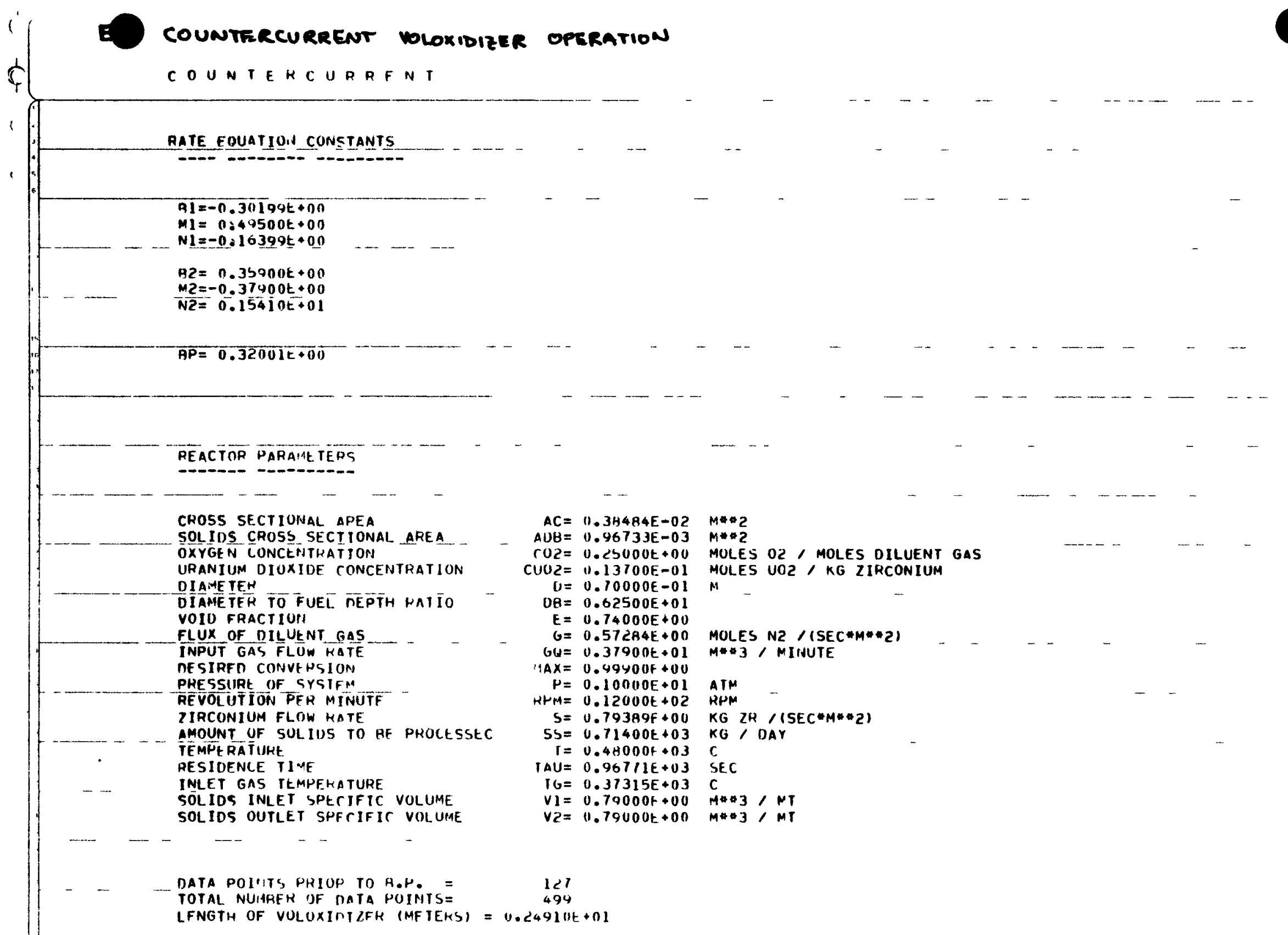




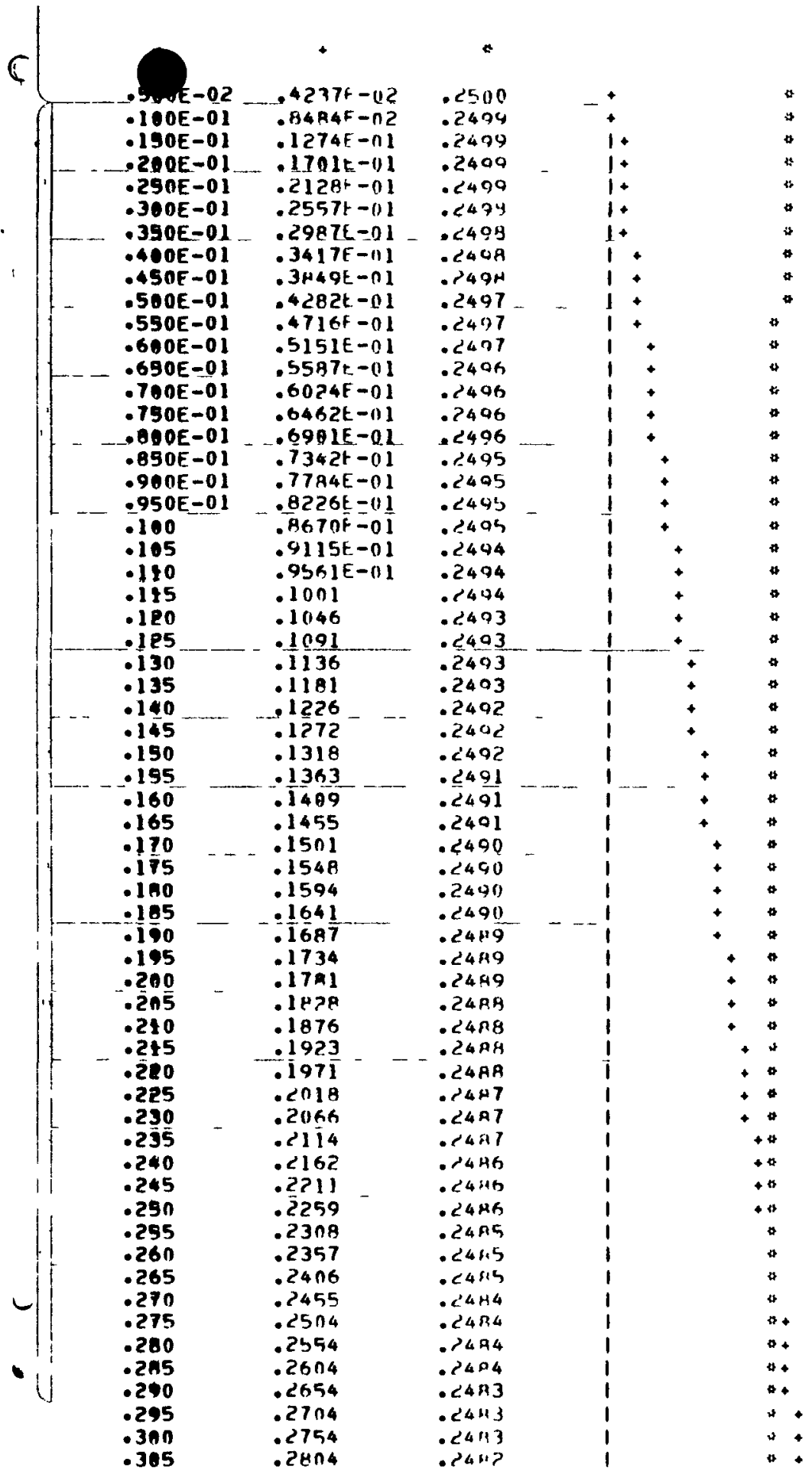




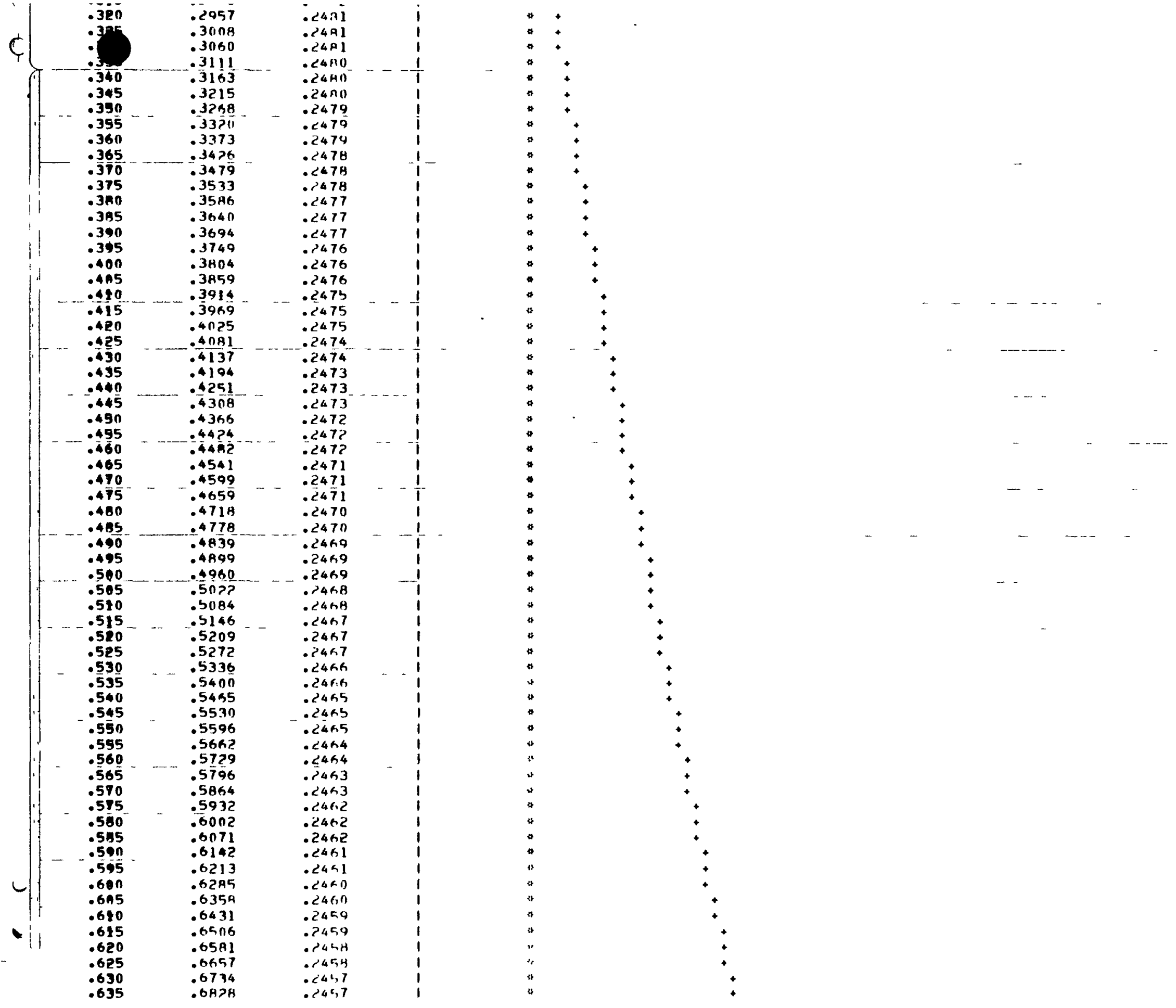




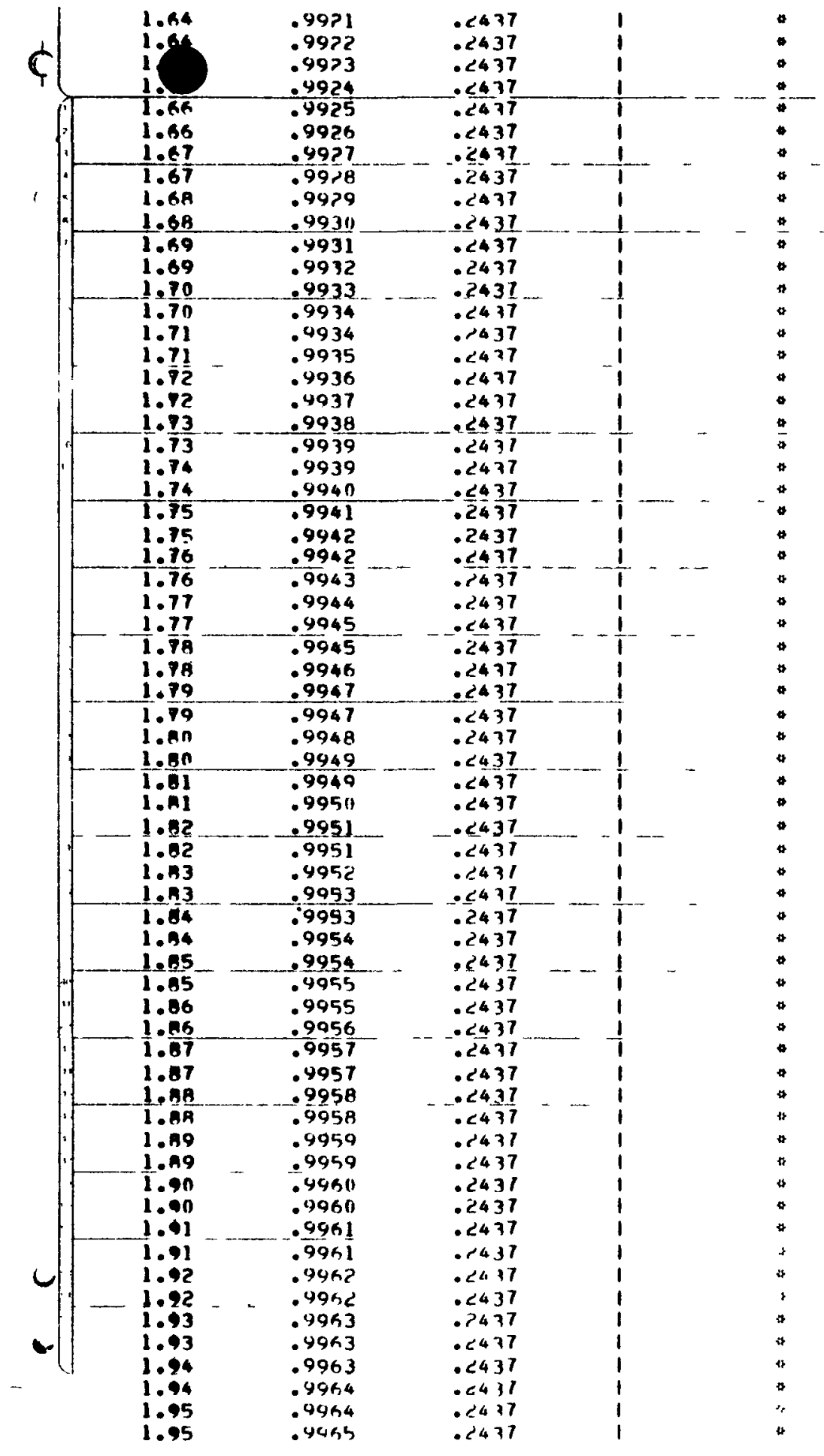




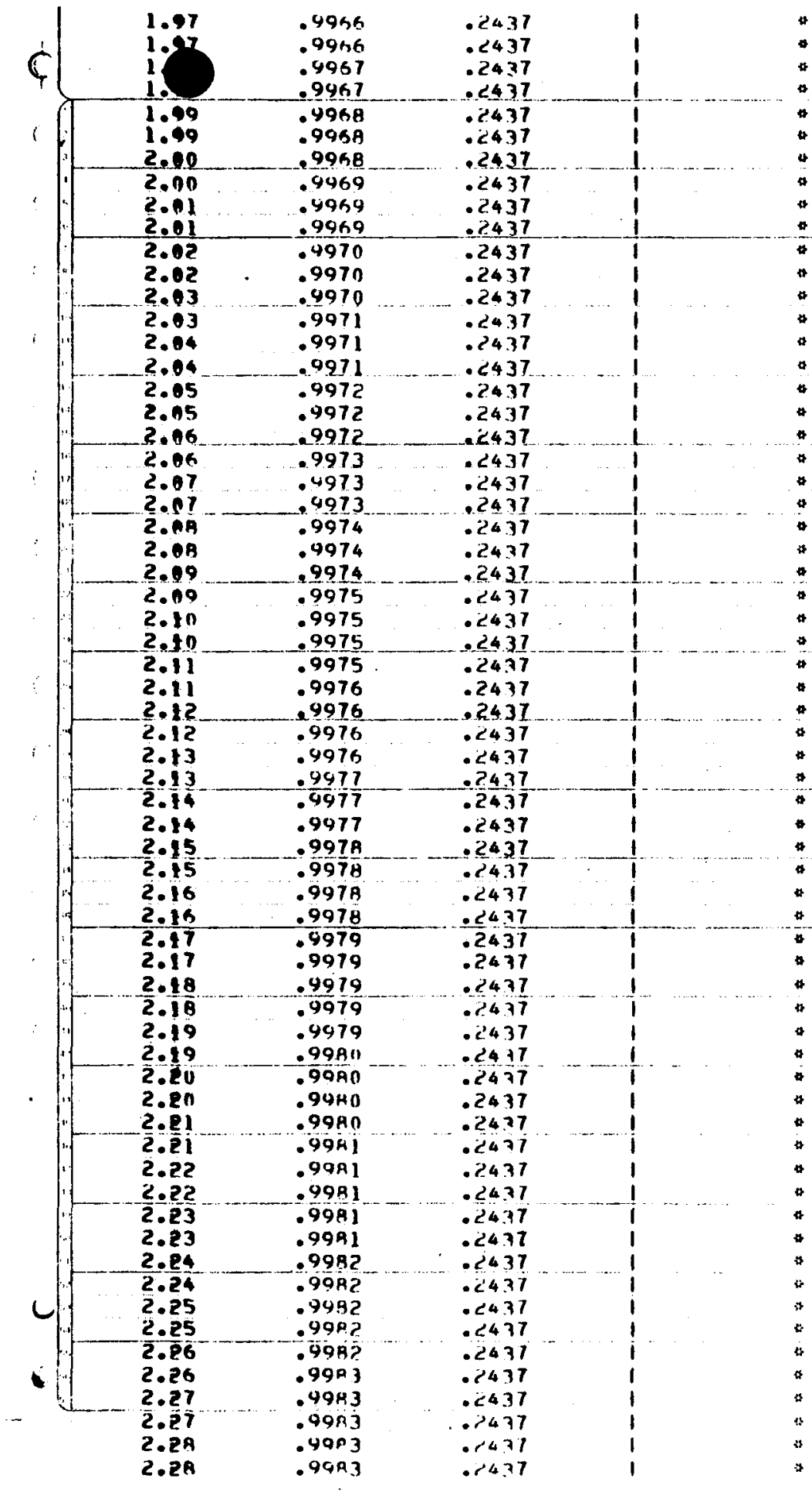




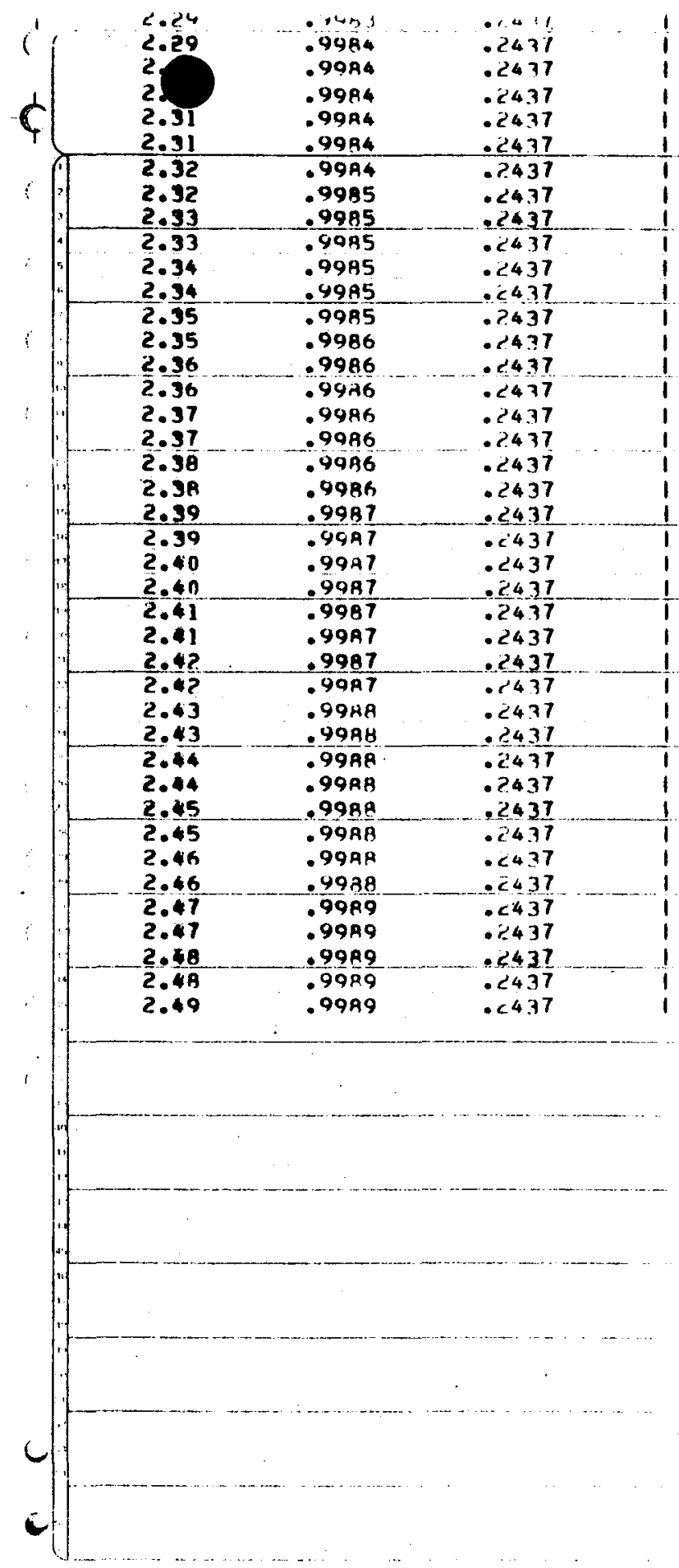




\section{'C O SEMI-BATEH VOLOXIDIZER OPERATION}

St, IHAICH

RATE EOUATIUN CONSTANTS

$B 1=-0.30199 t+00$

$M]=0.44500 t+00$

$N I=-n: 16399 t+00$

$P \bar{Z}=\overline{0}: 35900 t+00$

$M 2=-0.37900 t+00$

$N 2=0: 15410 t+01$

$\theta P=0.32001 t+00$

RE ACTOR PARAMAETERS

PO- -

OXYGEN CONCENTHATION

URANIUM DIOXIOE CONCENTRATION

GAS FLOW PATE

DILUENT GAS MOLE FRAC

DESIRED CONVERSION

PRE SSURE

AMOUNT OF SULIDS TO BE PHOCESSED

TEMPERA TUPE

RESINENCE TIMIE

VOLUMF OF RLACTOH

CO2 $=0.25000 E+00$ MOLES 02, MOLES DILUENT GAS

CUU2 $=0.13700 E-01$ MOLES UO2, KG ZIRCONIUM

$G=0.16700 E-01 M * 3 / S E C$

$G A S 2=0 . B 0000 E+00$

MAX $=0.99900 E+00$

$P=0.10000 E+01$ ATM

$S S=0.71400 E+03 \quad \mathrm{KG} / \mathrm{DAY}$

$T=0.4 \mathrm{BOOOE}+03 \mathrm{C}$

TAU $=0.96771 \mathrm{E}+03$ SEC

$V=0.30000 E+00 \quad M * * 3$

DATA POINTS HRIUR TO R.P.
TOTAL NÜMIIEN UF DATA POINTSE

REDUIRED TIME FOR DESIRED CONVERSION (SEC) $=0.88200 E+05$ 


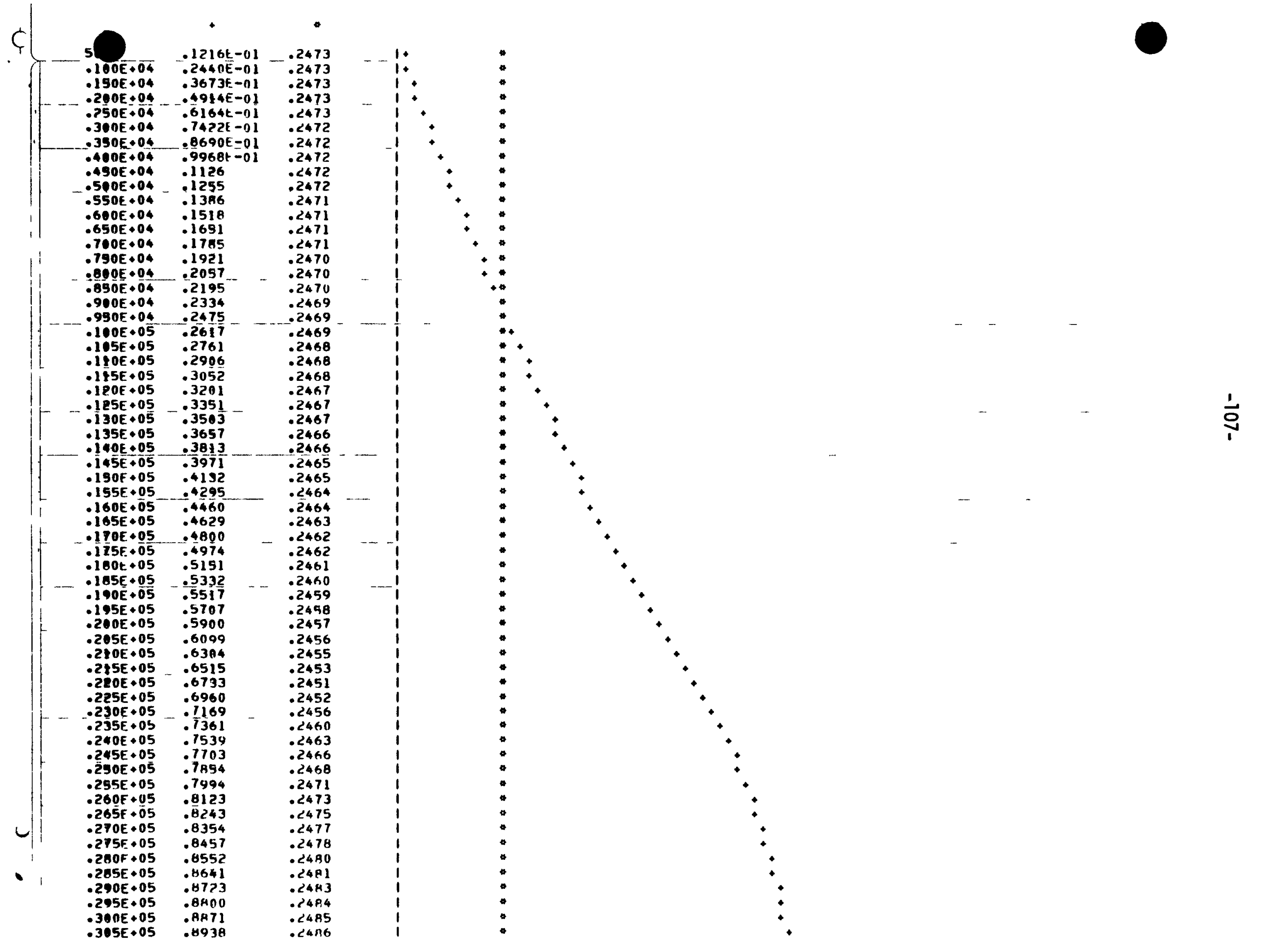




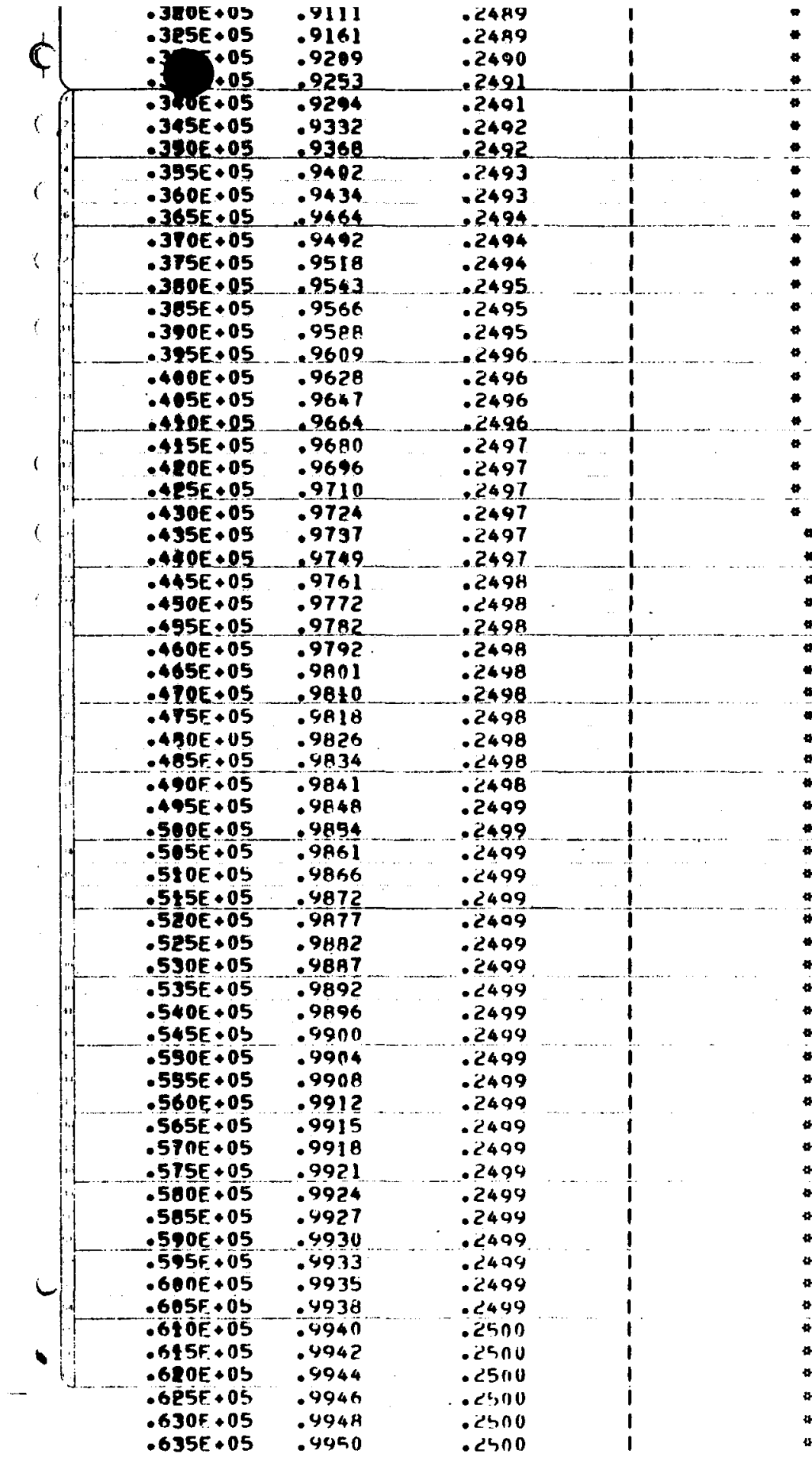




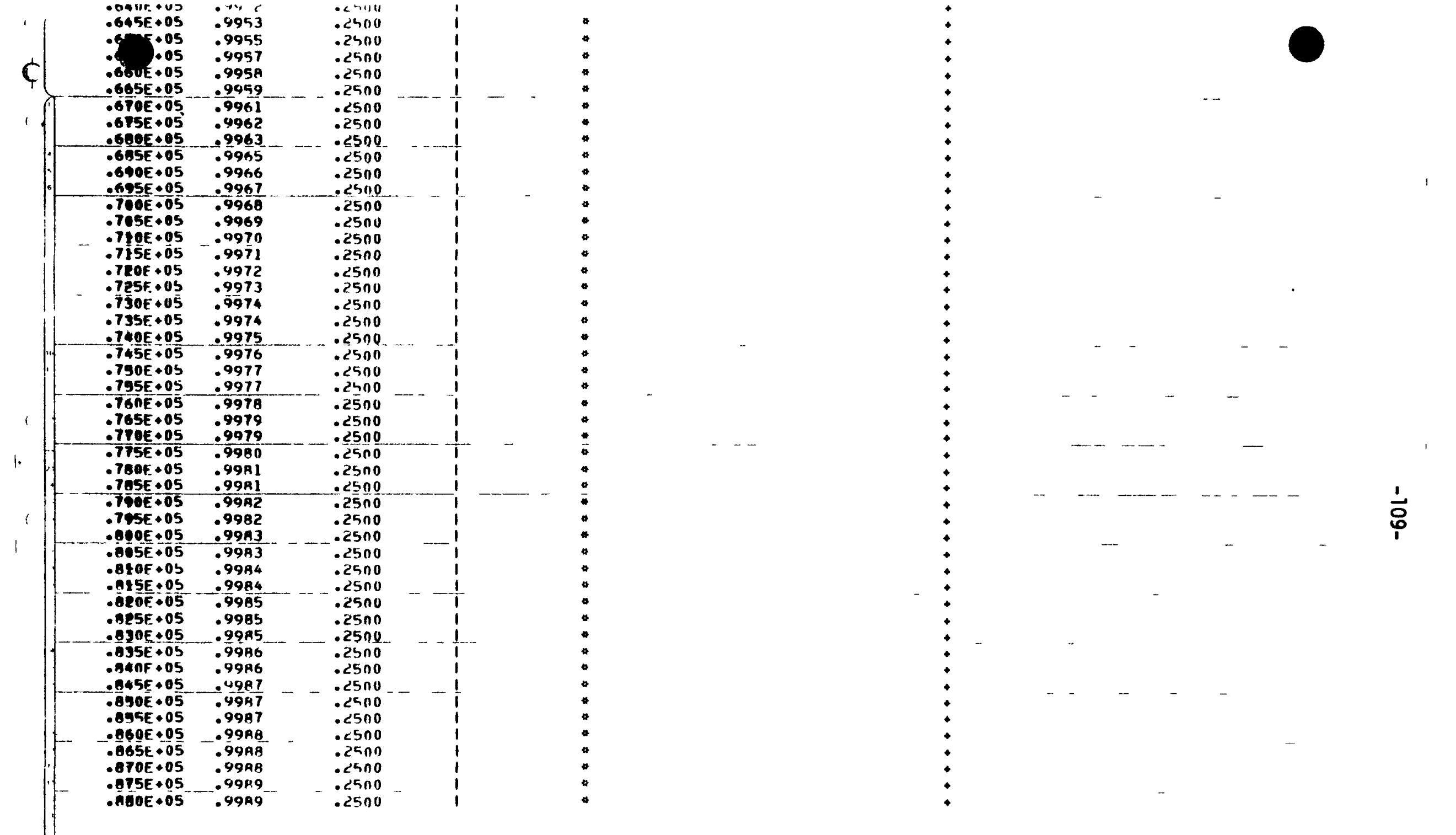

